\title{
Advanced Extended Plate and Beam Wall System in a Cold- Climate House
}

Dave Mallay, Joseph Wiehagen, and Vladimir Kochkin

Partnership for Home Innovation

January 2016 


\section{NOTICE}

This report was prepared as an account of work sponsored by an agency of the United States government. Neither the United States government nor any agency thereof, nor any of their employees, subcontractors, or affiliated partners makes any warranty, express or implied, or assumes any legal liability or responsibility for the accuracy, completeness, or usefulness of any information, apparatus, product, or process disclosed, or represents that its use would not infringe privately owned rights. Reference herein to any specific commercial product, process, or service by trade name, trademark, manufacturer, or otherwise does not necessarily constitute or imply its endorsement, recommendation, or favoring by the United States government or any agency thereof. The views and opinions of authors expressed herein do not necessarily state or reflect those of the United States government or any agency thereof.

Available electronically at SciTech Connect http:/www.osti.gov/scitech

Available for a processing fee to U.S. Department of Energy and its contractors, in paper, from:

U.S. Department of Energy

Office of Scientific and Technical Information

P.O. Box 62

Oak Ridge, TN 37831-0062

OSTI http://www.osti.gov

Phone: 865.576 .8401

Fax: 865.576.5728

Email: reports@osti.gov

Available for sale to the public, in paper, from:

U.S. Department of Commerce

National Technical Information Service

5301 Shawnee Road

Alexandria, VA 22312

NTIS http://www.ntis.gov

Phone: 800.553 .6847 or 703.605 .6000

Fax: 703.605.6900

Email: orders@ntis.gov 


\title{
Advanced Extended Plate and Beam Wall System in a Cold-Climate House
}

\author{
Prepared for: \\ The National Renewable Energy Laboratory \\ On behalf of the U.S. Department of Energy's Building America Program \\ Office of Energy Efficiency and Renewable Energy \\ 15013 Denver West Parkway \\ Golden, CO 80401 \\ NREL Contract No. DE-AC36-08GO28308 \\ Prepared by: \\ Home Innovation Research Labs \\ Partnership for Home Innovation \\ 400 Prince George's Boulevard \\ Upper Marlboro, MD 20774 \\ NREL Technical Monitor: Stacey Rothgeb \\ Prepared under Subcontract No. KNDJ-0-40335-05
}

January 2016 
The work presented in this report does not represent performance of any product relative to regulated minimum efficiency requirements.

The laboratory and/or field sites used for this work are not certified rating test facilities. The conditions and methods under which products were characterized for this work differ from standard rating conditions, as described.

Because the methods and conditions differ, the reported results are not comparable to rated product performance and should only be used to estimate performance under the measured conditions. 


\section{Contents}

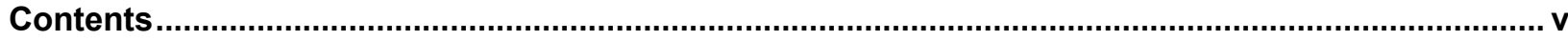

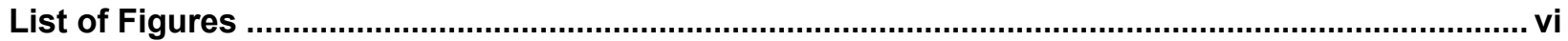

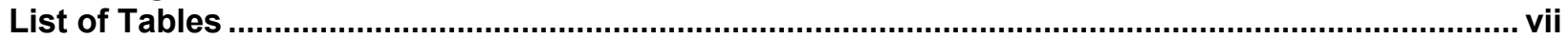

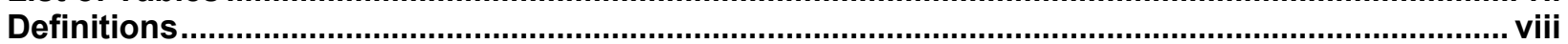

Executive Summary ................................................................................................................. ix

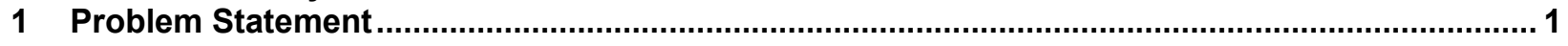

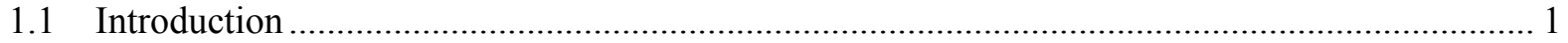

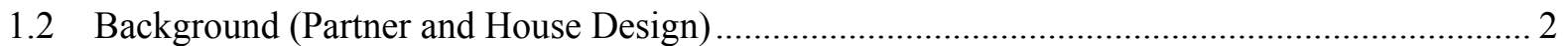

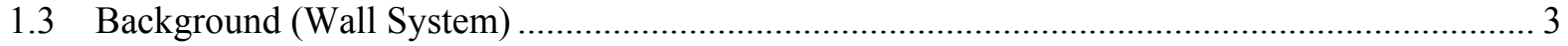

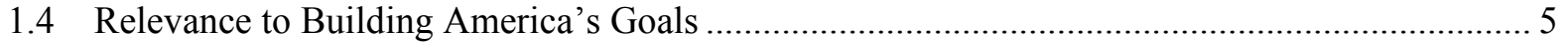

1.5 Cost-Effectiveness......................................................................................... 6

1.6 Trade-Offs and Other Benefits ......................................................................... 16

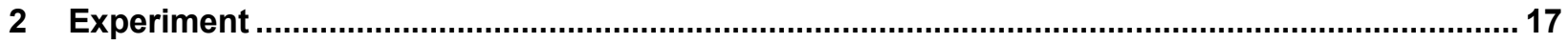

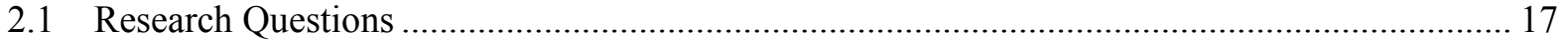

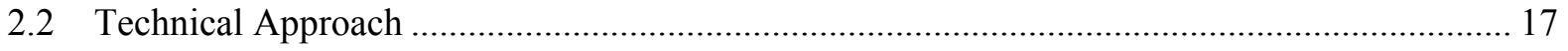

2.3 Assessments and Measurements ......................................................................... 17

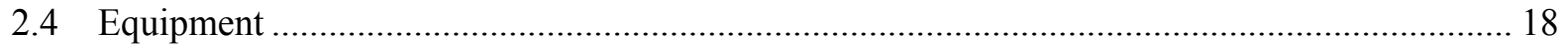

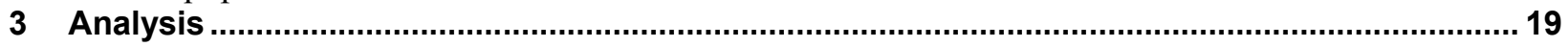

3.1 Extended Plate and Beam Wall System Design and Construction...................................... 19

3.2 Wall Cavity Moisture Characteristics .................................................................. 26

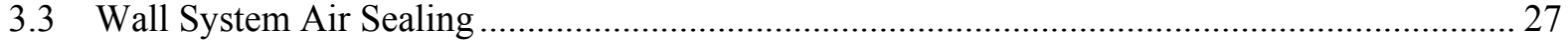

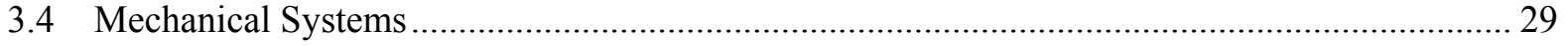

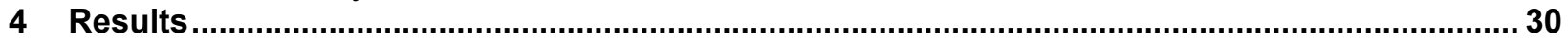

4.1 Extended Plate and Beam Wall System ............................................................... 30

4.1.1 Extended Plate and Beam System Implementation .......................................... 30

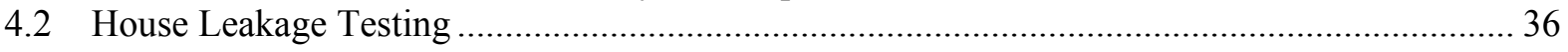

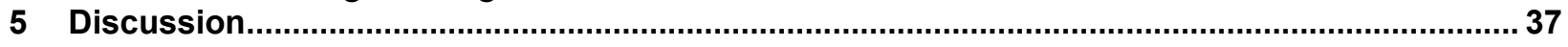

5.1 U.S. Department of Energy Zero Energy Ready Home Certification .................................. 37

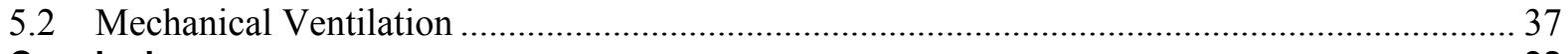

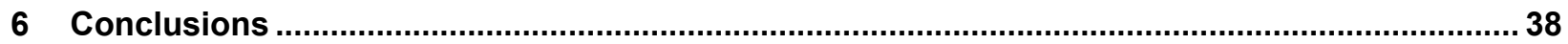

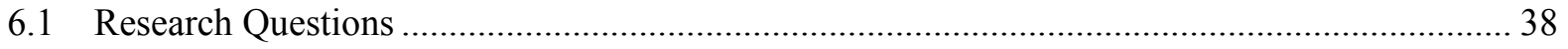

6.2 Key Findings and Lessons Learned................................................................... 39

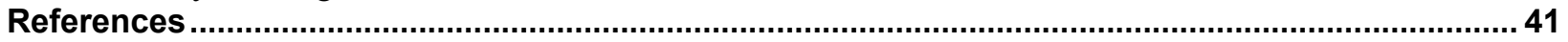

Appendix A: New Construction Test House Plans ..................................................................... 43

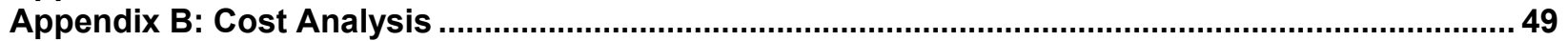

Appendix C: Wood Moisture Content Sensor Calibration .......................................................... 51

Appendix D: New Construction Test House Certifications ........................................................... 53 


\section{List of Figures}

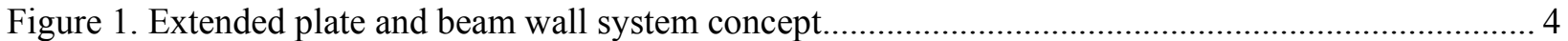

Figure 2. BEopt software optimization graphical results ................................................................... 10

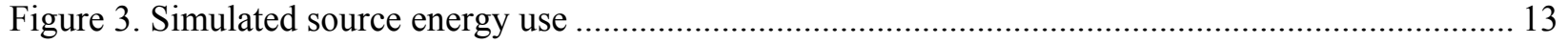

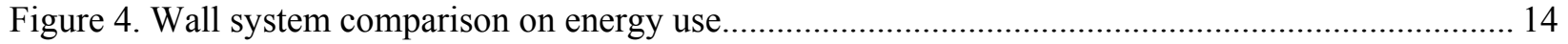

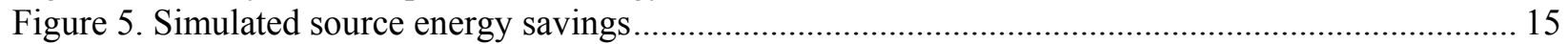

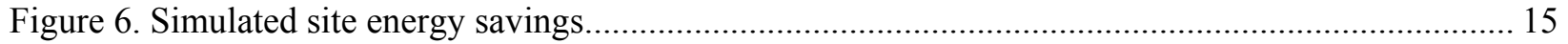

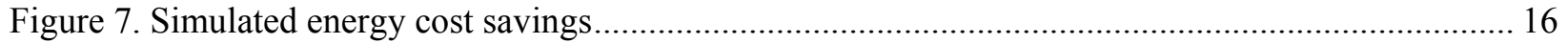

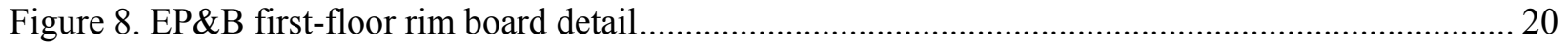

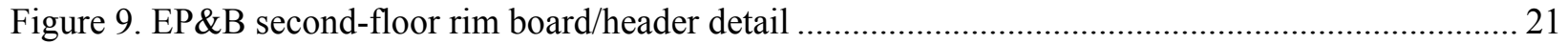

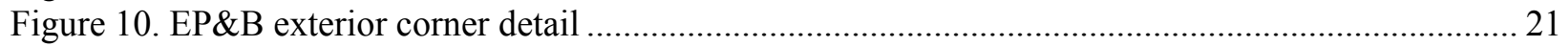

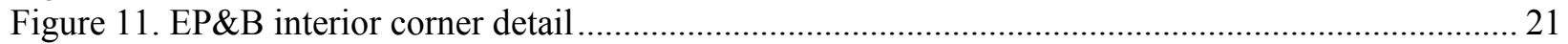

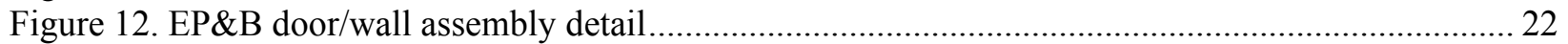

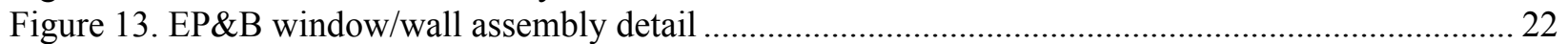

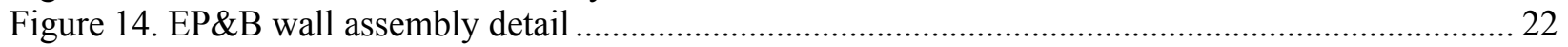

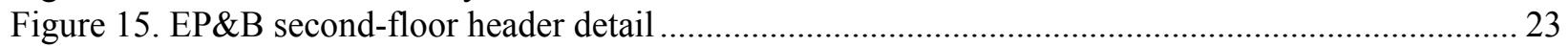

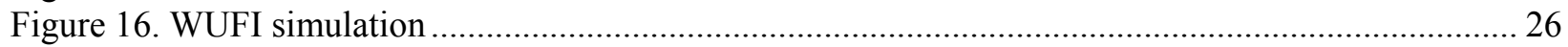

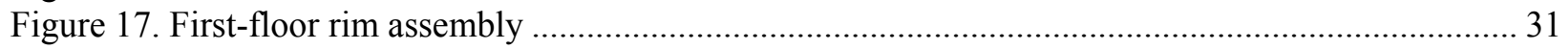

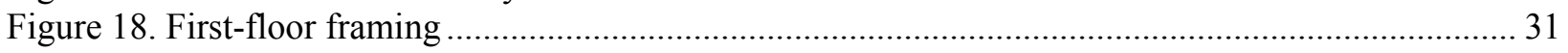

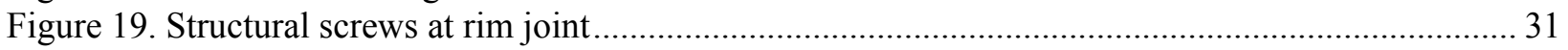

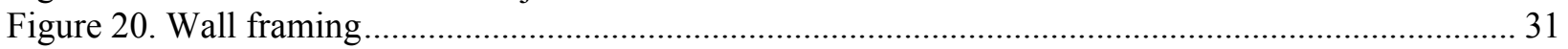

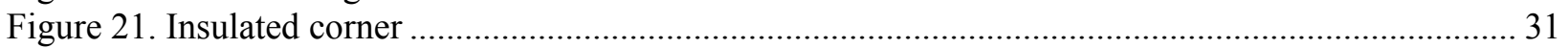

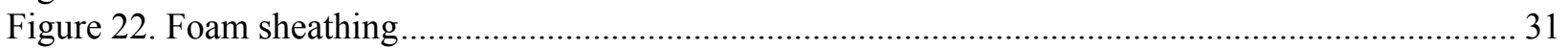

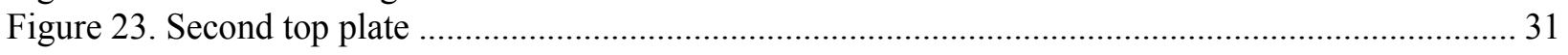

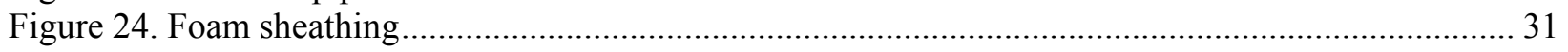

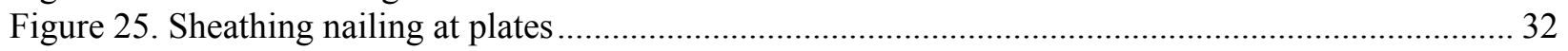

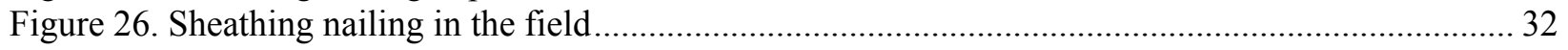

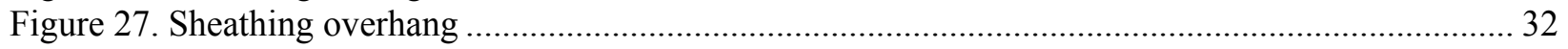

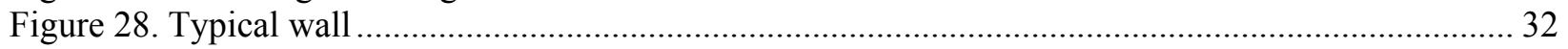

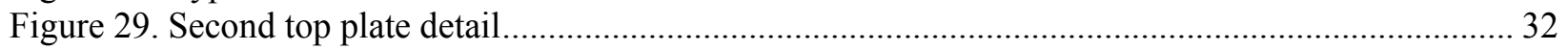

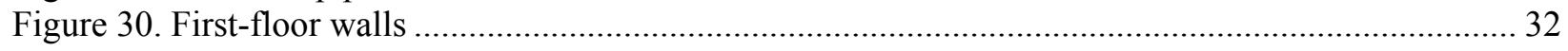

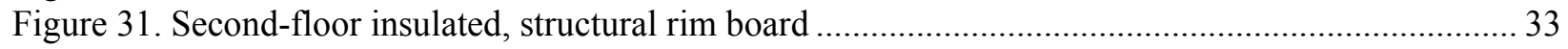

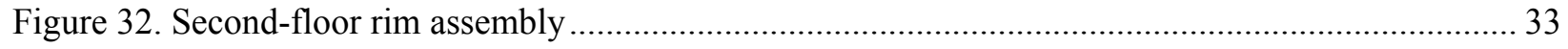

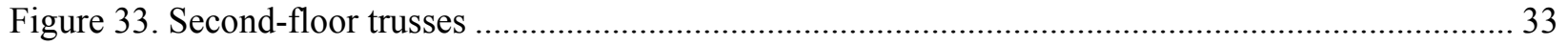

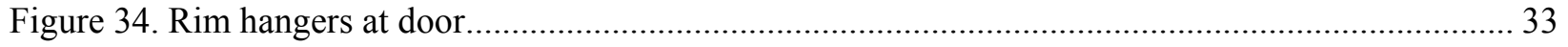

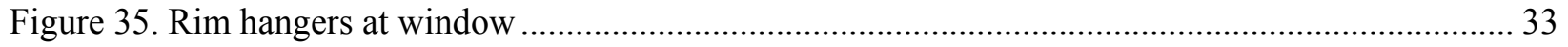

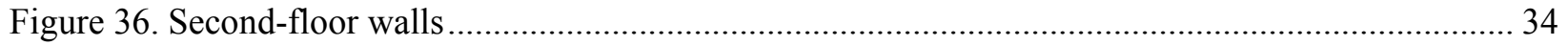

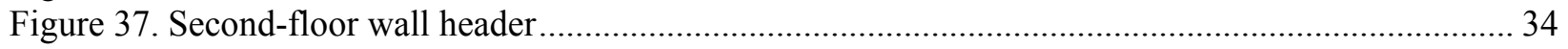

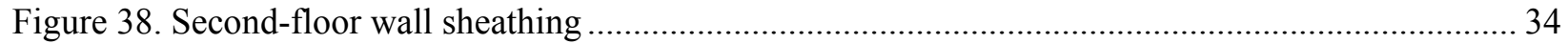

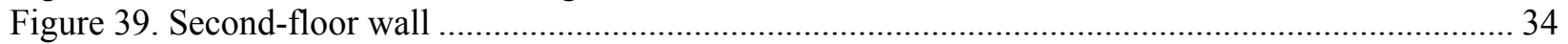

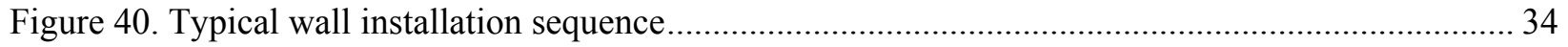

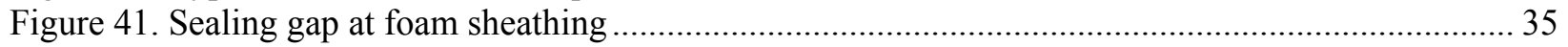

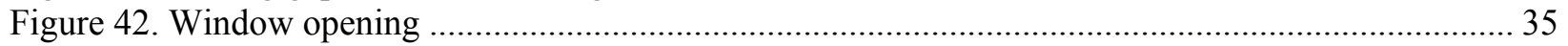

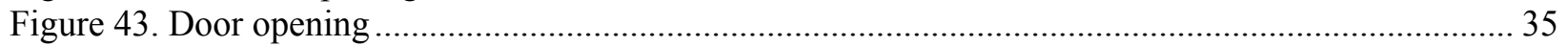

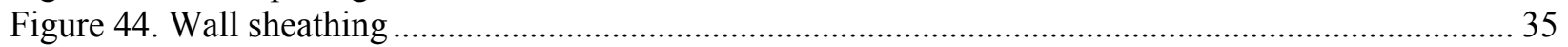

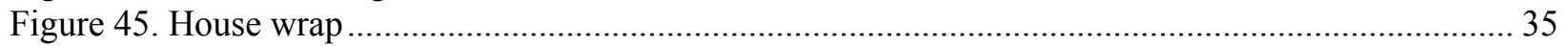

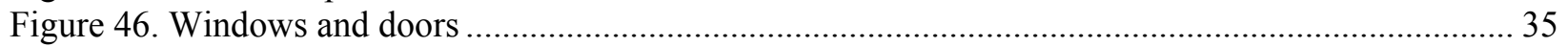

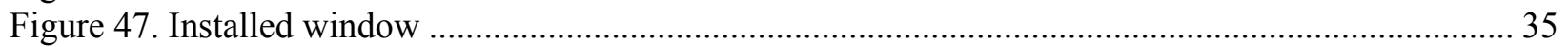

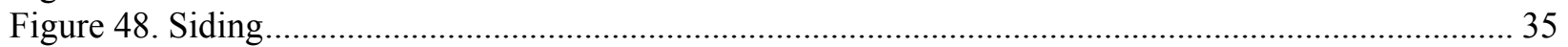

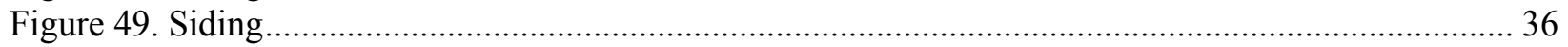




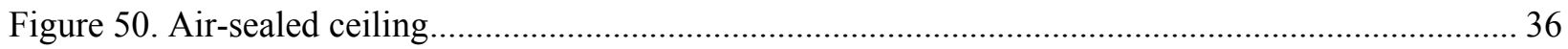

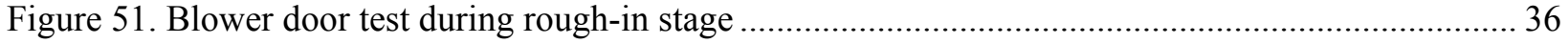

Figure 52. Wall sheathing moisture sensor before covered with foam .................................................. 36

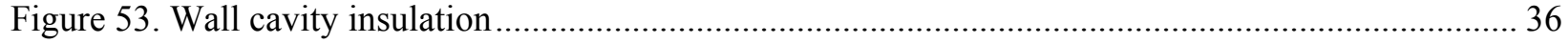

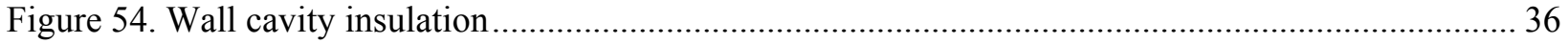

Figure 55. Sensors in the environmental chamber for calibration ........................................................ 51

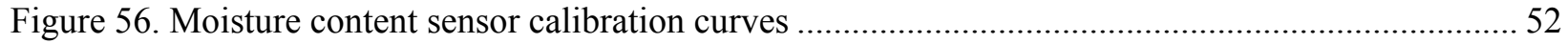

Unless otherwise noted, all figures were created by the Partnership for Home Innovation team.

\section{List of Tables}

Table 1. EP\&B Wall System Initial Material Cost Assessment ........................................................... 9

Table 2. Preliminary LCCTC Energy Feature Estimated Incremental Costs ........................................ 12

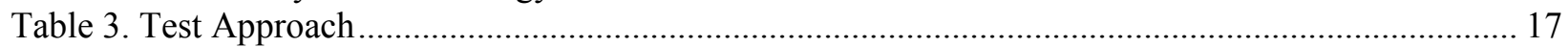

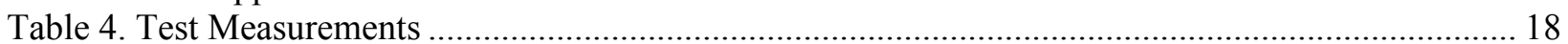

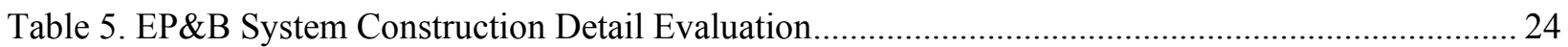

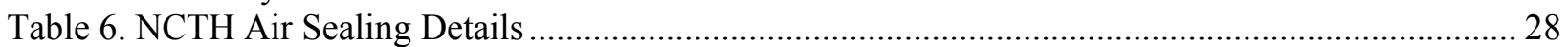

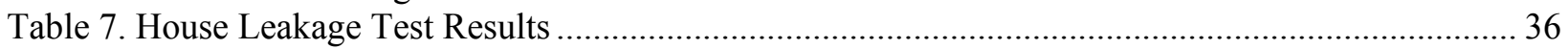

Table 8. Representative Wall Section Configuration Cost Estimates ....................................................... 50

Unless otherwise noted, all tables were created by the Partnership for Home Innovation team. 


\section{Definitions}

ACH50

ASHRAE

BEopt ${ }^{\mathrm{TM}}$

CFM

DOE

EP\&B

ICF

LCCTC

Measure

$\mathrm{NCTH}$

Net investment cost

o.c.

OSB

R-value

SEER

SHGC

U-value

WRB

XPS

ZERH
Air Changes per Hour at 50 Pascals

American Society of Heating, Refrigerating and Air-

Conditioning Engineers, Inc.

Building Energy Optimization Software

Cubic Feet per Minute

\section{U.S. Department Of Energy}

Extended Plate and Beam, a light-frame wall system under development at the Home Innovation Research Labs

Insulated Concrete Foundation

Lancaster County Career and Technology Center

A specific reference to a building component or system specifically employed to increase the energy efficiency of the building

New Construction Test House

With respect to energy-efficiency improvements, the net increased cost over the defined reference practices

On Center

Oriented Strand Board

Quantitative measure of resistance to conductive heat flow $\left(\mathrm{h} \cdot{ }^{\circ} \mathrm{F} \cdot \mathrm{ft}^{2} / \mathrm{Btu}\right)$

Seasonal Energy Efficiency Ratio

Solar Heat Gain Coefficient

Quantitative measure of conductive heat flow $\left(\mathrm{Btu} / \mathrm{h} \cdot{ }^{\circ} \mathrm{F} \cdot \mathrm{ft}^{2}\right)$, reciprocal of $\mathrm{R}$-value

Weather-Resistive Barrier

Extruded Polystyrene

Zero Energy Ready Home 


\section{Executive Summary}

This report presents the design and evaluation of extended plate and beam (EP\&B), an innovative wall system. This highly insulated (high-R) light-frame wall system is intended for use above grade in residential buildings. The EP\&B design is the first of its kind to be featured in a new construction test house (NCTH) for the U.S. Department of Energy (DOE) Building America program.

The EP\&B wall design integrates standard building methods and common building products to construct a high-R wall that minimizes transition risks and costs to builders. The EP\&B design combines optimized framing with integrated rigid foam sheathing to increase the wall system's $\mathrm{R}$-value and reduce thermal bridging. The foam sheathing is installed between the wall studs and structural wood sheathing. The exterior wood sheathing is attached directly to a framing extension formed by extended top and bottom plates. The exterior wood sheathing can dry to the exterior and provides bracing, a clear drainage plane and flashing surface for window and door openings, and a nailing surface for the siding attachment. The structural rim boards eliminate headers. The EP\&B wall system provides design flexibility in the selection of insulation and framing combinations to optimize the overall $\mathrm{R}$-value as required. The target nominal insulation values (wall cavity plus rigid foam insulation) are R-25 for $2 \times 4$ walls and R-30 for $2 \times 6$ walls.

The Building America research team Home Innovation Research Labs partnered with Lancaster County Career and Technology Center to build an NCTH in Lancaster, Pennsylvania, to demonstrate the EP\&B wall design in a cold climate (International Energy Conservation Code Climate Zone 5A). This research project will help achieve Building America goals to improve energy efficiency, occupant health and comfort, durability, and affordability.

This research project demonstrated the successful design and construction of a high- $\mathrm{R}$ wall system that is practical for the building industry to adopt:

- The EP\&B wall and rim assemblies were constructed in accordance with the approved design. This first field demonstration of the EP\&B system received positive feedback from the design team and construction crew.

- The architectural firm submitted plans and details to the local building code department. No issues were raised by the code officials or code inspectors throughout the plan approval or construction phases.

- The nominal insulation value of the wall assembly for this project was R-31 (R-10 rigid foam plus R-21 cavity insulation).

- The wall air-sealing methods were conventional and did not require specialized airsealing measures or equipment to achieve the low measured infiltration rate.

- The EP\&B design is expected to minimize moisture accumulation in the wall cavity and sheathing.

- Energy simulations for this NCTH predict a $44 \%$ whole-house source energy savings compared to the Building America B10 benchmark. The energy-solution package for the $\mathrm{NCTH}$ is considered cost-effective and market ready. 
- The cost of the EP\&B high-R wall assembly is comparable to and in some cases lower than the cost of other high-R wall systems of similar thermal performance in a cold climate. 


\section{Problem Statement}

\subsection{Introduction}

This report presents the design and evaluation of extended plate and beam (EP\&B), a new, innovative wall system. This highly insulated (high-R) light-frame wall system is intended for use above grade in residential buildings. The EP\&B design is the first of its kind to be featured in a new construction test house (NCTH) for the U.S. Department of Energy (DOE) Building America program.

Above-grade wall system improvements to achieve $40 \%$ to $50 \%$ Building America energy savings goals, and the necessary wall R-values greater than about R-23, have challenged the residential building industry. Residential building energy codes have increased minimum wall R-values steadily over code cycles since 2006 until the most recent 2015 code cycle in which wall R-values remained unchanged. This is due in part to the difficulty in confidently constructing wall systems that achieve higher R-values when the integration of cavity and exterior insulation, attachment details, air sealing, and the differing material characteristics to handle moisture all function together through climatic extremes throughout the life of the building. Equally as important, however, is the builder's and tradespeople's familiarity with the building materials and the construction methods necessary to achieve consistent and reliable results. New wall systems that require a major shift in materials (e.g., insulated concrete foundation $[\mathrm{ICF}]$ ), new framing systems (e.g., double-wall designs), or the incorporation of new layers and details (e.g., thick foam with furring) all require builders to make large changes in architectural designs, material and work specifications, training, purchasing, quality control, and warranties. Sensitivity to these challenges when developing or modifying wall designs for higher efficiency can help encourage a larger segment of the building industry to shift to higherperforming walls by undertaking less risk.

The Building America research team Home Innovation Research Labs conducted this research project to demonstrate the high-R advanced EP\&B wall system in a cold climate (International Energy Conservation Code Climate Zone 5A) that minimizes the risk of transition from standard wall-framing systems.

This report presents the design, construction, and performance characterization of an advanced wall system with a development goal to achieve a nominal R-30 insulating level that can be constructed using standard framing, air-sealing, and water management methods that are common to the industry today. The primary performance goals for this effort are to outline a solution package to achieve $40 \%$ estimated energy savings over the Building America benchmark and achieve DOE Zero Energy Ready Home (ZERH) designation.

As with the Building America program and similarly with energy codes and above-code programs, the cost-benefit ratio for higher R-value walls often discourages investments. This is due in part to the much higher cost for the wall R-values, which are much higher than the R-23, resulting from the complexity and uncertainty in the wall system. For example, the cost of the moisture-management details and the attachment details for the windows and doors when using foam thicker than $1 \mathrm{in}$. increases much faster relative to the insulation cost. 
High-R wall system designs have been researched for decades. This is the $30^{\text {th }}$ anniversary of a research home, EER-2, investigated by the National Association of Home Builders Research Foundation (now the Home Innovation Research Labs) that, among other energy features, incorporated $2 \times 6$ advanced framing and exterior plastic insulating sheathing (Luebs 1983). Numerous other concepts for higher R-value walls have emerged, primarily in custom home designs. Examples include double-wall framing; thick, rigid exterior foam panels over standard framing; closed-cell, foam-filled cavity framing; oriented strand board (OSB) wall structural panels thicker than 1 in.; insulated structural sheathing products; and $2 \times 8$ or $2 \times 10$ dimensional wall-framing systems. Monolithic wall systems such as structural insulated panels, ICFs, and versions of these technology approaches are available, now with prescriptive design requirements that can help enable the use of these technologies. However, to date they represent less than $5 \%$ of the above-grade wall residential construction market. ${ }^{1}$ These systems are designed primarily to achieve nominal R-values in the range of R-20 to R-30; the higher Rvalues add cost and complexity. Most of the wall system designs to achieve R-values higher than R-30 have a significant learning curve and require the addition of largely unfamiliar structural and flashing details compared to typical construction methodologies currently used by the trades.

Many of these High-R wall systems do not lend themselves to adoption by production builders due to many factors such as limited availability of design and material integration details, lack of trade contractor training and work scopes, quality assurance processes that are geared toward standard construction processes, and a lack of field experience that has worked through the inevitable problems when switching to a new structural technology that must be durable for decades. In this $\mathrm{NCTH}$, an innovative wall design is evaluated that integrates rigid foam sheathing with standard framing practices into a system that preserves many conventional construction features and minimizes the risk and cost of transition to builders.

\subsection{Background (Partner and House Design)}

With support from the Building America program, Home Innovation Research Labs (Home Innovation) partnered with Lancaster County Career and Technology Center (LCCTC) to build an NCTH in Apprentice Green, a community next to the school in Mount Joy, Lancaster County, Pennsylvania (International Energy Conservation Code Climate Zone 5A). LCCTC is a vocational high school with a Construction Technology program that prepares students for careers in the construction trades. The students gain practical experience building real houses that incorporate state-of-the-art energy-efficiency and green technologies. The homes are listed for sale upon completion. Construction for this NCTH began in September 2013 and was completed in June 2015.

Home Innovation consulted with LCCTC on four NCTH projects. The first two investigated wall systems with advanced framing and 1 in. of exterior insulation. The third house featured an ICF wall system and an estimated 40\% whole-house energy savings. This fourth NCTH (Green Home 4) is a single-family, 2,660- $\mathrm{ft}^{2}$, above-grade, two-story design with a full conditioned basement, vented attic, and detached garage (see Appendix A for floor plan). Energy-saving features include the nominal R-31 EP\&B wall system, a high-efficiency air-source heat pump, all space-conditioning ducts within the thermal envelope, solar thermal preheat for domestic hot water, cross-linked polyethylene manifold plumbing distribution, and efficient lighting and

\footnotetext{
${ }^{1}$ Based on the Home Innovation Research Labs' Builder Practices Survey
} 
appliances. Water efficiency is enhanced with a 3,500-gal rainwater collection and distribution system for landscape, toilet, and laundry.

\subsection{Background (Wall System)}

In 2012, the Home Innovation Research Labs (formerly the National Association of Home Builders Research Center) submitted a test plan as part of its Building America research for a new wall-framing concept. The purpose for developing the concept wall design was to simplify the process and cost for builders to transition to higher R-value wall designs. The target nominal R-values were R-25 for $2 \times 4$ walls and R-30 for $2 \times 6$ walls. The concept that emerged was the EP\&B wall-framing design, an advanced wall system design that incorporates foam sheathing integrated with a framing system that allows the structural shear panels to be mounted exterior to the foam insulation (foam between the sheathing and studs). The sheathing is attached directly to a framing extension formed by extended top and bottom plates of an otherwise standard lightframe wall. For double top plate applications, the first top plate is the same width as the studs. The major design benefits include:

- Reduced thermal shorts of framing members through the use of foam sheathing over the studs

- Structural sheathing installed on the exterior for the siding attachment and nailed directly to the extended top and bottom plates to provide shear load resistance

- Clear drainage plane and flashing surface for window and door openings

- Cold surface exterior sheathing capable of drying to the exterior and limited exposure from interior moisture diffusion

- Flexibility in the selection of wall cavity and foam sheathing materials

- Flexibility in the use of framing combinations for optimum overall wall thermal resistance

- Band beam design to eliminate headers in all wall sections below the top floor.

This EP\&B advanced wall design, diagramed in Figure 1, relies on common construction methods and materials. However, the unique design proposed here enables the integration of foam sheathing into a conventional wall system in a manner that provides continuous structural backing for the siding attachment and relies on wood structural panels nailed directly to the framing for shear resistance. The integrated rim beam also eliminates requirements for headers within the wall plane, enhances design flexibility, and allows field modifications. 


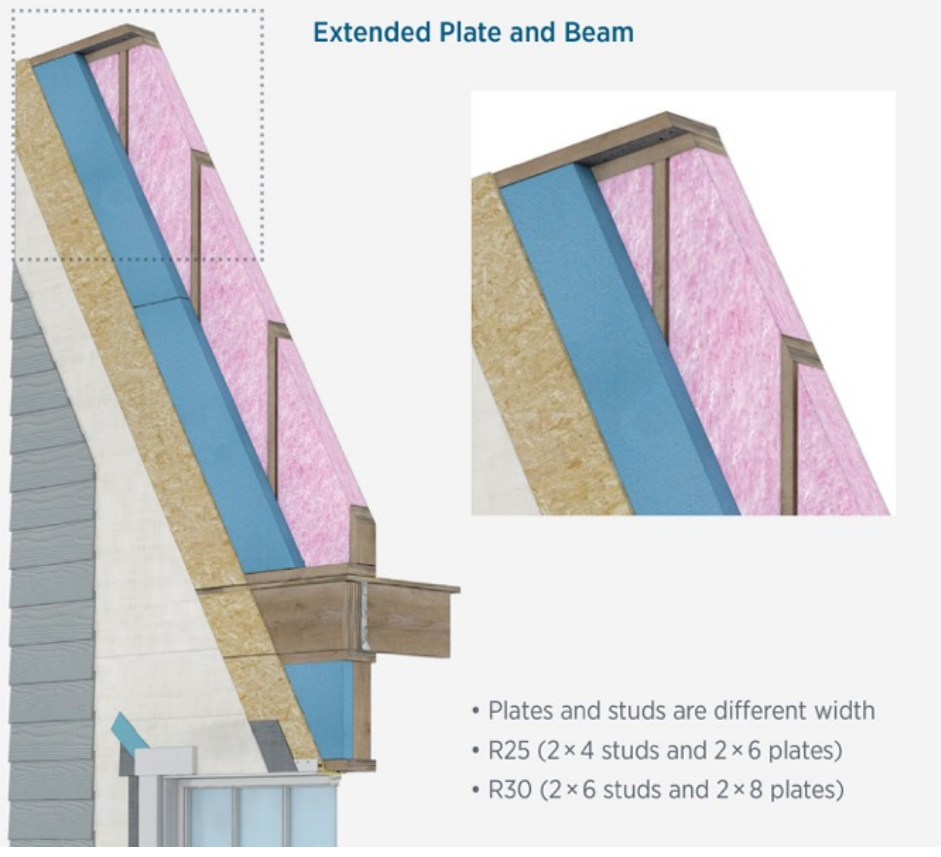

Figure 1. EP\&B wall system concept

The EP\&B wall system is a high-R light-frame wall system. For this research, light-frame wall system designs ${ }^{2}$ that have a nominal wall ${ }^{3} \mathrm{R}$-value of $30 \mathrm{~h} \cdot{ }^{\circ} \mathrm{F} \cdot \mathrm{ft}^{2} /$ Btu are considered (with wholewall R-values higher than $\left.20 \mathrm{~h} \cdot{ }^{\circ} \mathrm{F} \cdot \mathrm{ft}^{2} / \mathrm{Btu}\right)$. Most recent research into high-R wall systems as part of the Building America program and from other similar research efforts has generally taken two distinct paths: (1) increase the thickness of the wall system so the structural framing incorporates higher levels of cavity insulation, and (2) add insulation to the exterior of the structural framing. Common goals for these wall system designs include higher thermal resistance, reduced thermal shorts through framing members, resistance to moisture diffusion, drying capability when wetted, constructability, and cost containment. Both approaches to nominal R-30 and higher wall systems have been analyzed extensively by industry experts (Straube and Smegal 2009; Straube 2010; Aldrich, Arena, and Zoeller 2010; Minnesota Sustainable Housing Initiative 2012, Cold Climate Housing Research Center 2010) with similar conclusions:

- For thick-wall systems, the double-wall design can provide the highest performance with a combination of insulation and air-sealing materials while maintaining constructability and "marketable" construction costs. ${ }^{4}$ Other thick-wall systems include the truss wall

\footnotetext{
${ }^{2}$ This work focuses solely on wood frame wall systems, particularly framing systems that use nominal $2 x$ lumber stock (excluding structural insulated panels, logs, and heavy timber), because this residential construction method represents about $90 \%$ of the market.

${ }^{3}$ Nominal wall R-value is cavity + sheathing insulation only. Whole-wall R-Value considers framing as well and is defined as "R-value estimation for the whole opaque wall including the thermal performance of not only the "clear wall' area, with insulation and structural elements, but also typical envelope interface details, including wall/wall (corners), wall /roof, wall/floor, wall/door, and wall/window connections" (Kosny and Christian 2001).

${ }^{4}$ Marketable construction costs refer to construction costs that have been vetted through actual bid/sales agreement in multiple projects.
} 
design that has been demonstrated but has limited details on constructability and actual costs.

- Uses of $2 \times 6$ and $2 \times 4$ framing have been analyzed for exterior insulated systems to achieve whole-wall R-values higher than 30 . Exterior insulation, typically foam board products thicker than 3 in., is necessary; the insulation is coupled with some type of supplemental framing for finish attachment. A growing experience base that includes constructability and costs is developing for wall systems that employ thick exterior insulation.

Although these approaches have been successful in some demonstrations and projects, each is hindered by significant trade contractor learning curves (driven in large part by uncommon framing and attachment details), high cost premiums over standard framing practices, and in some cases complex finishing details (Straube 2010). Furthermore, neither system lends itself to factory panelization, although fabrication and transportation mechanisms may certainly be developed. However, in the development of construction details and in field demonstrations, these systems have been successfully employed, including in projects with multiple homes in the same development. Widespread deployment of these framing and insulation systems appears slow to gain traction, especially for use in production home designs wherein longer-term performance analysis is yet to be elucidated.

Experiences with some production builders also reveal a notable hesitancy in using wall systems either with exterior insulation or walls thicker than $2 \times 6$ framing. This hesitancy is demonstrated in residential building material use data ${ }^{5}$ and in anecdotal conversations with production managers.

\subsection{Relevance to Building America's Goals}

The energy performance goal of the Building America program has been simplified as the research has achieved success. "The goal of Building America is to demonstrate how costeffective strategies can reduce home energy use by up to $50 \%$, for both new and existing homes, in all climate regions by 2017."6 This reduction is in reference to the 2009 energy codes for new homes and pre-retrofit energy use for existing homes. Toward this end, Building America teams conduct research to develop market-ready energy solutions that improve the efficiency of new and existing homes in each U.S. climate zone while increasing comfort, safety, and durability.

This research project aligns well with Building America goals. The EP\&B wall design enables deeper wall cavities and the use of foam sheathing; it simplifies each approach and maintaining wall design and material selection flexibility to adapt to climate and cost constraints or choices. The EP\&B design can be applied to and is most practical for Climate Zone 4 through Climate Zone 8 , because the advantage of the framing method is in locations where the nominal wall Rvalues of 25 and higher would be desired for high-performance homes. Design simplification and a focus on a consistent construction methodology are expected to enable the use of much higherperformance wall systems by:

\footnotetext{
${ }^{5}$ Survey data from Home Innovation market research show virtually no change from the more than $90 \%$ market share for $2 \times 4$ and $2 \times 6$ framing from 2001 to 2012 .

${ }^{6}$ www1.eere.energy.gov/buildings/residential/ba research.html\#goals, accessed 12-6-2013
} 
- Standardizing a framing system methodology that can be adapted to desired thermal performance

- Minimizing transition costs, including plan changes that affect interior floor space

- Maintaining flexibility in the selection of insulation materials

- Providing trade contractors with a consistent approach to framing details, air sealing, insulating, and flashing that can be applied to various thermal designs

- Minimizing transition risk to builders.

This effort aligns with the Building America program research-to-market approach in which an individual measure, the EP\&B system, is analyzed in a whole-house assessment that sets the stage for a community-wide application. This effort focuses on taking the next step in the measure development to analyze constructability, cost, and durability aspects of the technology within the framework of a test house.

\subsection{Cost-Effectiveness}

A detailed cost comparison of nine wall configurations, including the EP\&B wall system and other wall systems with similar R-values, is presented in Appendix B. The results indicate that the cost of the EP\&B system is comparable to and in some cases lower than that of walls with the same R-value. The cost normalized by the R-value is also similar among wall types within the same R-value range. Therefore, the added benefits of the EP\&B system do not come with higher costs, and in some cases they result in moderate cost savings relative to comparable Rvalue alternatives.

A number of cost constraints are imposed on the concepts and the cost-benefit estimates developed for comparison to traditional framing systems. These selected cost constraints are bounded by both the double-wall and thick exterior insulation methodologies now used as high$\mathrm{R}$ wall systems, including material and labor costs.

The cost-effectiveness of technologies designed to save energy has a complicated history based on the chosen analysis methodology (Straube 2010). Most often, the addition of efficiency measures in homes is based on the cost savings in the utility bills. If the investment in efficiency is less than the cost savings in utilities, a positive cost attribute is assigned to the efficiency measure. This type of cost analysis is further complicated by the selected methodology, including the cost of borrowing, utility rates, utility rate escalation, life cycle of the measure, and the effect on other systems in the home.

For the EP\&B advanced wall system the cost comparison is made relative to other wall systems that are designed to achieve a similar level of energy performance, namely the double-wall and the thick exterior foam insulation systems. The cost comparison for the proposed advanced wall design must show that when compared to other high-R wall designs, it is:

- No more costly when all aspects of design and construction, including field modifications, inspections, and finishes, are incorporated

- More expedient to frame, balancing labor costs with increased insulation materials 
- Less disruptive to construction schedules when quality assurance processes are implemented at various stages of construction

- More flexible with the use of material combinations to optimize the overall R-value of the wall system while maintaining the same construction methodology

- Equally capable of being field fabricated as well as panelized and shipped

- Applicable to prescriptive design methodologies to simplify design and inspection processes.

Other aspects of a detailed cost analysis that are considered in the concept development potentially include costs to ensure satisfactory moisture performance, costs associated with trim finishes, construction schedule to close-in, and costs associated with field changes to the framing system.

The Building America program measure and NCTH cost-effectiveness analysis is most often evaluated based on energy cost savings relative to net invested costs. Specifically for the EP\&B wall system, the cost of the components $(2 \times 6$ lumber, foam sheathing, rim boards, nailing patterns, etc.) combined with installation costs, must be compared to some reference system to develop the net investment cost of the advanced wall system. This cost is then analyzed relative to the energy cost savings. ${ }^{7}$ However, because this wall system and its use in a home are new to the industry, the initial cost analysis is considered in two respects:

- It is performed relative to the wall system alone, comparing the EP\&B to a more typical configuration of a wall with a similar R-value.

- A whole-house cost analysis is based on more typical wall configurations that would result in at least the same energy savings as with a wall system (and other building components) as the EP\&B system.

The cost analysis approach that has led to an initial positive cost assessment of the technology system results from a comparison between the EP\&B system components and a $2 \times 6$ wall system with 2 in. of foam sheathing. ${ }^{8}$ LCCTC selected the EP\&B configuration with $2 \times 6$ studs and $2 \mathrm{in}$. of extruded polystyrene (XPS) for a total R-value of R-31 over the $2 \times 4$-based EP\&B configuration in an effort to achieve a high-performance envelope and meet the aggressive energy-saving targets. The cost comparison between the EP\&B wall and a standard $2 \times 6$ wall with 2 in. of exterior foam sheathing is outlined in Table 1 using relative cost factors rather than specific costs.

An NCTH whole-house cost-effectiveness analysis was evaluated through a theoretical comparison relative to the Building America benchmark house (which is fairly representative of standard construction in the area). The Building America cost and performance optimization tool Building Energy Optimization (BEopt $\left.{ }^{\mathrm{TM}}\right) \mathrm{E}+$, Version 2.1.0.0 was used to simulate energy consumption and annualized related energy costs based on assumed financial parameters. Estimated incremental costs for energy features were based on costs established in the National

\footnotetext{
${ }^{7}$ This analysis incorporates a net present value methodology that considers the financed investment using guidelines in the House Simulation Protocols of the Building America program.

${ }^{8}$ Simulation analysis has shown that these two configurations, the EP\&B system and the $2 \times 6$ standard with 2 in. of exterior foam result in very similar energy savings.
} 
Residential Efficiency Measures Database ${ }^{9}$ supported by the National Renewable Energy Laboratory for DOE. This methodology was used because the EP\&B system is expected to perform in a very similar manner to a $2 \times 6$ wall system with 2 in. of exterior foam sheathing. These building features are now available in the BEopt software and the cost database.

\footnotetext{
${ }^{9}$ www.nrel.gov/ap/retrofits/, last accessed 12/10/2013
} 
Table 1. EP\&B Wall System Initial Material Cost Assessment

\begin{tabular}{|c|c|c|c|}
\hline Wall System Component & EP\&B Detail & $\begin{array}{l}\text { Reference Detail: Standard } \\
\qquad 2 \times 6+2 \text {-in. XPS }\end{array}$ & $\begin{array}{l}\text { Cost Change of } \\
\text { EP\&B from } \\
\text { Reference Detail }\end{array}$ \\
\hline Stud Framing & $2 \times 6$ & $2 \times 6$ & Neutral \\
\hline Wall Plate Framing $(2 \text { of } 3)^{a}$ & $2 \times 8$ & $2 \times 6$ & + Cost \\
\hline Door Framing & $2 \times 8$ & $2 \times 6$ & + Cost \\
\hline Structural Sheathing (OSB) ${ }^{b}$ & $\begin{array}{l}\text { Vertical orientation only (full } \\
\text { height to plates) }\end{array}$ & $\begin{array}{l}\text { Vertical or horizontal with } \\
\text { blocking }\end{array}$ & Neutral \\
\hline OSB Nailing & $\begin{array}{l}\text { 4-in.-long nails in field } \\
2-3 \text { in. o.c. }{ }^{c} \text { at plates }\end{array}$ & $\begin{array}{c}\text { Standard nails } 6 \text { in. o.c. at } \\
\text { plates }\end{array}$ & + Cost \\
\hline $\begin{array}{l}\text { Foam Sheathing } \\
\text { (2-in. thickness) }\end{array}$ & $\begin{array}{l}\text { Installed coincident with } \\
\text { framing }\end{array}$ & $\begin{array}{c}\text { Installed as second sheathing } \\
\text { layer }\end{array}$ & - - Cost \\
\hline$W_{R B}{ }^{d}$ & Standard over OSB & $\begin{array}{l}\text { Over foam (or no WRB, tape } \\
\text { foam joints) }\end{array}$ & Neutral \\
\hline Furring Strips & N/A & Installed at $16-24$ in. o.c. & - - Cost \\
\hline Siding & Standard over OSB & Attachment through foam & - Cost \\
\hline Window Jambs/Trim & Additional material & Additional material & Neutral \\
\hline Anticipated Cost Difference & \multicolumn{3}{|c|}{ Modest to medium savings with EP\&B over defined Reference } \\
\hline
\end{tabular}

${ }^{a}$ Only the outside plates are extended.

${ }^{\mathrm{b}}$ EP\&B requires full sheathing panels from the top plate to the bottom plate; OSB panels of 9-ft or 10-ft length may be required in taller walls. With full sheets, interior cavity blocking at the standard panel seams is not required.

${ }^{\mathrm{c}}$ On center

${ }^{\mathrm{d}}$ Weather-resistive barrier 
BEopt was used to simulate combinations of wall framing systems; exterior insulation levels; attic insulation and basement insulation levels; air leakage levels; and ventilation, heat pump, and water-heating systems. BEopt combines efficiency features with cost estimates and determines the optimal energy savings for the lowest annualized cost. ${ }^{10}$ Figure 2 is a graphical representation of the optimization results that evaluate combinations of energy features based on energy use and cost.

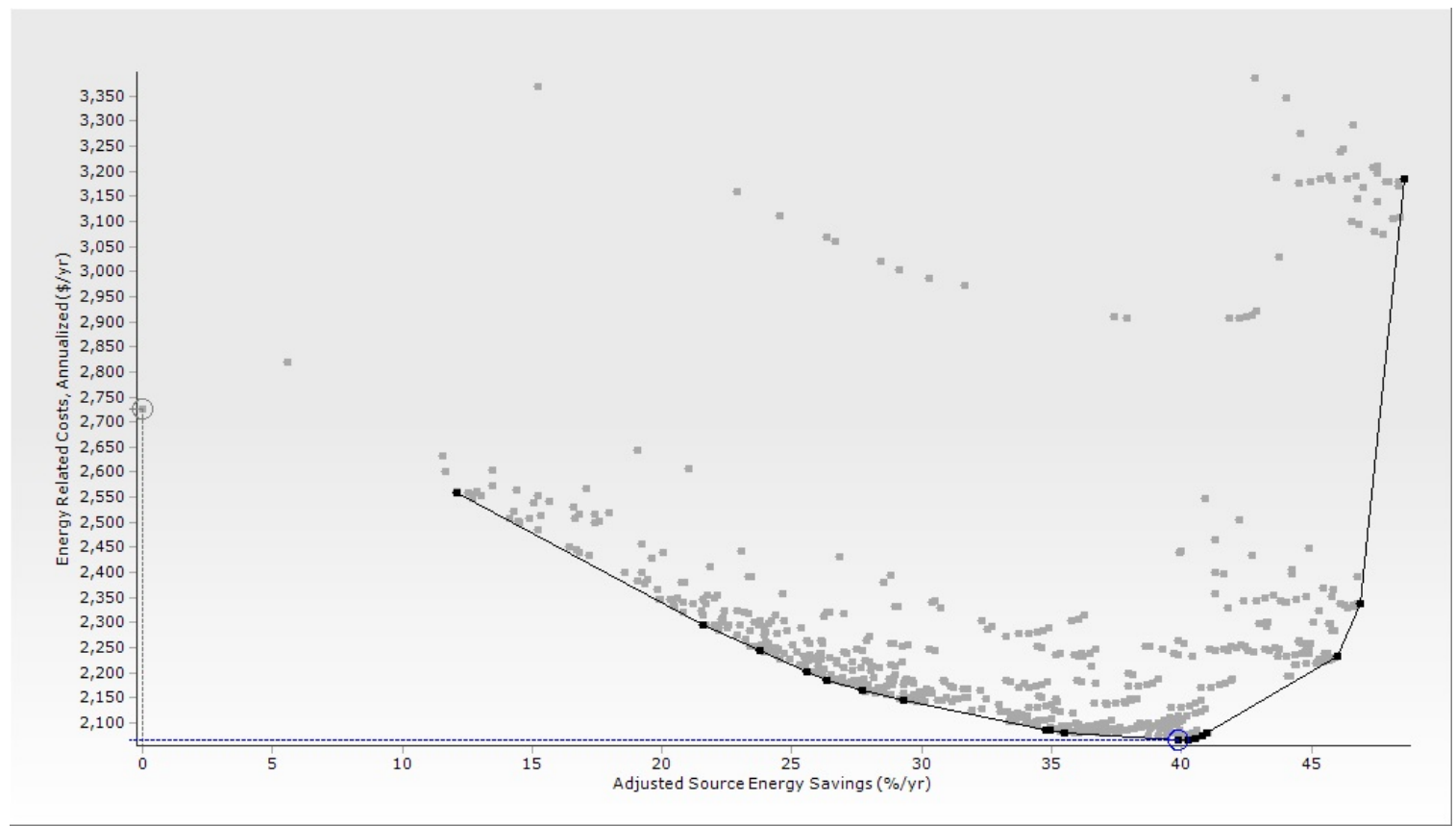

Figure 2. BEopt graphical results

The optimization results for simulated energy use and savings show that the greatest cost benefit is realized at about $40 \%$ source energy savings. After $40 \%$ the cost increases markedly relative the increased savings such that the cost benefit quickly diminishes after about $47 \%$ energy savings. The major energy features of one of the $40 \%$ energy savings design scenarios based on the optimization includes:

- $2 \times 6$ walls with R-19 batt insulation

- 2 in. of exterior insulation (R-10)

- $\mathrm{R}-38$ ceiling insulation

- Double-pane, low-e insulated glazing with air fill

- Heat pump rated at 22 seasonal energy efficiency ratio (SEER)/10 heating seasonal performance factor (HSPF)

- Electric water heating energy factors of at least 2.

\footnotetext{
${ }^{10}$ The lowest annualized cost combines the financed increased cost of features with energy savings over a 30 -year period using a net present value calculation to determine an annual cost of energy for the home relative to a defined reference home.
} 
The simulation results are indicative of the direction for energy savings in this climate and demonstrate the overall direction for optimized energy efficiency for an electric home (no gas available):

- Orient the house with the larger glazings facing south.

- Use a $2 \times 6$ wall system with exterior insulation thicker than 1 in.

- Use low-e windows with a moderate solar heat gain coefficient (SHGC).

- Use a heat pump system with a higher HSPF. (Close to 10, the SEER rating is not as important in this climate.)

- Use water-heating equipment with energy factors close to 2.

Using this approach, the NCTH was initially designed with the primary energy features as outlined in Table 2 and compared to the Building America benchmark house design (typical of regional practice). 
Table 2. Preliminary LCCTC Energy Feature Estimated Incremental Costs

\begin{tabular}{|c|c|c|c|}
\hline Group & Category & $\begin{array}{c}\text { Standard Regional Practice } \\
\text { Building America Benchmark }\end{array}$ & NCTH Energy-Efficiency Feature \\
\hline Walls & Exterior walls above grade & $\begin{array}{l}\text { Frame } 2 \times 4 \times 16 \text { in. o.c., } 1 / 2 \text { OSB, } \\
\mathrm{R}-13 \text { batt cavity }+1 \text { in. } \\
\text { R-5 rigid exterior insulation; WRB }\end{array}$ & $\begin{array}{l}2 \times 6 \text { EP\&B framing }(2 \times 8 \text { plates }) \text {, } \\
\text { R-21 cavity insulation, R-10 rigid } \\
\text { insulation, OSB sheathing, WRB }\end{array}$ \\
\hline Foundation & $\begin{array}{l}\text { Foundation walls below } \\
\text { grade }\end{array}$ & $\begin{array}{c}8 \text { in. poured concrete, interior } \\
\text { frame } 2 \times 4 \times 16 \text { in. o.c., } \\
\text { R-13 fiberglass insulation }\end{array}$ & $\begin{array}{c}\text { Superior walls, R-10 rigid }+ \text { R- } \\
19 \text { batt insulation in preformed } \\
\text { cavities }\end{array}$ \\
\hline Windows $^{a}$ & $\begin{array}{c}\text { Area } \\
\text { characteristics }\end{array}$ & $\begin{array}{c}15 \% \text { of wall area } \\
0.35 \mathrm{U} / 0.44 \text { SHGC }\end{array}$ & $\begin{array}{l}12.3 \% \text { of wall area } \\
0.29 \mathrm{U} / 0.31 \mathrm{SHGC}\end{array}$ \\
\hline Air Sealing & Ceiling plane & $7 \mathrm{ACH} 50$ & $1 \mathrm{ACH} 50$ \\
\hline Attic, Vented & Insulation & R-38 blown & R-49 blown cellulose \\
\hline $\begin{array}{l}\text { Heating, } \\
\text { Ventilating, } \\
\text { and Air } \\
\text { Conditioning }\end{array}$ & $\begin{array}{l}\text { Space-conditioning } \\
\text { equipment } \\
\text { Duct distribution } \\
\text { Mechanical ventilation }\end{array}$ & $\begin{array}{c}\text { Heat pump, 3-t, } 13 \text { SEER, HSPF } \\
\text { 7.7, 1-stage } \\
\text { Standard } \\
\text { Bath exhaust fan }\end{array}$ & $\begin{array}{c}\text { Heat pump, 2-t, } 16 \text { SEER, HSPF 9.8, } \\
\text { 2-stage } \\
\text { Simplified central return } \\
\text { Energy recovery ventilation }\end{array}$ \\
\hline Water Heater & & $\begin{array}{l}\text { Electric, } 50 \text { gal, } 0.91 \text { energy } \\
\text { factor }\end{array}$ & $\begin{array}{l}\text { Solar thermal, } 80 \text { gal, } 0.95 \text { energy } \\
\text { factor, electric backup, solar energy } \\
\text { factor } 2\end{array}$ \\
\hline Hot water & Fixture use & $\begin{array}{c}\text { Standard Building America } \\
\text { assumption }\end{array}$ & Low-flow faucets/shower \\
\hline Lighting & Percent high efficacy & $50 \%$ & $100 \%$ \\
\hline Appliances & $\begin{array}{l}\text { Refrigerator } \\
\text { Dishwasher } \\
\text { Clothes washer }\end{array}$ & $\begin{array}{l}\text { Standard } \\
\text { Standard } \\
\text { Standard }\end{array}$ & $\begin{array}{l}\text { ENERGY STAR }^{\circledR} \\
\text { ENERGY STAR } \\
\text { Standard }\end{array}$ \\
\hline
\end{tabular}

${ }^{\mathrm{a}} \mathrm{U}=\overline{\mathrm{U}}$-value in $\mathrm{Btu} / \mathrm{h} \cdot{ }^{\circ} \mathrm{F} \cdot \mathrm{ft}^{2} ; \mathrm{SHGC}$ between 0 and 1 
Based on simulation results and stated features, the source energy savings over the Building America Benchmark was only 40\% (Figure 3).

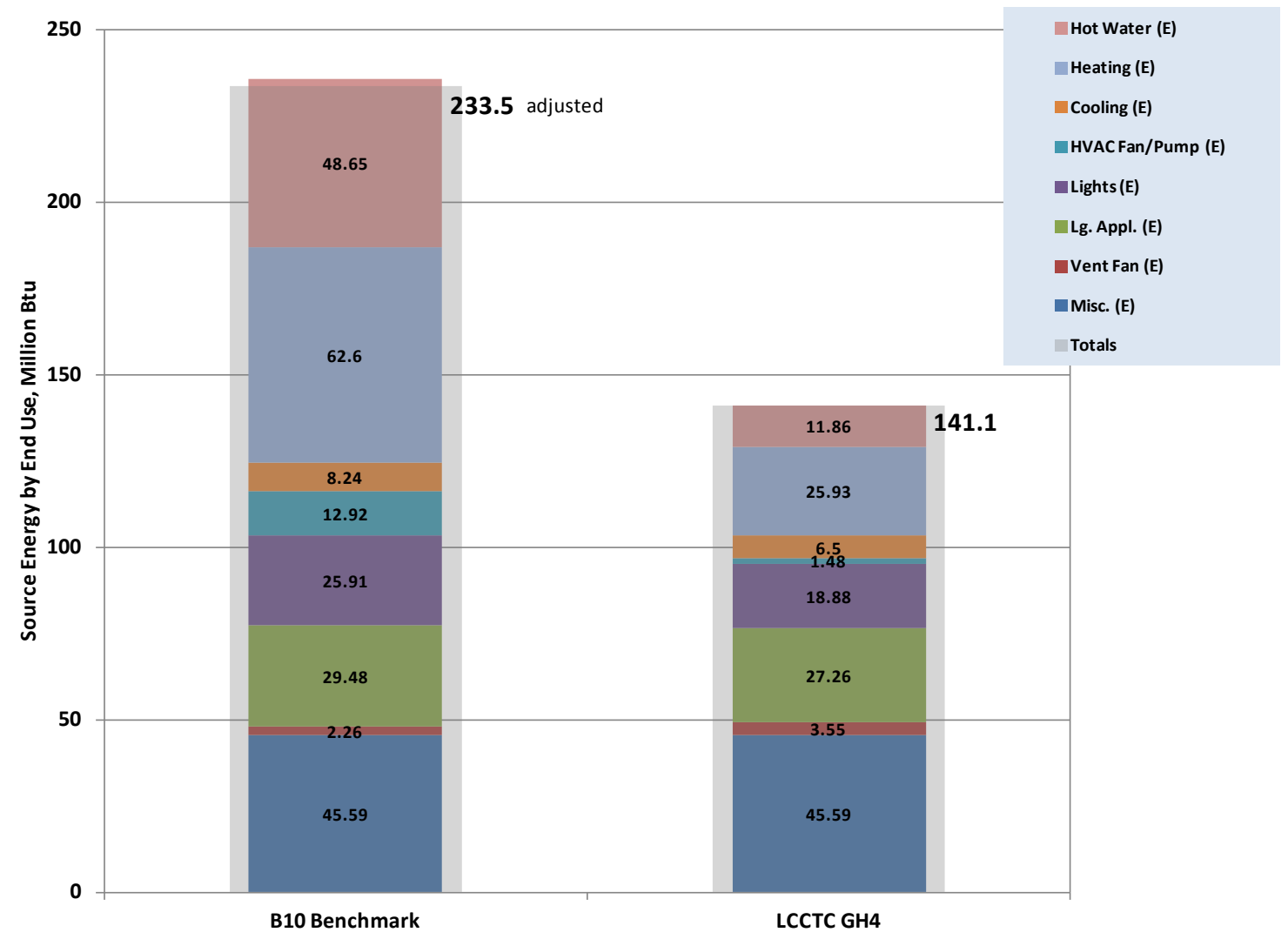

Figure 3. Simulated source energy use

The simulation results, $40 \%$ energy savings over the Building America benchmark, combine energy savings through improved insulation (wall, foundation, and attic), lower infiltration, an efficient heat pump, an energy recovery ventilator for whole-house mechanical ventilation, and a solar domestic hot water system. Because the building site does not have access to natural gas fuel, the Building America benchmark house incorporates a minimum-efficiency heat pump system for space conditioning. The savings from the solar hot water system, though it is not expected to be cost-effective, can be comparable to savings from a heat pump water heater. A detailed analysis was performed by Mallay and Wiehagen (2014).

As a further perspective on the relative affordability, a number of additional simulations were performed to compare the EP\&B wall system to alternative wall systems that have been analyzed in the Building America program and used by builders. The analysis is based on the available models in BEoptE+, Version 2.1.0.0 (expanded in the more recent versions). The wall systems included in the comparison have a range of R-values but are between R-22 and R-30; the ICF has the lowest R-value. ICF technology is included because the previous LCCTC NCTH was constructed using ICF technology and was estimated at $40 \%+$ source energy savings. The simulation analysis was based on the reference home design with all features of the design home (orientation, window areas, finishes, insulation for other envelope features, etc.) the same as the 
reference except the wall system. Figure 4 shows the effect of the wall system alone on heating and cooling source energy use and the savings percent over the reference Building America benchmark home.

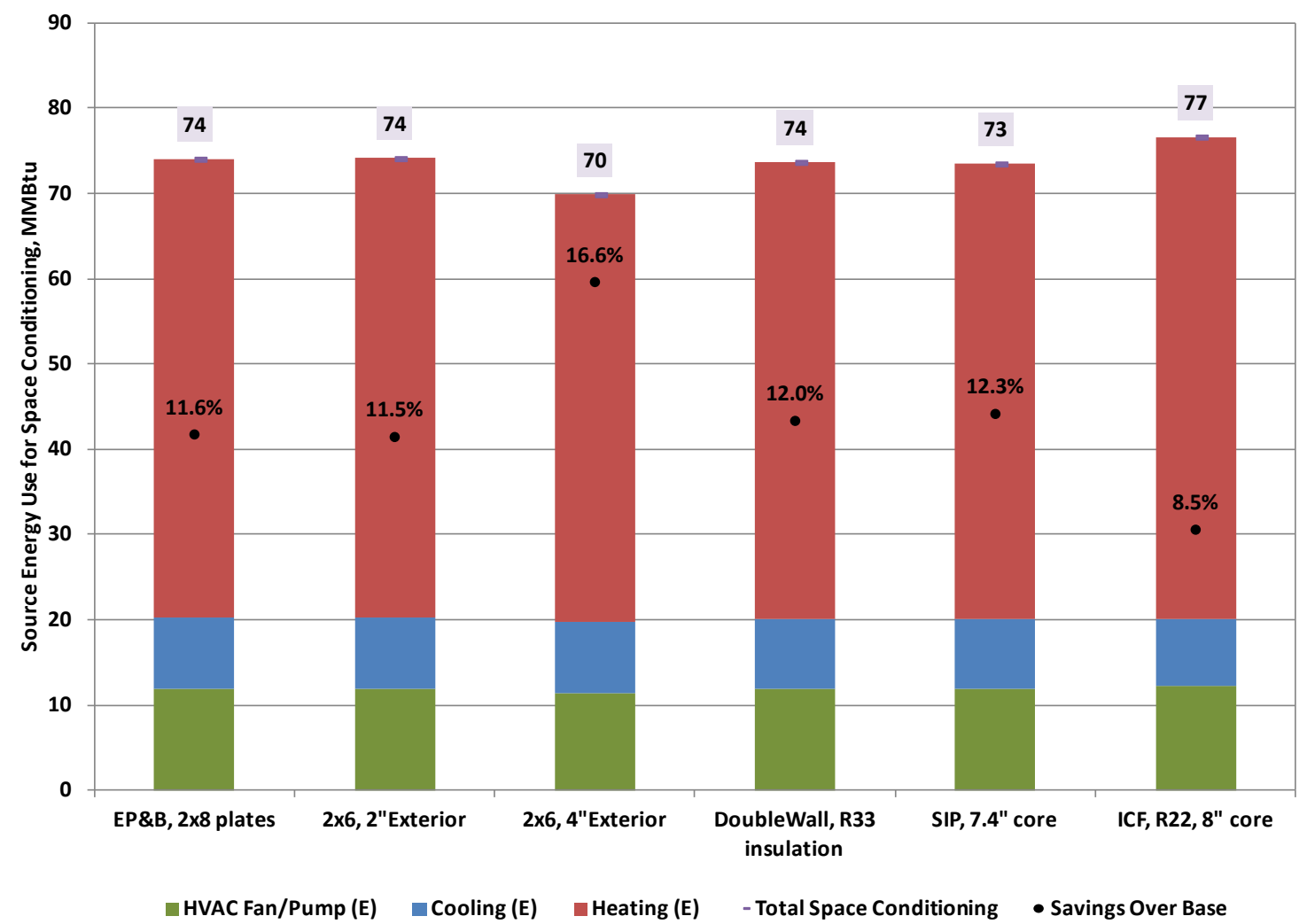

Figure 4. Wall system comparison on energy use

Based on the complement of cost-effectiveness analyses, the EP\&B wall system is expected to compete well with alternative wall solutions that demonstrate similar energy savings.

At the NCTH, the energy recovery ventilator was not installed (see Section 5.2) and the measured house leakage rate was $1.9 \mathrm{ACH} 50$ (see Section 4.2). BEoptE+, Version 2.2.0.1 was used to simulate energy consumption and annualized related energy costs based on these changes using continuous exhaust-only mechanical ventilation and a house leakage rate of 2 ACH50. (All else was the same as the original simulation.)

Figure 5 through Figure 7 show source energy savings of $44.3 \%$ and projected annual energy cost savings of $\$ 1,163$. The estimated incremental cost of energy-efficiency measures is $\$ 14,309$, and the incremental annual mortgage is $\$ 828$. This results in an annual cash flow of $\$ 335$, a simple payback of 12.3 years, and a simple return on investment of $8.1 \%$. 


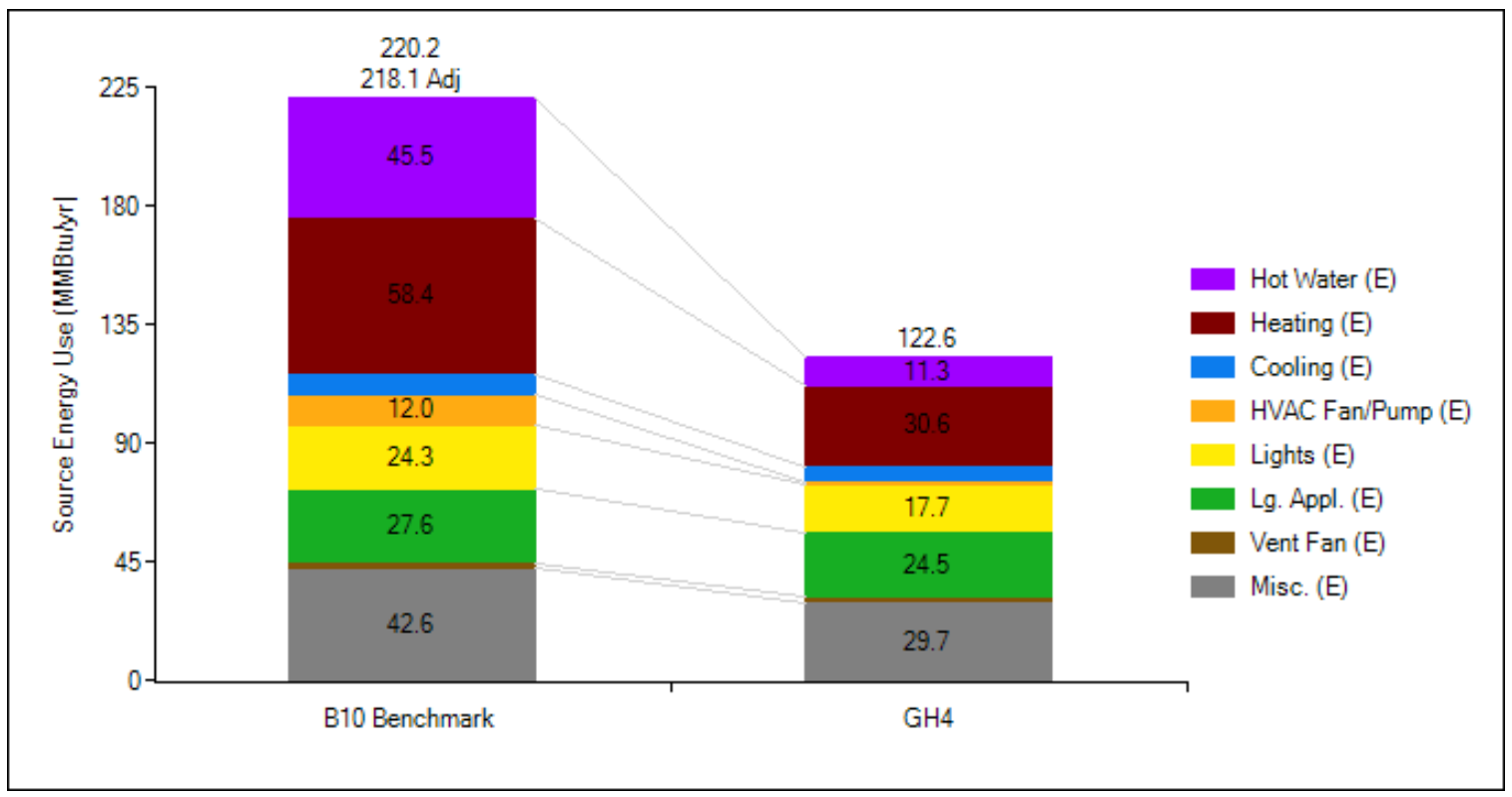

Figure 5. Simulated source energy savings

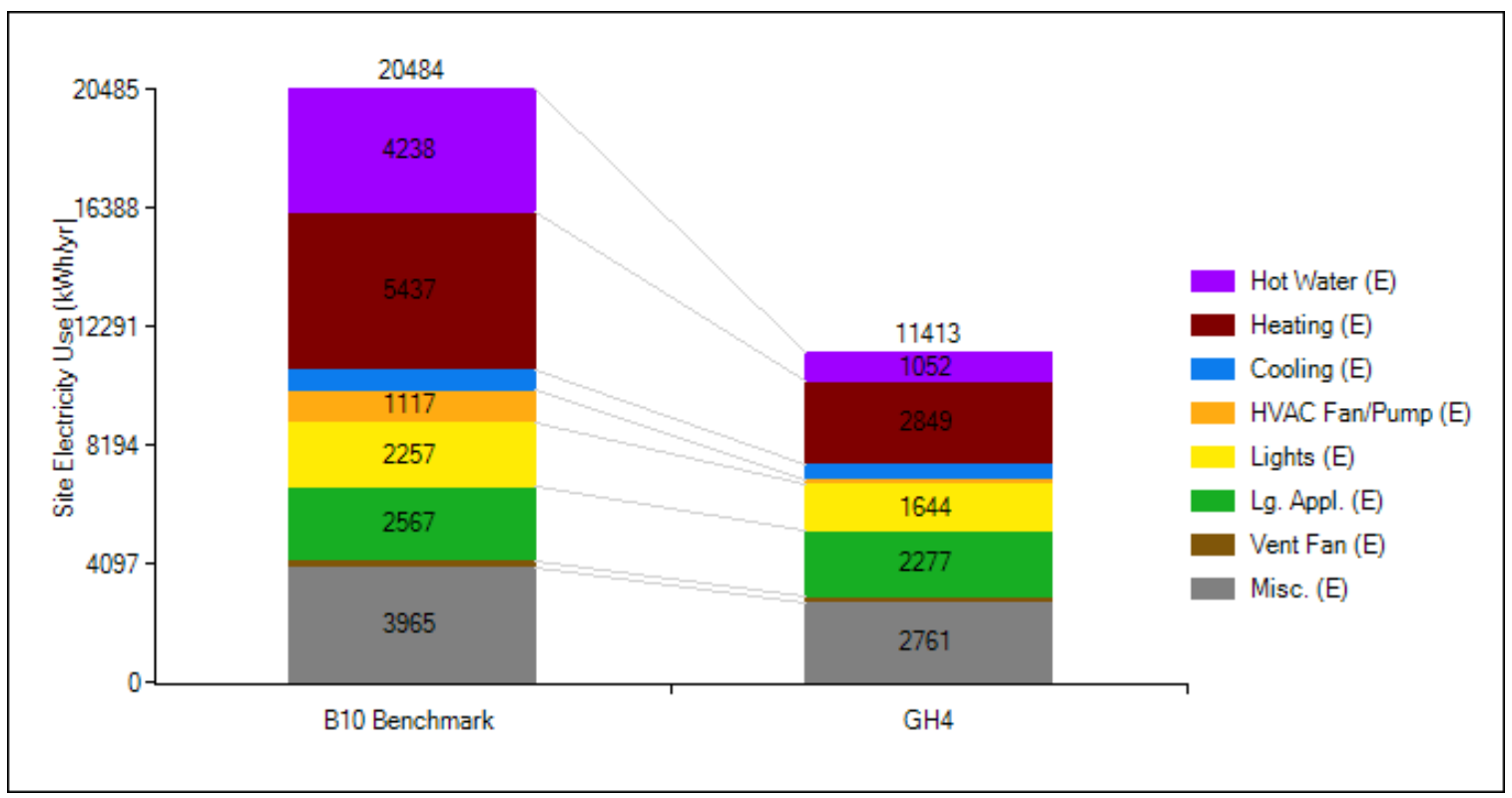

Figure 6. Simulated site energy savings 


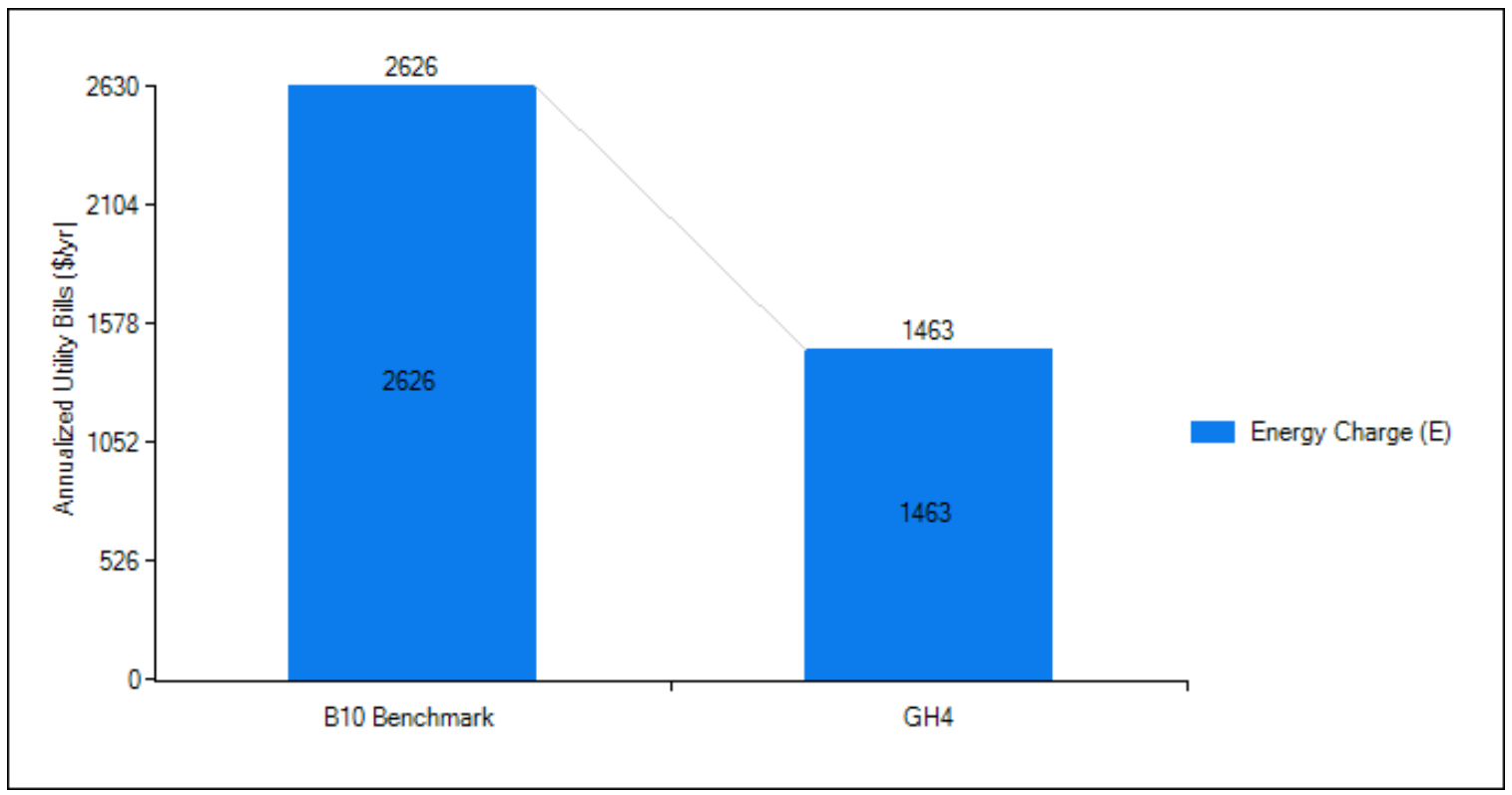

Figure 7. Simulated energy cost savings

\subsection{Trade-Offs and Other Benefits}

Apart from the whole-house savings, this research focuses on the more specific testing and evaluation of the EP\&B wall system, including framing details for the wall, rim headers, and sheathing. Also, air-sealing methods for this unique wall system will be evaluated in more detail. The results will be useful for builders considering switching to higher-efficiency wall systems and for meeting the requirements of the 2012/2015 International Energy Conservation Code.

For heating, natural gas was not available, oil was not considered, and a ground-source heat pump was considered cost-prohibitive. (Although the first two LCCTC project houses did use donated ground-source heat pump units, this option is not available for this home.) In its most recent project, GH3, LCCTC considered a condensing, direct-vent propane gas furnace for the heating system. In that analysis, which was based on preliminary estimated operating costs, a high-efficiency air-source heat pump was determined to be the ideal solution to provide efficient, effective, and affordable space conditioning for this low-load house. In particular, the two-stage equipment was considered to be more flexible in meeting the performance goals of comfort and efficient operation.

Additional benefits of this project include the student education and practical experience gained by learning the construction of the innovative wall system, air-sealing details that are applicable to any house design, and incorporation of high-performance mechanical systems. The local building community was exposed to alternative, advanced technologies and construction methods. The eventual homeowner will also benefit from a durable, healthy, comfortable, and energy- and water-efficient house. 


\section{Experiment}

\subsection{Research Questions}

Based on research gaps and project goals, the research questions for this project are:

1. Were the EP\&B wall and rim construction details implemented as designed, or were field modifications necessary?

2. Given the unique configuration of the sheathing attachment to the wall plates and rim, what questions related to structural details were raised by the code authority having jurisdiction, and how were the structural requirements satisfied to comply with the International Residential Code?

3. What air-sealing details were necessary to achieve a measured infiltration rate design goal of approximately 1 ACH50?

4. Is the EP\&B wall system considered "affordable" compared to similarly performing alternative wall designs?

5. How do the moisture characteristics of the wall cavity and sheathing change over seasonal exterior and interior conditions?

6. Are the elements of the energy-solution package for the NCTH cost-effective and market ready?

\subsection{Technical Approach}

Evaluation of the wall structural system encompasses the implementation of initial design details and modifications developed for this house design, on-site observations during construction, discussions with the project manager to assess implementation issues, staged air infiltration testing to determine airtightness at various levels of construction, and simulation software to analyze expected moisture characteristics of the wall system. Ideally, the moisture analysis would include results from moisture data sensors in the wall system; however, because the house was constructed very recently, no direct moisture data are available at this writing.

Testing of the NCTH was performed as detailed in Table 3 to evaluate the research questions.

Table 3. Test Approach

\begin{tabular}{c|c|c}
\hline Parameter & Method & Purpose \\
\hline $\begin{array}{c}\text { Wall and House Moisture } \\
\text { Performance }\end{array}$ & $\begin{array}{c}\text { Temperature, relative } \\
\text { humidity, and moisture } \\
\text { sensors } \\
\begin{array}{c}\text { House } \\
\text { Leakage/Infiltration }\end{array}\end{array}$ & $\begin{array}{c}\text { Direct measurement of air and } \\
\text { material moisture characteristics }\end{array}$ \\
\hline
\end{tabular}

\subsection{Assessments and Measurements}

On-site construction assessment and a variety of tests and measurements are required to answer the research questions. Specific tests, measurements, equipment, and collected data planned for 
the NCTH to address the testing are detailed in Table 4. The test house will be sold and occupied. The moisture characteristics will continue to be monitored as part of a separate longterm study.

\subsection{Equipment}

In addition to measurement data, Table 4 includes specific test equipment that was used.

Table 4. Test Measurements

\begin{tabular}{|c|c|c|c|}
\hline Parameter & Equipment & Measurement & Range (\#-\#) Accuracy \\
\hline $\begin{array}{l}\text { Wall Sheathing and } \\
\text { House Moisture } \\
\text { Characteristics }\end{array}$ & $\begin{array}{c}\text { Omnisense S-900-1 } \\
\text { sensors }\end{array}$ & $\begin{array}{c}\text { Humidity } \\
\text { Moisture content }{ }^{\mathrm{a}}\end{array}$ & $\begin{array}{c}-40^{\circ} \text { to } 85^{\circ} \mathrm{C} \\
\pm 0.5^{\circ} \mathrm{C} / 2^{\circ} \mathrm{C} \text { maximum } \\
0 \%-100 \% \\
\pm 3.5 \% / \pm 5 \% \text { maximum } \\
7 \%-40 \% \\
\text { (Douglas Fir calibrated) }\end{array}$ \\
\hline $\begin{array}{c}\text { House } \\
\text { Leakage/Infiltration }\end{array}$ & $\begin{array}{l}\text { Minneapolis Model } 3 \\
\text { blower door and } \\
\text { DG700 manometer }\end{array}$ & $\begin{array}{l}\text { CFM50, multipoint } \\
\text { depressurization test }\end{array}$ & $\begin{array}{c}11-6,100 \mathrm{CFM}^{\mathrm{c}} \\
\text { greater of } \pm 4 \% / 1 \mathrm{CFM}\end{array}$ \\
\hline
\end{tabular}

${ }^{a}$ Moisture content of wood-based materials, primarily OSB sheathing

${ }^{\mathrm{b}}$ Sensor calibrated to Douglas Fir wood species; see Appendix C for calibration to OSB.

${ }^{\mathrm{c}}$ Flow range dependent on ring, calibration based on DG700 (accuracy: greater of $\pm 1 \% / 0.15 \mathrm{~Pa}$ )

${ }^{\mathrm{d}}$ Flow rate dependent on metering plate dimension, accuracy with DG700 


\section{Analysis}

\subsection{Extended Plate and Beam Wall System Design and Construction}

This is the initial field application of the EP\&B wall system design. The design of the EP\&B wall system was an iterative process. Proof-of-concept structural testing of full-size wall specimens was performed at the accredited laboratory of Home Innovation to evaluate the shear and gravity capacity of the EP\&B system. For the NCTH, Home Innovation staff worked with an experienced structural engineer, LCCTC staff, and an architectural design firm from Pennsylvania to develop a set of details and plans. Due to the unique characteristics of the framing system, Home Innovation developed initial drawings on which the design team based the final plan details, modifying aspects of the structural design and material selection for this specific project.

The NCTH plans included wall and rim details, attachment requirements, and a material takeoff list. The wall framing consists of $2 \times 6,24$-in. o.c. studs, nominal $2 \times 8$ bottom plate and second top plate, $2 \times 6$ first top plate, $2 \times 6$ window rough opening, and nominal $2 \times 8$ door rough opening (for a more solid door attachment). For the nominal $2 \times 8$ framing components, $2 \times 10$ lumber was ripped to 7.5 -in. width. This width allows for a full 2-in. thickness of foam (a nominal $2 \times 8$ measures an inconsistent $7.25 \mathrm{in}$.).

The first-floor rim boards were 1.25-in.-thick engineered and lumber factory laminated to 1-in.thick rigid foam insulation (foil-faced polyisocyanurate) and installed with the insulation facing indoors. Additional 2-in.-thick rigid foam insulation (XPS) was installed as the floor joists were installed. The rim boards were connected to the floor joists using 5/16-in. $\times 6$-in.-long structural screws.

The second-floor rim boards, designed as structural rim headers (to eliminate conventional headers above first-floor windows and doors) were 3.5-in.-thick engineered lumber laminated to 1.5-in.-thick insulation (polyisocyanurate) and 7/16-in.-thick OSB (total rim board thickness 5.5 in.) and installed with the OSB and insulation facing outdoors. This product was also installed as the window header in the second-story walls.

Windows were attached using 4-in.-long nails through the flange and foam and into the $2 \times 6$ framing. Doors were attached using conventional methods to the nominal $2 \times 8$ framing. Vinyl siding was attached using 1.5 -in.-long roofing nails 16 in. o.c.

The approved plans for the NCTH are presented in Appendix A. The EP\&B details (from page 6 of the full set of plans) are shown in Figure 8 through Figure 15. 


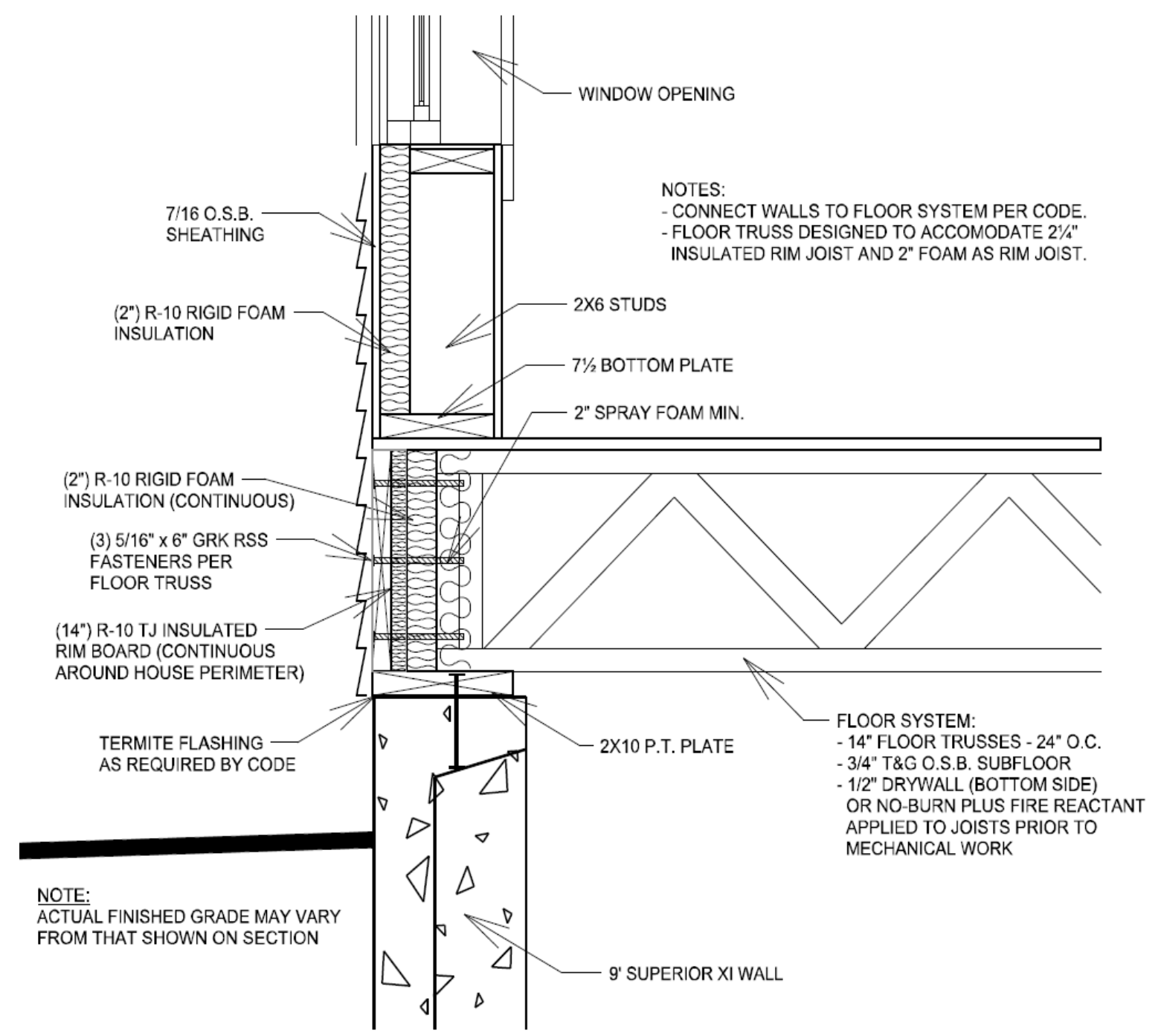

Figure 8. EP\&B first-floor rim board detail 


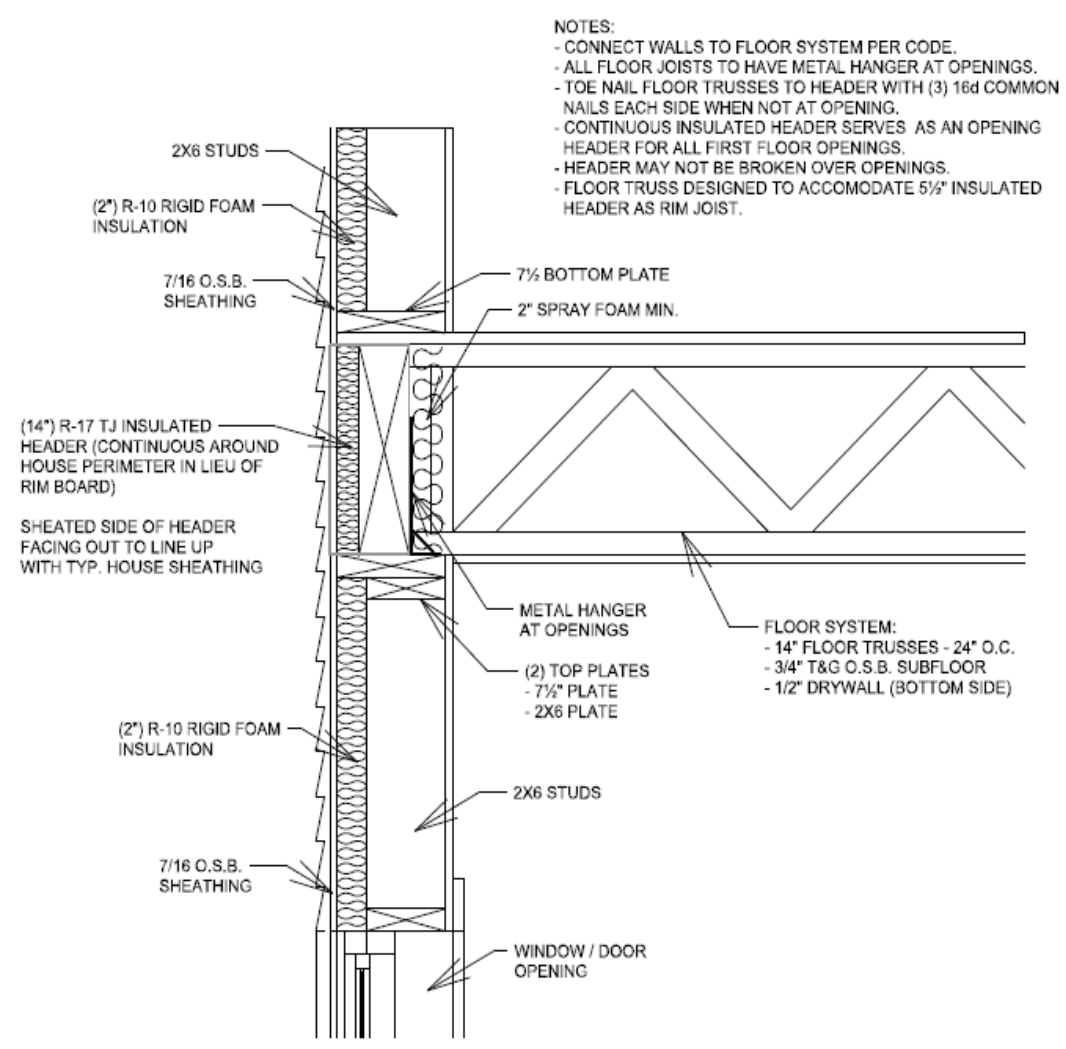

Figure 9. EP\&B second-floor rim board/header detail

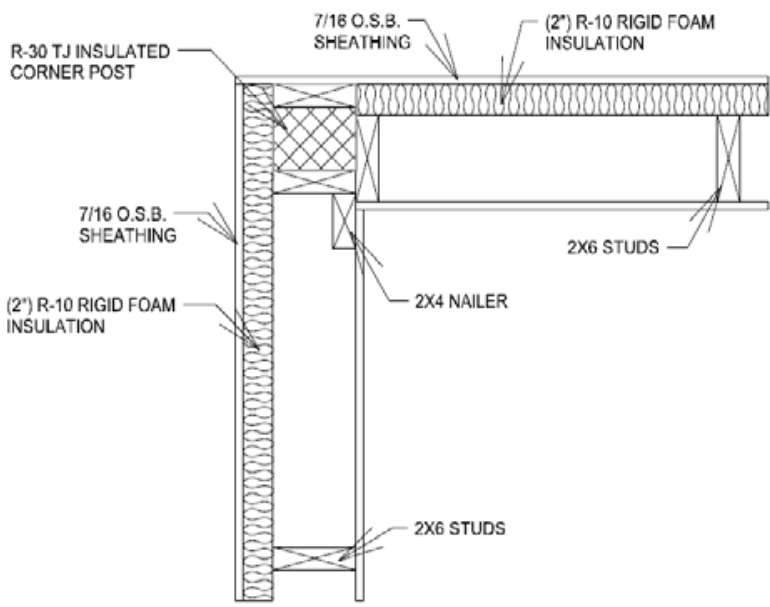

Figure 10. EP\&B exterior corner detail

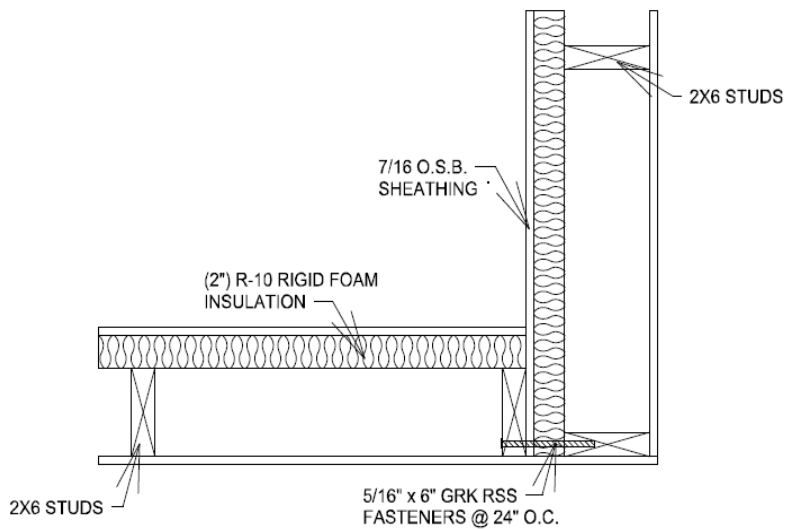

Figure 11. EP\&B interior corner detail 


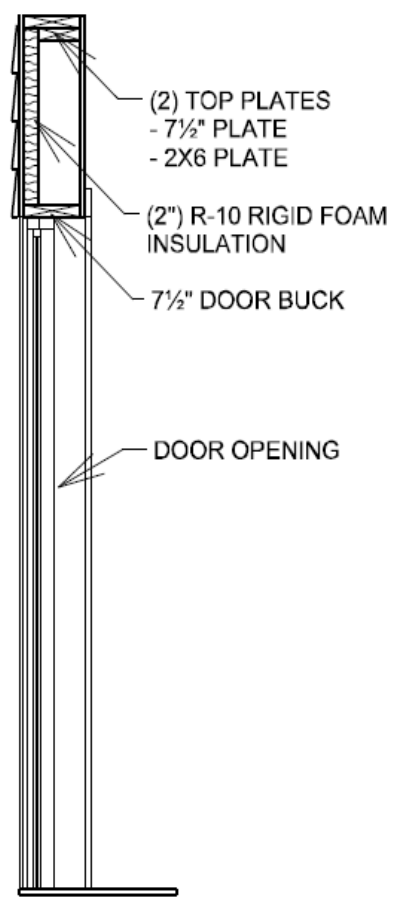

Figure 12. EP\&B door/wall assembly detail

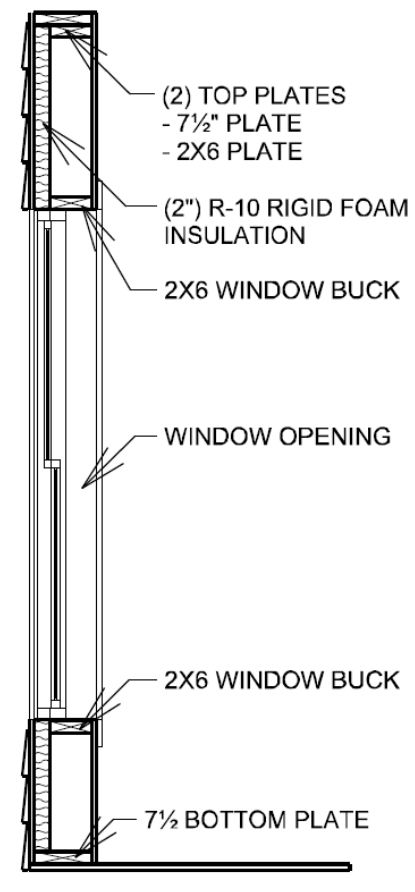

Figure 13. EP\&B window/wall assembly detail

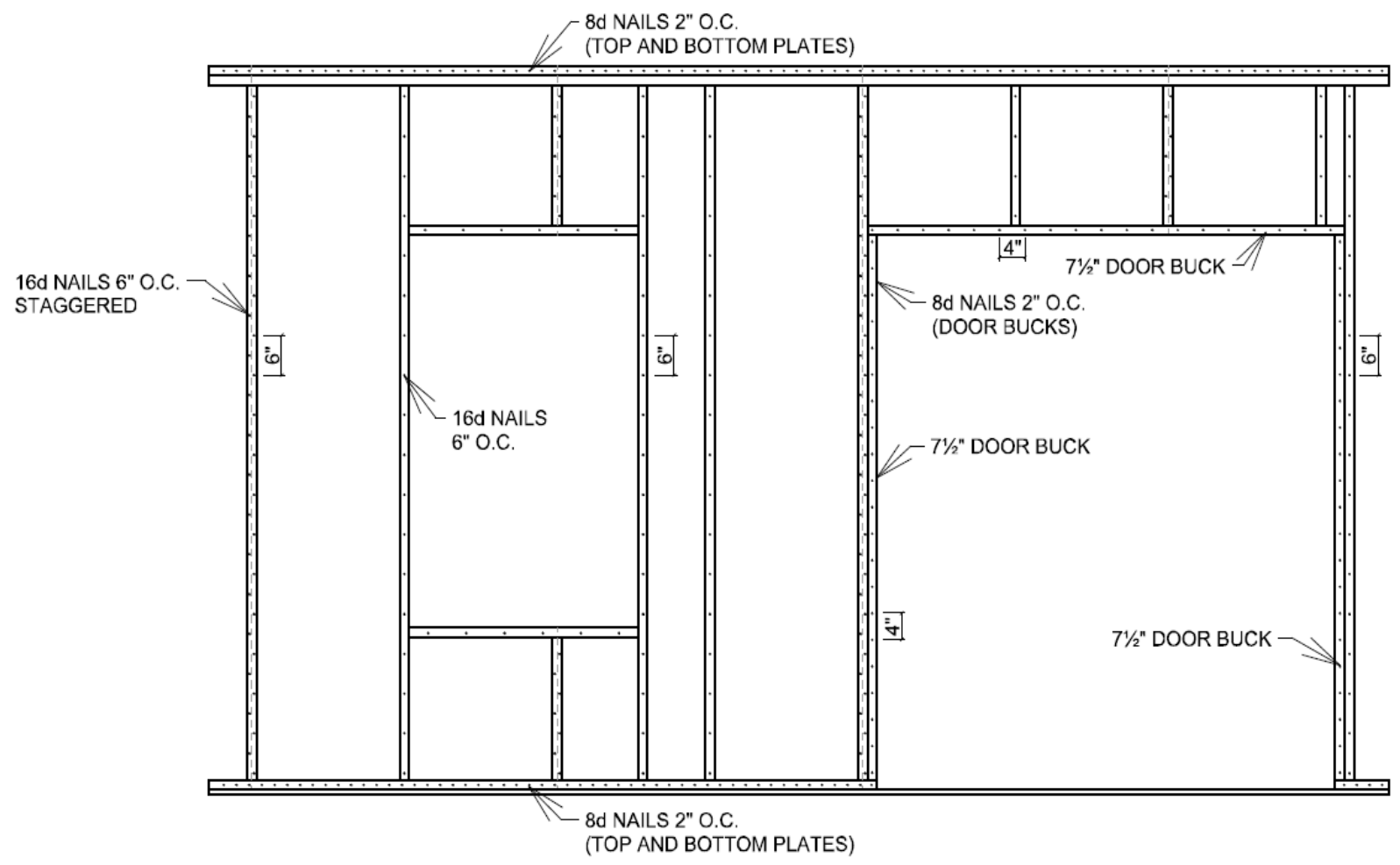

Figure 14. EP\&B wall assembly detail 


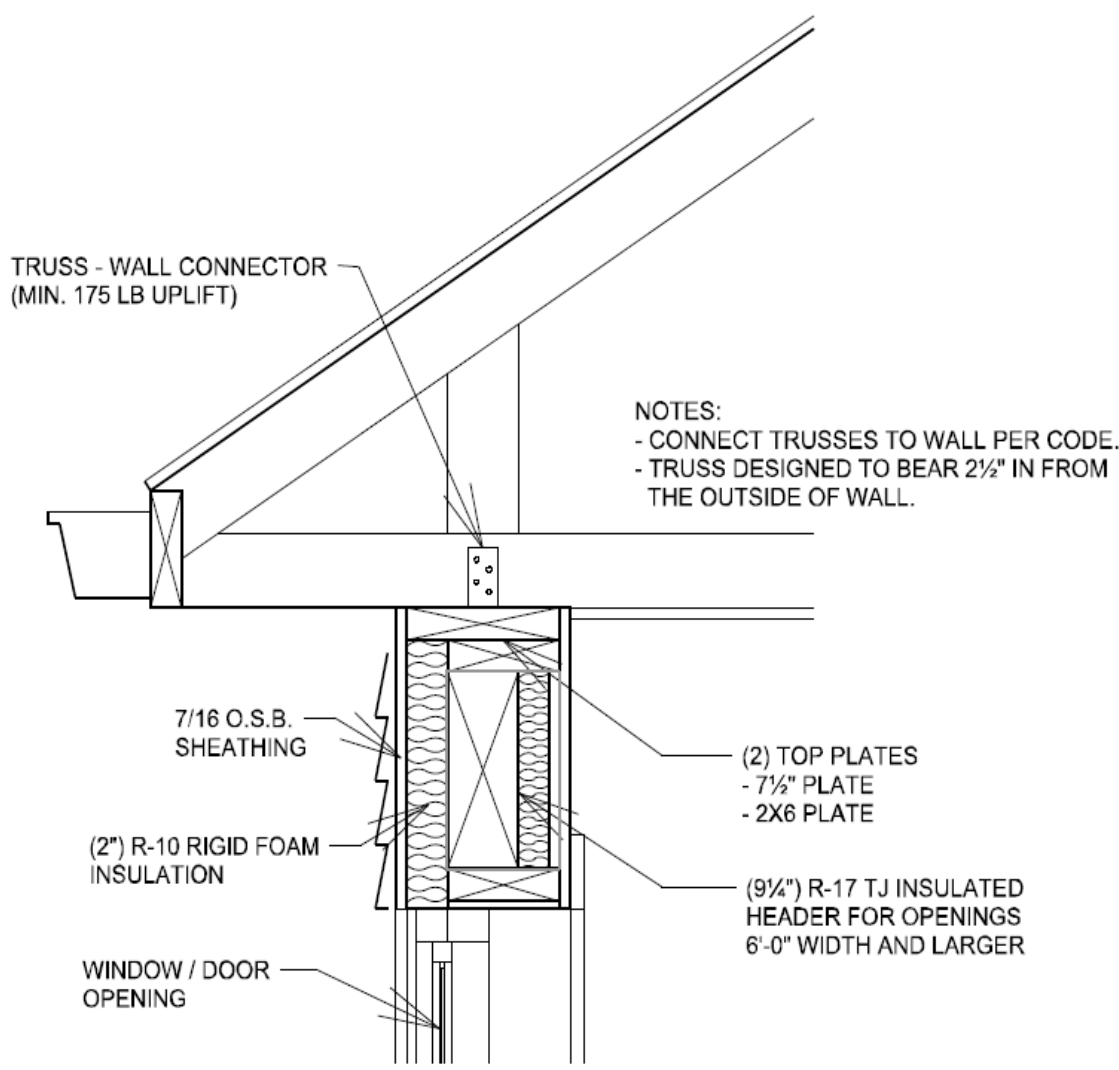

Figure 15. EP\&B second-floor header detail

Table 5 summarizes the wall framing details and their implications for the design and construction process. 
Table 5. EP\&B System Construction Detail Evaluation

\begin{tabular}{|c|c|c|}
\hline Construction Detail & $\begin{array}{c}\text { EP\&B System Implementation } \\
\text { Issues }\end{array}$ & Evaluation Aspect \\
\hline $\begin{array}{c}\text { Engineered Insulated } \\
\text { Rim Board }\end{array}$ & $\begin{array}{l}\text { - Effect on floor joist length } \\
\text { - Installation based on load path } \\
\text { - Rim-joist attachment }\end{array}$ & $\begin{array}{l}\text { - Additional rim thickness must be accommodated when floor } \\
\text { truss designs are used that cannot be field cut. I-joist and solid } \\
\text { lumber may be field modified } \\
\text { - Rim thickness reduces the floor joist bearing surface, which } \\
\text { must be accounted for in the design using sufficiently wide top } \\
\text { plates or joist hangars } \\
\text { - Care must be taken to avoid insulation distortion due to } \\
\text { attachments through the foam board }\end{array}$ \\
\hline Wall Framing & $\begin{array}{l}\text { - Layout of plates and studs and } \\
\text { rough opening framing } \\
\text { - OSB sheathing attachment } \\
\text { - Load path layout of plates and } \\
\text { studs (rim) }\end{array}$ & $\begin{array}{l}\text { - The plan must be carefully reviewed to identify locations for } \\
\text { extended plates and door opening framing members and } \\
\text { number of king studs at rough openings } \\
\text { - Use of 4-in. nails may require special tools and nail selection } \\
\text { - Installation of OSB using close nail spacing is outlined on } \\
\text { approved plans } \\
\text { - Attention must be paid to sheathing attachment through foam to } \\
\text { studs using guidelines } \\
\text { - Special attention must be paid to identify rim location to } \\
\text { support the extended plates }\end{array}$ \\
\hline Corner Framing & $\begin{array}{l}\text { - Standard corner details } \\
\text { - Installation of engineered } \\
\text { insulated outside corners } \\
\text { - Installation of EP\&B inside } \\
\text { corners }\end{array}$ & $\begin{array}{l}\text { - Advanced framing corner details may be used but must } \\
\text { accommodate the thicker wall profile } \\
\text { - Special materials must be specified if engineered corner } \\
\text { product } \\
\text { - Nail length must be specified to achieve penetration depth } \\
\text { - Load capacity and insulating values must be identified for } \\
\text { engineered products } \\
\text { - Nailing surfaces must be accommodated for finishes }\end{array}$ \\
\hline
\end{tabular}




\begin{tabular}{|c|c|c|}
\hline Construction Detail & $\begin{array}{c}\text { EP\&B System Implementation } \\
\text { Issues }\end{array}$ & Evaluation Aspect \\
\hline Windows and Doors & $\begin{array}{l}\text { - Installation over wood sheathing } \\
\text { through foam board to stud } \\
\text { - Flashing details } \\
\text { - Window finishing }\end{array}$ & $\begin{array}{l}\text { - Nail or screw length must accommodate foam thickness to stud } \\
\text { - Plumb/square methodology must be used } \\
\text { - WRB must be integrated similar to standard guidelines } \\
\text { - Sill and flange flashing need to be installed } \\
\text { - Window jamb features need to accommodate additional wall } \\
\text { thickness (custom order or field cuts) } \\
\text { - Interior finish options and attachments must be specified to } \\
\text { accommodate foam at edges of openings }\end{array}$ \\
\hline Air Sealing & $\begin{array}{l}\text { - Wall cavity, plates, rim, and } \\
\text { openings }\end{array}$ & $\begin{array}{l}\text { - Rim edges must be foamed or caulked as standard practice } \\
\text { - Area between plates must be foamed or caulked at base plate } \\
\text { - Intersections of engineered products and wall system (corners, } \\
\text { rim, windows) must be foamed or caulked } \\
\text { - foam board must be sealed at studs (all cavities, optional) } \\
\text { - Product compatibility and timing must be identified to } \\
\text { minimize trade conflicts }\end{array}$ \\
\hline
\end{tabular}




\subsection{Wall Cavity Moisture Characteristics}

Of particular interest to builders for the EP\&B wall system (and for all advanced wall systems), are the moisture characteristics in the cavity and sheathing. In a high-performance home where the infiltration leakage is minimized for the wall system and for the whole house, the moisturehandling characteristics of the wall are critical. Detailed analyses of the moisture capability of the EP\&B wall system are being evaluated in other related projects; the measurements for this $\mathrm{NCTH}$ support the ongoing evaluation of the EP\&B wall design. Initial moisture performance simulations using WUFI ${ }^{11}$ software were performed to provide a baseline confidence in the moisture performance of the wall system. These initial estimates have shown that the moisture characteristics of the wall cavity and the moisture content of the wall sheathing raise no particular concerns about the long-term durability of the wall system. As an example of a WUFI simulation performed for a cold climate and for the two types of EP\&B systems with vinyl siding, the sheathing moisture content in a north-facing wall section changes only slightly (see Figure 16). The sheathing is to the exterior of the cavity and the foam board.

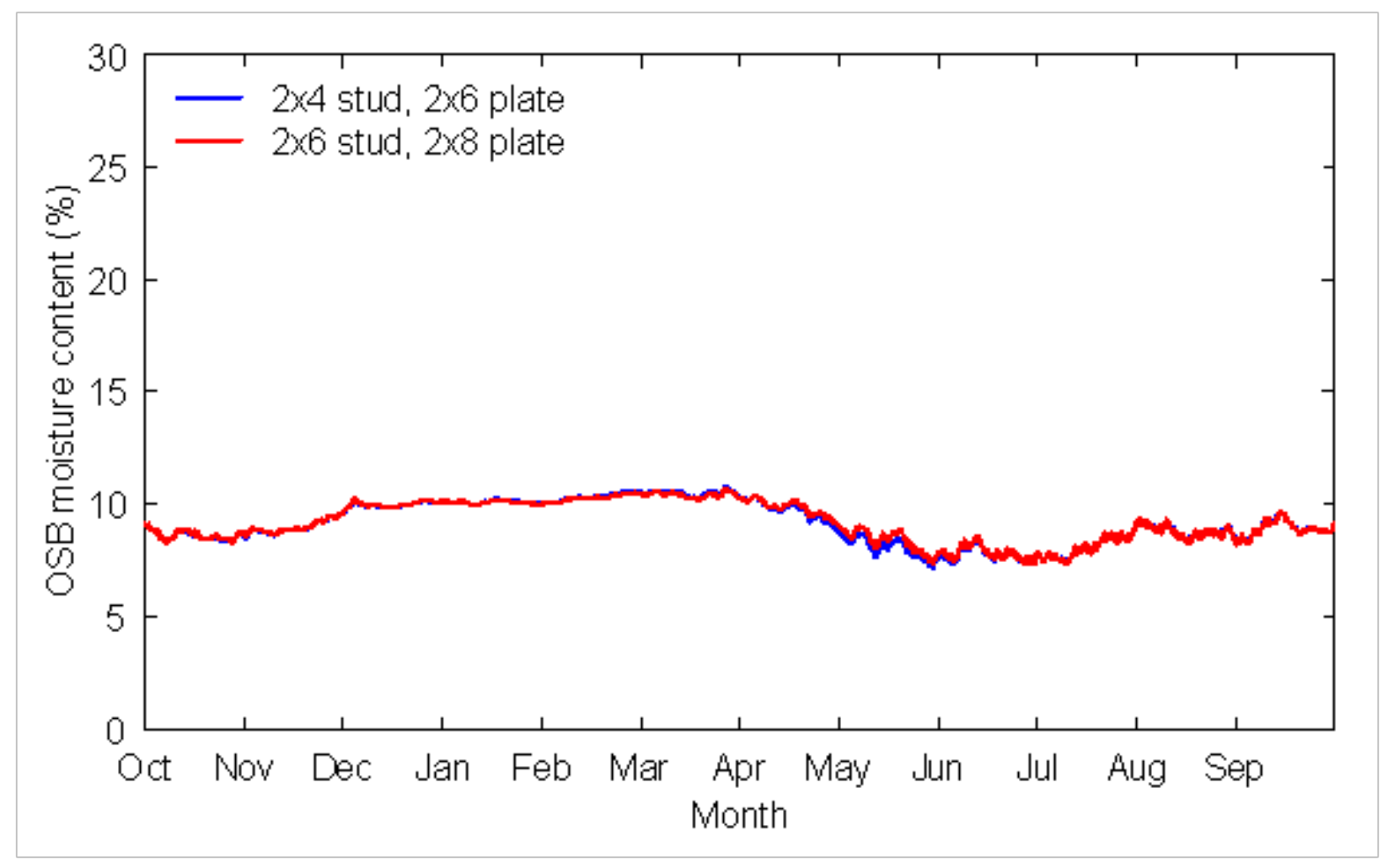

Figure 16. WUFI simulation

\footnotetext{
11 "WUFI is a family of software products that allows realistic calculation of the transient coupled one- and twodimensional heat and moisture transport in walls and other multilayered building components exposed to natural weather. WUFI is an acronym for Wärme Und Feuchte Instationär, which, translated, means heat and moisture transiency. WUFI software uses the latest findings regarding vapor diffusion and moisture transport in building materials. The software has been validated by detailed comparison with measurements obtained in the laboratory and on IBP's outdoor testing field." Description from www.wufi.de/index e.html, last accessed 12/12/2013.
} 
WUFI simulations are based on assumed conditions of the interior and long-term weather data for the exterior, so actual field measurements provide direct data about changes in the moisture levels at various locations in the wall system and qualify simulation results.

Omnisense moisture sensors were installed in the wall cavities in various locations. A set of sensors was installed in the wood structural sheathing between the foam and sheathing. Another set of sensors were installed in the framing on the interior side of the foam sheathing. Data from these sensors will indicate the dew point level in the cavity and the moisture accumulation in the wood sheathing and in the framing inside the cavity.

\subsection{Wall System Air Sealing}

The maximum house leakage allowed by code in this climate is $3 \mathrm{ACH} 50$. The house leakage goal for the NCTH was 1-2 ACH50. LCCTC was interested in using conventional and readily available air-sealing products to meet this goal. The air-sealing approach for the NCTH is detailed in Table 6. 
Table 6. NCTH Air Sealing Details

\begin{tabular}{|c|c|c|c|}
\hline Critical Area & Details & Product $^{\mathrm{a}}$ & When Sealed \\
\hline \multicolumn{4}{|c|}{ Ceiling } \\
\hline Top Plates & Exterior and partition walls, from attic & Canned foam & After ceiling \\
\hline Penetrations & Bath fans and electrical boxes, from attic & Canned foam & After ceiling \\
\hline Framed Cavities & Duct chase air barrier, from attic & Canned foam & After ceiling \\
\hline Access Panel & Gasket and insulate to R-38 & Gasket & After ceiling \\
\hline \multicolumn{4}{|l|}{ Rim Joist Area } \\
\hline Rim Board & At butt joints, sill/top plates, floor deck & Canned foam & During framing \\
\hline Sill Plate & At foundation capillary break & Caulk & During framing \\
\hline \multicolumn{4}{|c|}{ Walls } \\
\hline Rigid Foam & At edges before sheathing — not specified & N/A & N/A \\
\hline Rigid Foam & At stud cavity (picture frame) & Canned foam & $\begin{array}{l}\text { After first intermediate } \\
\text { house leakage test }\end{array}$ \\
\hline Top Plates & Between, from interior & Caulk & After framing \\
\hline Bottom Plates & At deck & Caulk & After framing \\
\hline Wall Panels & At corners and panel-to-panel seams & Canned foam & Framing \\
\hline Sheathing & From exterior & $\mathrm{N} / \mathrm{A}$ & N/A \\
\hline House Wrap & All seams taped shingle fashion & Builder tape & During installation \\
\hline Penetrations & Opening, seal, and flash minimized & Canned foam & After framing \\
\hline Windows and Doors & At rough opening & W\&D foam & After framing \\
\hline Behind Bathtub & At the air barrier (house wrap) & Canned foam & Before drywall \\
\hline Behind Stairs & At drywall interrupted by framing & Canned foam & Before drywall \\
\hline Framed Cavities & Soffits or tray ceilings & $\mathrm{N} / \mathrm{A}$ & N/A \\
\hline \multicolumn{4}{|c|}{$\begin{array}{l}\text { Fireplace } \\
\end{array}$} \\
\hline $\begin{array}{l}\text { Bump-Out behind } \\
\text { Fireplace }\end{array}$ & $\begin{array}{l}\text { At walls (seal, insulate, seal air barrier), floor } \\
\text { (cantilevered), and ceiling }\end{array}$ & Canned foam & After framing \\
\hline
\end{tabular}

a Product: "Canned foam" indicates DOW Great Stuff Pro Gaps \& Cracks applied using application gun. "W\&D foam" indicates DOW Great Stuff Window and Door low expansion sealant applied using application gun. "Gasket" indicates foam weather strip or equivalent. 
Drywall was installed and sealed on the second-floor ceiling (only) before wall insulation and other drywall to test the air-sealing functionality of the EP\&B wall design as constructed. This unusual sequence allows for intermediate house leakage testing to investigate leakage areas, particularly in the EP\&B wall system before wall insulation and drywall, when resealing is relatively simple and inexpensive.

During construction - and due to the student trade educational component - air sealing was added at some of the rim components and between wall foam sheathing pieces where larger gaps were observed. These locations are out of sequence for typical air-sealing methods but are easily addressed during wall fabrication.

\subsection{Mechanical Systems}

The entire heating and cooling system is installed in conditioned space in the NCTH. This minimizes energy loss to outdoors and reduces house leakage by eliminating the pressure drivers caused by duct leakage where ducts are not in conditioned space. The air handling unit and ductboard supply trunk duct are in the basement. Metal supply branch ducts feed perimeter floor registers for the first and second floors. The supply branches rise through interior walls for the second floor. Manual airflow balancing dampers are specified for each supply branch at the trunk. Although supply duct layout is relatively conventional, the return duct layout is a simplified central return, through a two-story chase, serving one return grille per level. Transfer grilles for the bedrooms and den provide a low-resistance return air path when doors are closed.

The heating and cooling air distribution duct layout was designed using software in accordance with ACCA Manual J (ACCA 2006) load calculations and Manual D (ACCA 2009a) duct design. The two-stage air-source heat pump was selected, in accordance with ACCA Manual S requirements (ACCA 2004), to meet cooling loads in low-stage. This selection enables the heat pump system to provide additional heat in high stage during the heating season to reduce reliance on the electric resistance supplemental heaters in the air handling unit.

Source-exhaust and whole-house mechanical ventilation equipment was selected for quiet and efficient operation and capacities in accordance with building codes and industry standards. The associated duct layouts were designed in accordance with ACCA Manual D procedures (similar to the heating and cooling duct layout). These duct layouts were inspected during the rough-in stage to confirm duct sealing, insulation, and geometry to ensure the shortest path to outdoors. The systems were tested to confirm that measured airflow rates meet design requirements.

The water heater (solar-thermal storage tank with electric supplemental heater) was placed in the basement near the riser to the second-floor bathrooms (a different location than shown on the house plans) to minimize piping lengths for the cross-linked polyethylene manifold plumbing system. Domestic hot water pipe lengths were measured after installation. The volume of water from the water heater to the furthest fixture (master bath shower), including the manifold, was estimated at 62.6 ounces, slightly less than the 64-ounce volume requirement for hot water delivery under the ZERH program. 


\section{Results}

\subsection{Extended Plate and Beam Wall System}

A significant element of the successful design and construction of an advanced wall system is the integrated effort of the designers, builder, engineering consultants, product suppliers, and trade contractors. Each key stakeholder understood his or her respective role and followed through to provide the information necessary at each stage of planning and development.

Design details included product selection, in particular engineered products that would simplify installation and achieve high levels of thermal performance. Sufficient levels of attachment specificity were necessary to achieve the structural performance and were key elements of the engineering design.

Based on the unique characteristics of the wall system, engineered designs are necessary at this stage in the development. However, with further development and construction experience, the wall design is intended to be developed in such a manner to be prescriptively designed using provisions in the International Residential Code.

At the time of construction, standard nail guns accepted nails as long as 3.5-in. A special nail gun was purchased to accommodate the required 4-in.-long, 0.131-in. diameter nails used in the wall sheathing over the 2 -in. foam board. Since then, new products have been identified that can handle nails longer than $4 \mathrm{in}$. and the shorter 3- or 3.5-in. nails commonly used for framing.

Overall, the changes were minimal and intuitive once an initial wall section was framed, and the production manager and framing lead successfully communicated the changes to standard framing practices to incorporate the EP\&B system. The learning curve was achievable and acceptable.

\subsubsection{Extended Plate and Beam System Implementation}

The insulated rim boards for the first floor consisted of 1.25-in.-thick engineered lumber laminated to 1-in.-thick insulation (foil-faced polyisocyanurate). These were installed with the insulation facing indoors. Additional 2-in.-thick rigid foam (XPS) was installed as the floor truss joists were installed (Figure 17 and Figure 18). The rim boards were connected to the floor joists using 5/16-in. $\times 6$-in.-long structural screws (Figure 19). The insulation did not appear to distort as the screws were installed. The $2 \times 10$ sill plate installed over the Superior Wall foundation provided approximately 5 in. of bearing surface for the floor joists (9.25-in. sill, less 2.25 -in. insulated rim, less 2-in. XPS). 


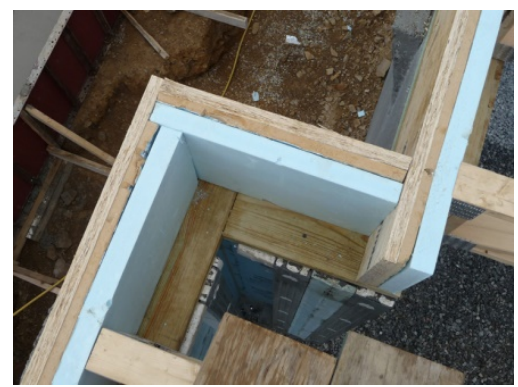

Figure 17. First-floor rim assembly

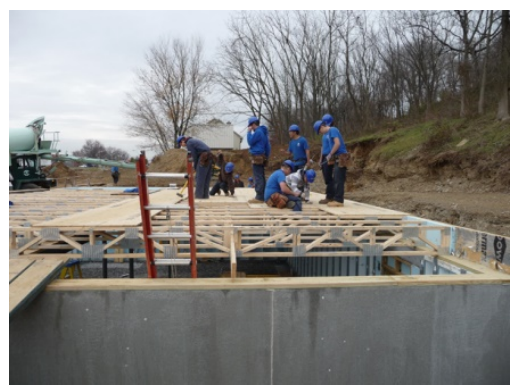

Figure 18. First-floor framing

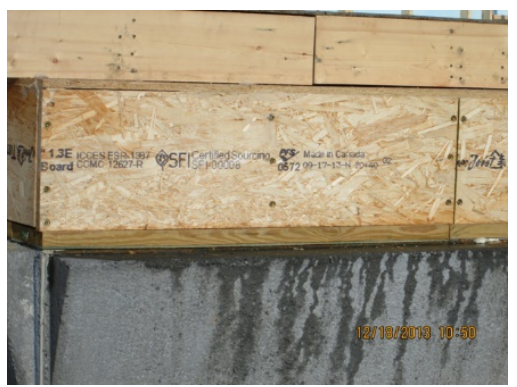

Figure 19. Structural screws at rim joint

Walls were framed on the floor deck (Figure 20) and squared in a conventional manner.

Insulated corners consisted of one 1.5-in.-thick engineered lumber stud laminated to 4-in.-thick foam insulation (5.5-in. $\times 5.5$-in. assembly). The factory-insulated corners installed quickly and provided structural nailing surfaces and nailing surfaces for siding and drywall (Figure 21). For some wall sections, the rigid foam was installed before the second top plate (Figure 22 and Figure 23). For most wall sections, the rigid foam was installed after the second top plate (Figure 24).

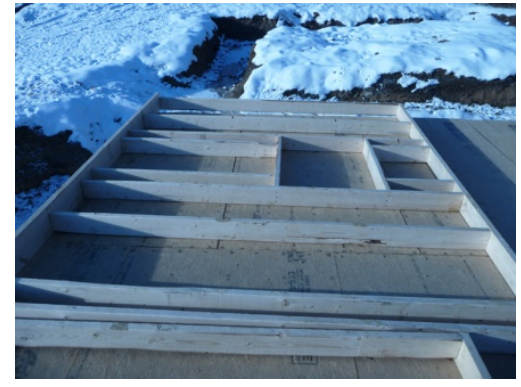

Figure 20. Wall framing

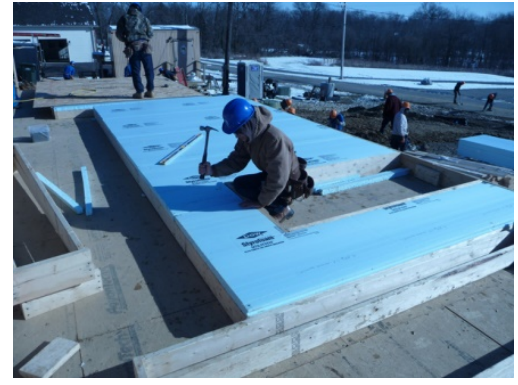

Figure 22. Foam sheathing

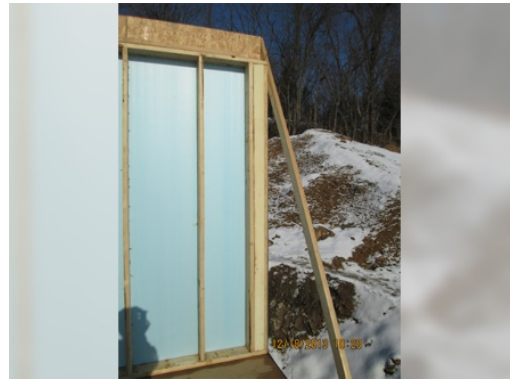

Figure 21. Insulated corner

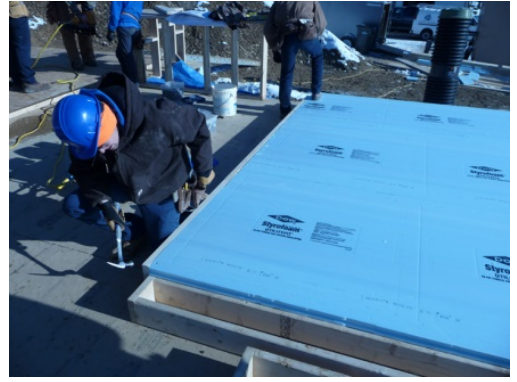

Figure 23. Second top plate

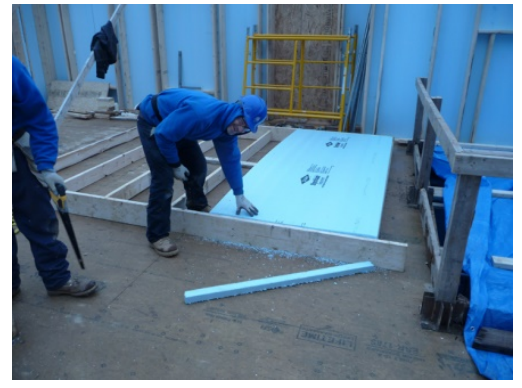

Figure 24. Foam sheathing

Wall sheathing was installed using an attachment nailing pattern of 2 in. o.c. at the bottom plate and second top plate and 6 in. o.c. in the field (Figure 25 and Figure 26). In the field of the sheathing, 4-in.-long nails were required to ensure a minimum 1.5-in. penetration of the wall studs through 2-in.-thick foam. A nail gun that could handle 4-in. nails was requisitioned for this project because LCCTC's standard gun was designed for nails up to 3.5-in. long. Standard length nails could have been used at the plates, but using two different length nails was not considered 
practical, so all sheathing attachment nails were 4-in. long. The close nailing pattern at the plates did not appear to cause any difficulty or sheathing deformation.

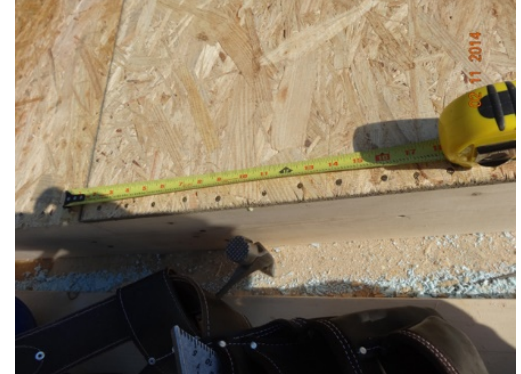

Figure 25. Sheathing nailing at plates

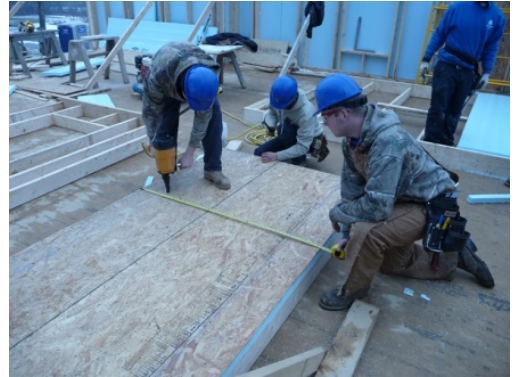

Figure 26. Sheathing nailing in the field

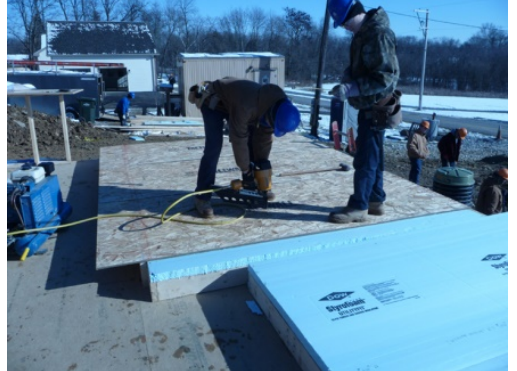

Figure 27. Sheathing overhang

The 10-ft long wall sheathing for the 9-ft tall first-floor wall was installed vertically and flush with the bottom plate. This installation resulted in an overhang above the top plates (Figure 27 and Figure 28). Some sections of second top plates were left off during wall framing to allow a second top plate overlap at corners and intersections (Figure 29). After these sections of second top plates were installed, the sheathing was secured to the second top plate from a ladder.

The second-floor structural rim headers were installed after the first-floor walls (Figure 30). The insulated rim boards consisted of 3.5-in.-thick engineered lumber laminated to 1.5-in.-thick insulation and 7/16-in.-thick OSB (total thickness 5.5 in.). These were installed with the insulation and OSB facing out (Figure 31). The 7.5-in.-wide top plate provide a 2-in.-wide bearing surface for the floor joists (Figure 32). Next, second-floor joists were installed (Figure 33). Joist hangers were installed at windows and doors (Figure 34 and Figure 35).

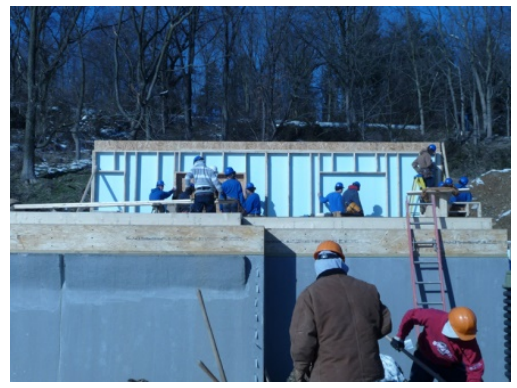

Figure 28. Typical wall

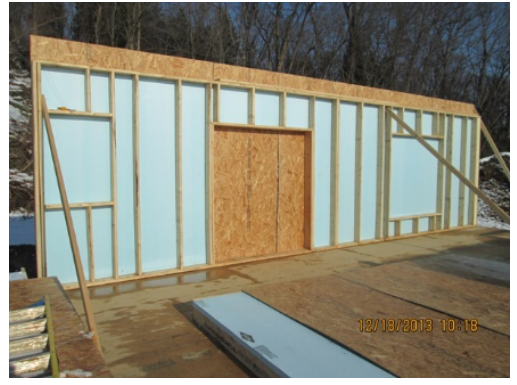

Figure 29. Second top plate detail

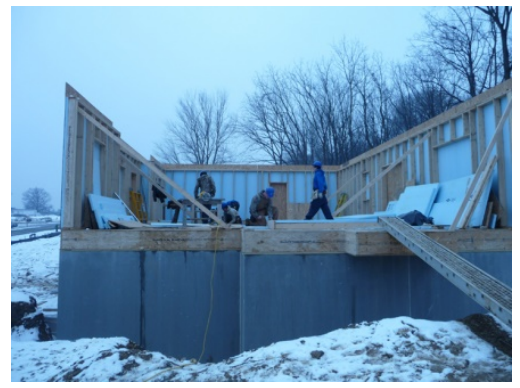

Figure 30. First-floor walls 

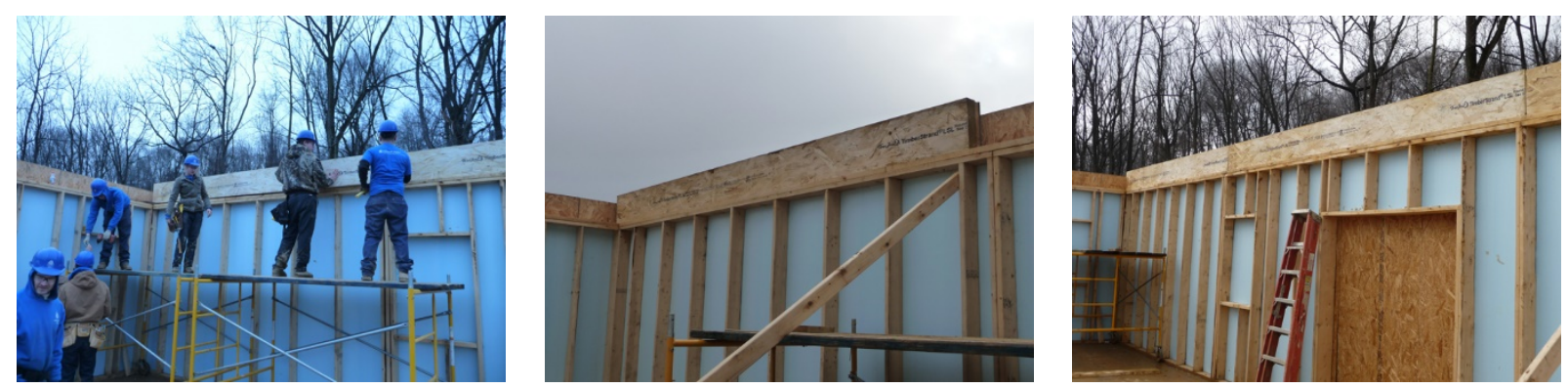

Figure 31. Second-floor insulated, structural rim board

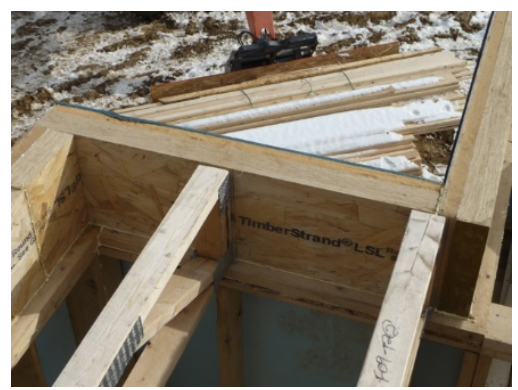

Figure 32. Second-floor rim assembly

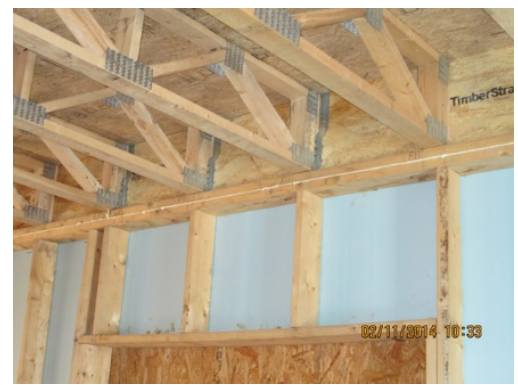

Figure 34. Rim hangers at door
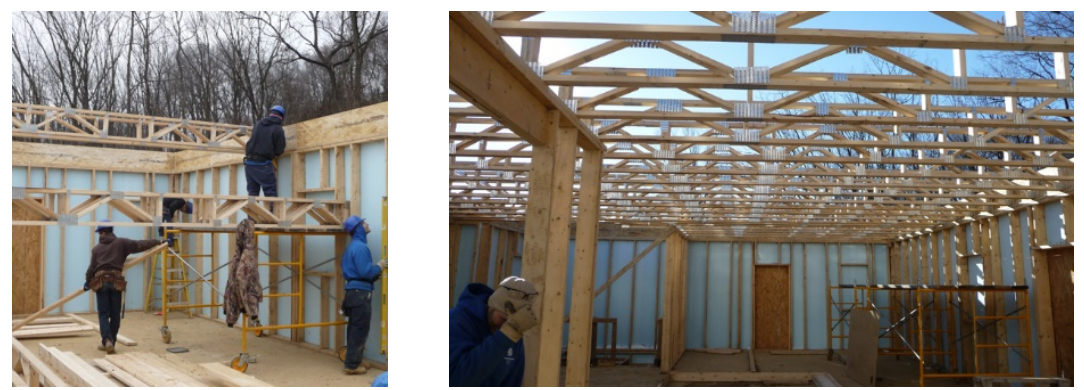

Figure 33. Second-floor trusses

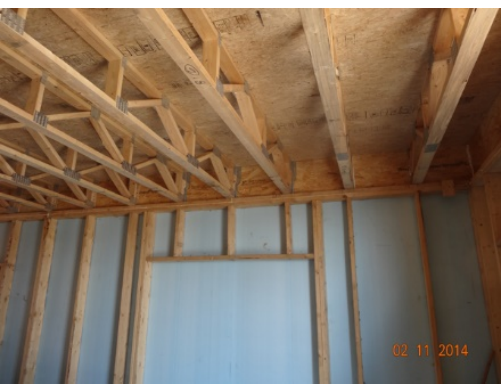

Figure 35. Rim hangers at window

The second-floor walls were framed in a similar fashion (Figure 36). The second-floor window headers were the same product as the second-floor rim (Figure 37). The wall sheathing for the second floor was installed flush with the second top plate, and the overhang below the bottom plate was cut to match up with the first-floor sheathing (Figure 38 and Figure 39). Figure 40 shows a typical wall section installation sequence. 


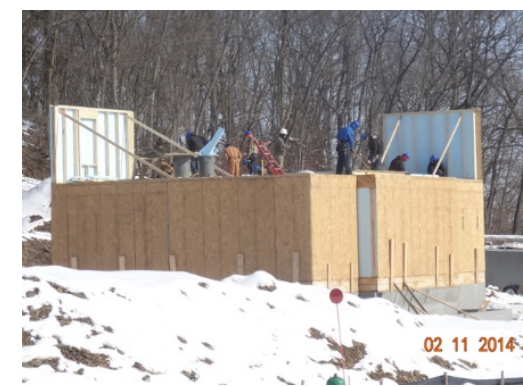

Figure 36. Second-floor walls

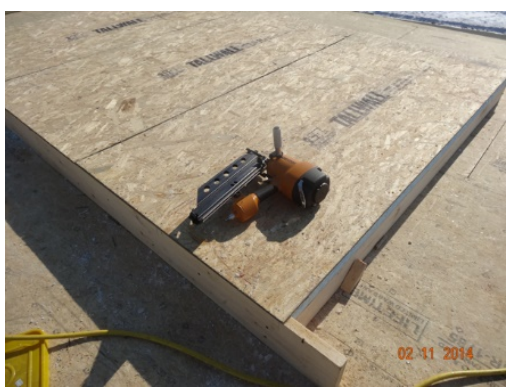

Figure 38. Second-floor wall sheathing
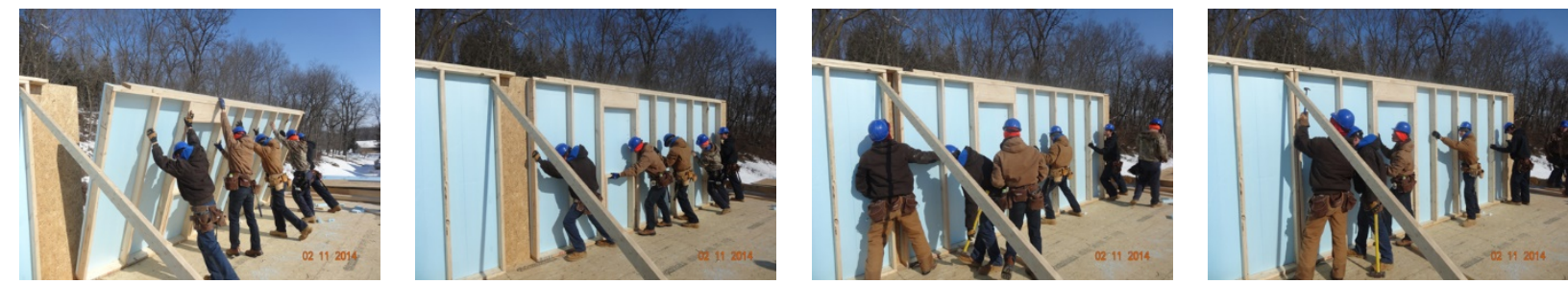

Figure 40. Typical wall installation sequence

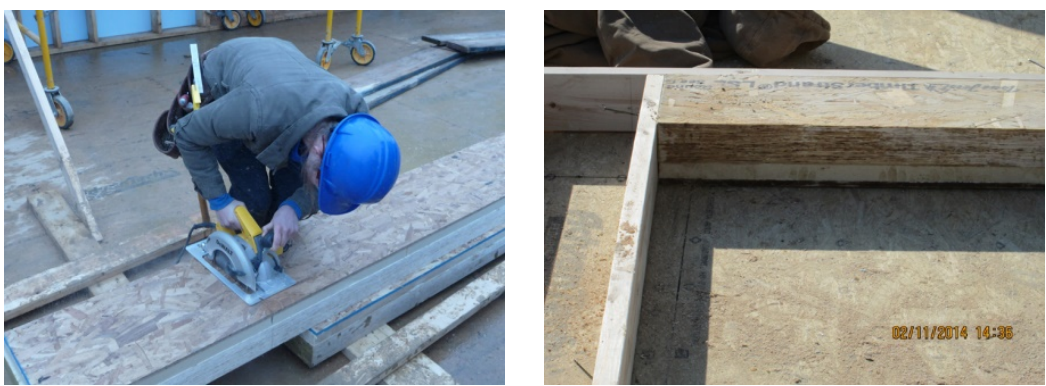

Figure 37. Second-floor wall header
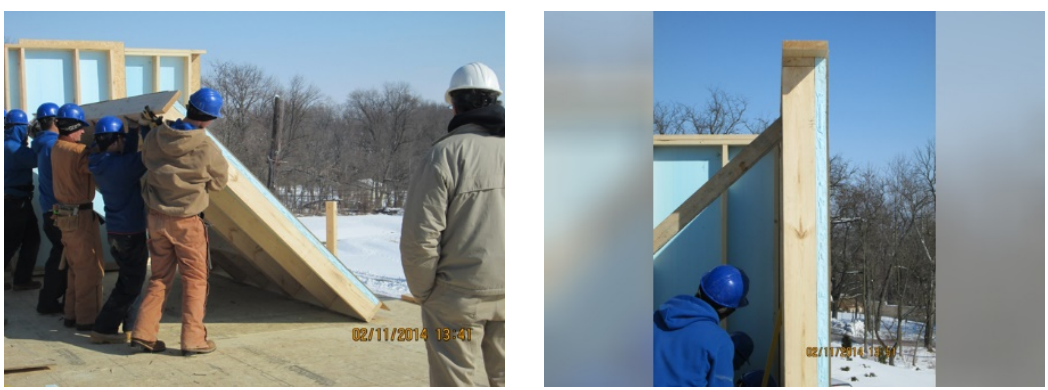

Figure 39. Second-floor wall 


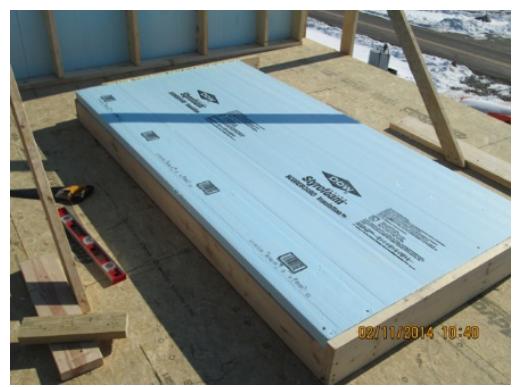

Figure 41. Sealing gap at foam sheathing

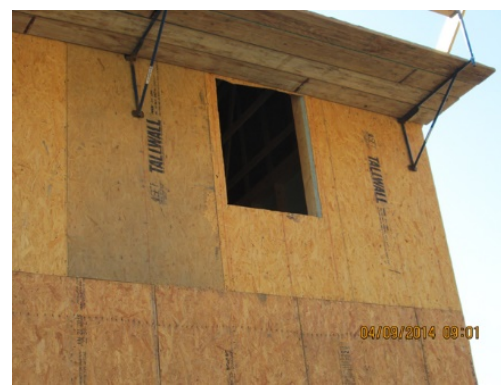

Figure 42. Window opening

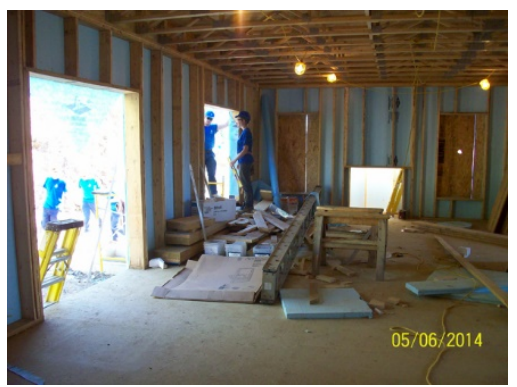

Figure 43. Door opening

After framing, the sheathing was cut out at window and door openings (Figure 42 and Figure 43) and house wrap was installed (Figure 44 and Figure 45). Windows were installed using 4-in.long nails through the flange (Figure 46 and Figure 47). Window and door flashing were installed conventionally using common self-adhesive flashing products. Standard depth windows were selected and installed in a conventional manner, and the jambs were finished from the interior using wood. Vinyl siding was attached using 1.5 -in.-long roofing nails 16 in. o.c. (Figure 48 and Figure 49).

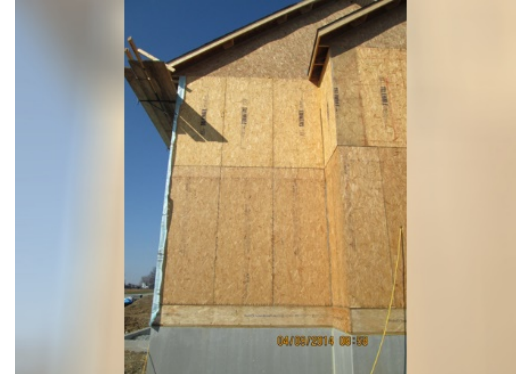

Figure 44. Wall sheathing

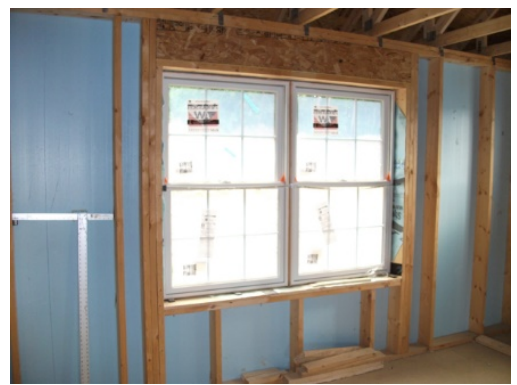

Figure 47. Installed window

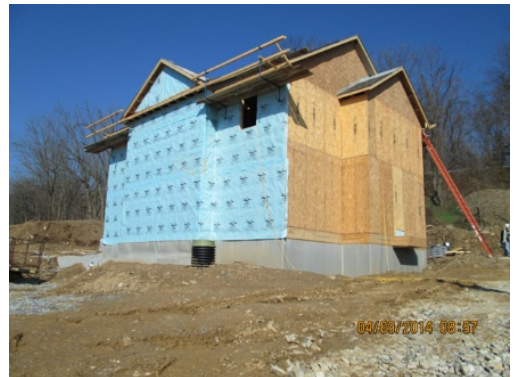

Figure 45. House wrap

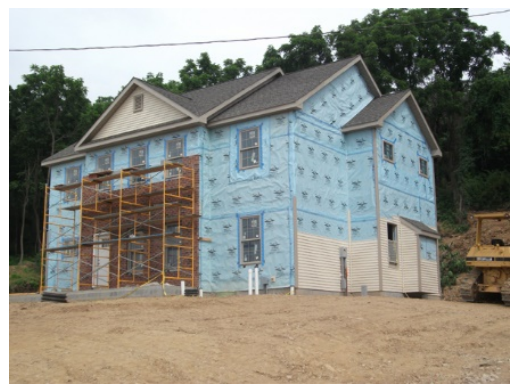

Figure 48. Siding

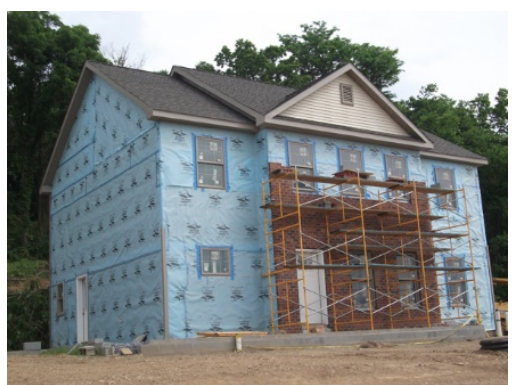

Figure 46. Windows and doors

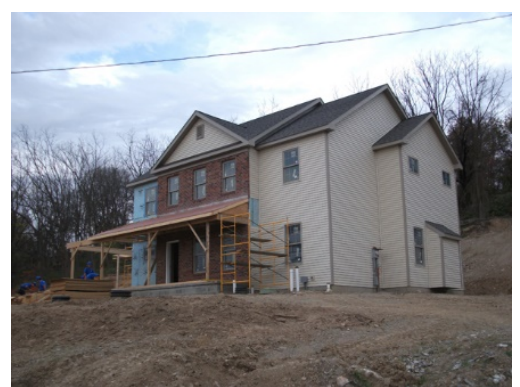

The second-floor ceiling was installed and sealed to allow blower door testing during the roughin stage (Figure 50 and Figure 51). Wireless moisture sensors were installed at the sheathing (Figure 52), and covered with rigid foam and in the wall cavity at the framing before wall cavity insulation (Figure 53 and Figure 54). 


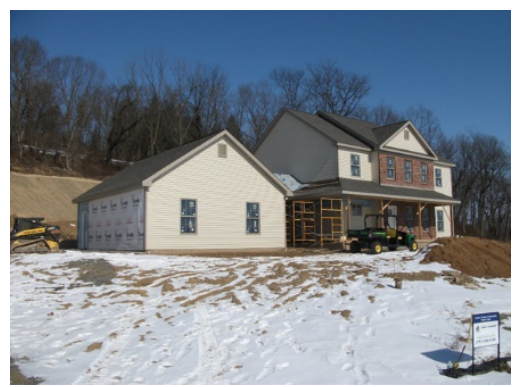

Figure 49. Siding

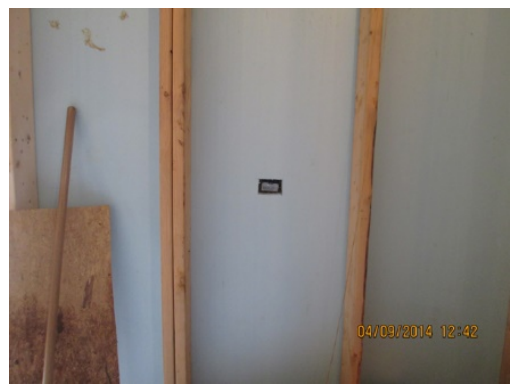

Figure 52. Wall sheathing moisture sensor before being covered with foam

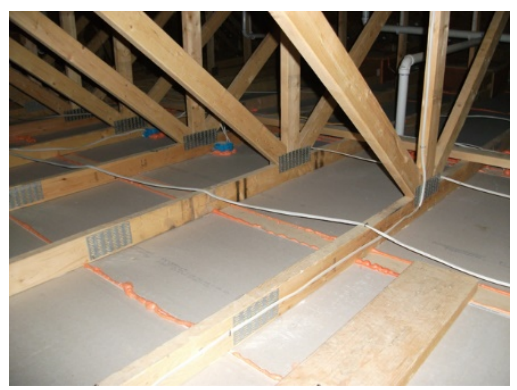

Figure 50. Air-sealed ceiling

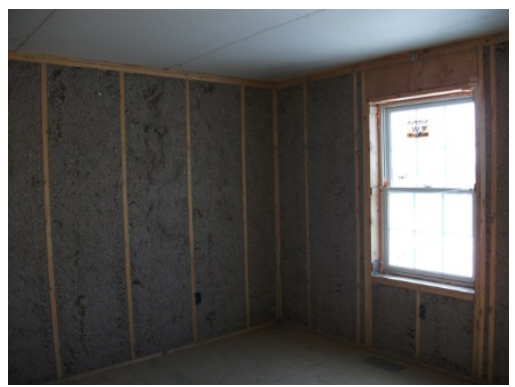

Figure 53. Wall cavity insulation

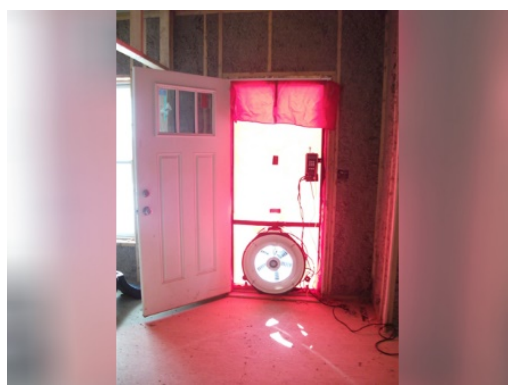

Figure 51. Blower door test during rough-in stage

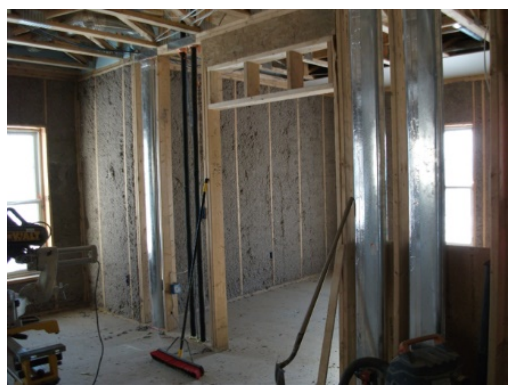

Figure 54. Wall cavity insulation

\subsection{House Leakage Testing}

House leakage testing at rough-in stage was performed before wall insulation and drywall were installed. To perform this rough-in stage testing, the second-floor ceiling was installed and sealed to isolate the attic at the ceiling plane. The house leakage test results are summarized in Table 7.

Table 7. House Leakage Test Results

\begin{tabular}{c|c|c|c}
\hline House Leakage Test & Notes & CFM50 & ACH50 \\
\hline Rough-In 1 & $\begin{array}{c}\text { Window and door rough openings, bottom plates } \\
\text { at the floor deck, and the attic access were not } \\
\text { sealed. Air leakage was also identified at some } \\
\text { ceiling penetrations. }\end{array}$ & 2,264 & 3.5 \\
\hline Rough-In 2 & $\begin{array}{r}\text { Following added sealing, except the bottom plates } \\
\text { at the floor deck were not sealed. }\end{array}$ & 1,460 & 2.3 \\
\hline Rough-In 3 & $\begin{array}{c}\text { Following sealing the bottom plates and installing } \\
\text { wall insulation (wet blown cellulose) }\end{array}$ & 1,420 & 2.2 \\
\hline Final & Following completion of the house. & 1,200 & 1.87 \\
\hline
\end{tabular}




\section{Discussion}

\subsection{U.S. Department of Energy Zero Energy Ready Home Certification}

The NCTH earned DOE ZERH certification and has met the following mandatory requirements: ENERGY STAR (Version 3 final inspection and testing); envelope (insulation and fenestration meet or exceed 2012 International Energy Conservation Code levels); duct system (entirely within the building thermal and air boundary); water efficiency; lighting and appliances (100\% high efficacy lighting and installed appliances are ENERGY STAR qualified); indoor air quality (EPA Indoor airPLUS certified); renewable ready (solar thermal is installed and solar electric is exempt in this location).

The NCTH Home Energy Rating System Index is 45. (DOE's ZERH Target Index is 48.) See Appendix D for the ZERH, ENERGY STAR, and Home Energy Rating certificates.

\subsection{Mechanical Ventilation}

LCCTC decided to not install the energy recovery ventilator based on comfort issues at the previous test house. That energy recovery ventilator was partially integrated with the heating and cooling duct system (a dedicated duct removed indoor "stale" air directly from the living area, and outdoor "fresh" was ducted directly to the return air duct) and provided a continuous 80CFM (measured) outdoor airflow, but the occupant complained that the house felt drafty during the winter, particularly when the heating system was off (that house measured $1 \mathrm{ACH} 50$ and so was not drafty). For the NCTH, the fresh air ventilation system of record became the 80-CFM master bath exhaust fan. Home Innovation recommended a supply-type outdoor air system (fresh air ducted from outdoors to the return plenum, controlled by an electronic damper that opens during heating, cooling, or fan-only operation) to supplement the exhaust fan and improve fresh air source control and distribution. This supply-type ventilation alone would not conform to American Society of Heating, Refrigerating and Air-Conditioning Engineers, Inc. (ASHRAE) Standard 62.2-2010 recommendations (ASHRAE 2010) unless the air handling unit was operating continuously, but this arrangement is a practical compromise between ventilation and comfort when used to supplement the exhaust-style ventilation. 


\section{Conclusions}

\subsection{Research Questions}

1. Were the EP\&B wall and rim construction details implemented as designed, or were field modifications necessary?

The students installed the EP\&B wall and rim assemblies in accordance with the approved design. The only exception: the second-floor window headers were installed with the laminated insulation facing outdoors, but this is not a structural concern, and the structural lumber facing indoors provides a nailing surface for the drywall and trim.

2. Given the unique configuration of the sheathing attachment to the wall plates and rim, what questions related to structural details are raised by the code authority having jurisdiction, and how were the structural requirements satisfied to comply with the International Residential Code?

The proposed attachment schedule was submitted to the architectural firm of record for review by its staff engineers. After the proposed design was accepted, the architectural firm submitted all plans and details to the local code department. No issues were raised by the code officials or code inspectors throughout the plan approval phase or construction phase. Until the system is listed in the International Residential Code as one of the bracing methods, working with the engineer of record is the most suitable path for obtaining code approval. Because the EP\&B system relies on standard materials and the difference in detailing is limited to the location and size of the nails, the changes were easily understood by all stakeholders, and the review and approval process did not generate follow-up questions.

3. Which air-sealing details were necessary to achieve a measured infiltration rate design goal of approximately $1 \mathrm{ACH} 50$ ?

The air-sealing methods for the NCTH (outlined in Table 4) were conventional and did not require specialized air-sealing measures or equipment to achieve the low measured infiltration rate. The rim areas and ceiling plane adjacent to the attic were carefully sealed but required no more effort than sealing a standard house to meet current code requirements. The only area that was not air sealed according to plan was the foam sheathing at the wall cavity. This area was specified to be sealed ("picture framed") after the first intermediate test to quantify how this step would contribute to the overall air-sealing goal. The final house leakage rate for the NCTH measured 1.9 ACH50. Sealing the foam sheathing at the wall cavity, particularly at the plates, may have improved the house leakage rate closer to 1 ACH50.

4. Is the EP\&B wall system considered "affordable" compared to similarly performing alternative wall designs?

A detailed cost comparison indicates that the cost of the EP\&B system is comparable and in some cases lower than the cost of walls with the same R-value. The cost normalized by the $\mathrm{R}$-value is also similar among wall types within the same $\mathrm{R}$-value range. Therefore, the added benefits of the EP\&B system do not come with an extra price, and in some cases it results in a moderate cost saving relative to comparable R-value alternatives. Regarding framing at the $\mathrm{NCTH}$, observations of the wall and rim framing indicate that construction proceeded in a normal manner with negligible delays due to the EP\&B design. The potential additional cost of a nail gun that will accommodate 4-in.-long nails is considered negligible. 
Further, standard air-sealing methods, which are typical for any new construction house, resulted in a very tight house.

Building according to the EP\&B method requires some details that are different than standard construction, but these are relatively straightforward for a builder that is interested in applying this method.

5. How do the moisture characteristics of the wall cavity and sheathing change over seasonal exterior and interior conditions?

Simulation data indicate that the wall system will minimize moisture accumulation in the wall sheathing and cavity. Empirical data are forthcoming because the NCTH was not complete until June (the time frame of this writing); therefore, no moisture data are available. The moisture of the wall cavity and sheathing will be monitored for this project as part of a separate, ongoing Building America research project. Monitored moisture data in the OSB sheathing and in the wall cavity will be analyzed based on seasonal changes. Indoor humidity conditions significantly affect the moisture diffusion through the wall in winter. The wall design, especially with regard to the material characteristics of air leakage and permeability, will be identified in conjunction with the measured moisture characteristics. Other factors that will influence the measured cavity moisture levels are the air infiltration rate of the home and the operation of the ventilation system.

6. Are the elements of the energy-solution package for the NCTH cost-effective and market ready?

BEopt simulations resulted in a $44 \%$ source energy savings and show that the energysolution package for the NCTH is cost-effective. The solar thermal hot water system provided a low estimated operating cost, but the installed cost was very high and is not considered cost-effective. LCCTC selected the solar hot water system because the other three houses in the community have this same system, and some of the cost was donated for educational purposes. Substituting a standard electric water heater would reduce the wholehouse energy savings percentage but improve cost-effectiveness. Analysis showed that the high-efficiency heat pump was much less expensive to operate than a propane gas furnace. (Natural gas is not available.) The two-stage heat pump provides sufficient heating capacity on high stage and effective cooling and humidity control on low stage. Further, the cost analysis shows the EP\&B design to be cost-effective compared to standard wall construction in this cold climate. The selected components of the energy-solution package for the NCTH are current technologies or available materials that are market ready, although the EP\&B design requires approval by the building code authority having jurisdiction.

\subsection{Key Findings and Lessons Learned}

This research project demonstrated the successful design and construction of a high-R wall system that is practical for the building industry to adopt. Standard and familiar building components were integrated to create an advanced wall system that has higher thermal performance than code minimums, is predicted to handle moisture diffusion into the wall cavity, and has a cost that is comparable to and in some cases lower than the cost of other high- $\mathrm{R}$ wall systems of comparable thermal performance. 
The EP\&B wall system benefits include:

- Design flexibility in the selection of insulation and framing combinations to optimize the overall R-value of the wall system

- Its ability to maintain conventional framing methods and use common building products

- The foam sheathing, which reduces thermal bridging at the wall studs

- Its structural rim boards, which eliminate headers

- The wood structural sheathing nailed directly to the plates, which provides shear load resistance

- The exterior sheathing, which can dry to the exterior and provides a clear drainage plane and flashing surface for window and door openings

- The exterior wood structural sheathing, which provides a nailing surface for the siding attachment

- Its reduced transition risk and costs to builders. 


\section{References}

ACCA. 2004. Manual S: Residential Equipment Selection (2004), Arlington, VA: Air Conditioning Contractors of America. www.acca.org.

ACCA. 2006. Manual J: Residential Load Calculations, Eighth Edition. Arlington, VA: Air Conditioning Contractors of America. www.acca.org.

ACCA. 2009a. Manual D: Residential Duct Systems, Third Edition. Arlington, VA: Air Conditioning Contractors of America. www.acca.org

Aldrich, R.A., L. Arena, and W. Zoeller. 2010. Practical Residential Wall Systems: R-30 and Beyond. Stephen Winter Associates, Inc. BEST2 Conference. 2010. (Cited: August 16, 2012.) http://best2.thebestconference.org/pdfs/017 EE6-5.pdf.

ASHRAE. 2010. ANSI/ASHRAE Standard 62.2-2010: Ventilation for Acceptable Indoor Air Quality in Low-Rise Residential Buildings. Atlanta, GA American Society of Heating and AirConditioning Engineers. www.ashrae.org.

Cold Climate Housing Research Center. 2010. CCHRC Snapshot RS 2007-03. Updated February 2010 .

ICC: International Code Council. International Energy Conservation Code (IECC) (2009) 500 New Jersey Ave NW, $6^{\text {th }}$ Floor, Washington, DC 20001, 888-422-7233, www.iccsafe.org

Kosny, J., and J.E. Christian. 2001. "Whole Wall Thermal Performance.” Oak Ridge, TN: Oak Ridge National Laboratory. Accessed November 9, 2015:

http://web.ornl.gov/sci/roofs+walls/research/detailed_papers/Whole_Wall_Therm/content.html.

Luebs, D. 1983. EER-2, Energy Efficient Residence, Demonstration and Evaluation of Energy Efficient Systems for Residential Structures, National Association of Home Builders Research Foundation.

Mallay, D., and J. Wiehagen. 2014. Insulated Concrete Form Walls Integrated with Mechanical Systems in a Cold Climate Test House (Subcontractor Report, NREL/SR-5500-62539). Golden, CO: National Renewable Energy

Laboratory. www.nrel.gov/docs/fy14osti/62539.pdf?gathStatIcon=true.

Minnesota Sustainable Housing Initiative. 2012. Wall Section. (Cited: August 16, 2012.) www.mnshi.umn.edu/kb/scale/wall.html.

RSMeans 2014. RSMeans Residential Cost Data 2014. Norwell, MA: RSMeans. 2013.

Straube, J. 2010. Building America Special Research Project: High R-Value Enclosures for High Performance Residential Buildings in All Climate Zones, Research Report-1005. Building Science Corporation. Westford, MA. October 2010, Rev. February 2011. 
Straube, J., Smegal, J. (2009). Building America Special Research Project: High-R Walls Case Study Analysis, Research Report 0903. Building Science Corporation. Westford, MA. March 11, 2009, Rev. June 8, 2011. 


\section{Appendix A: New Construction Test House Plans}

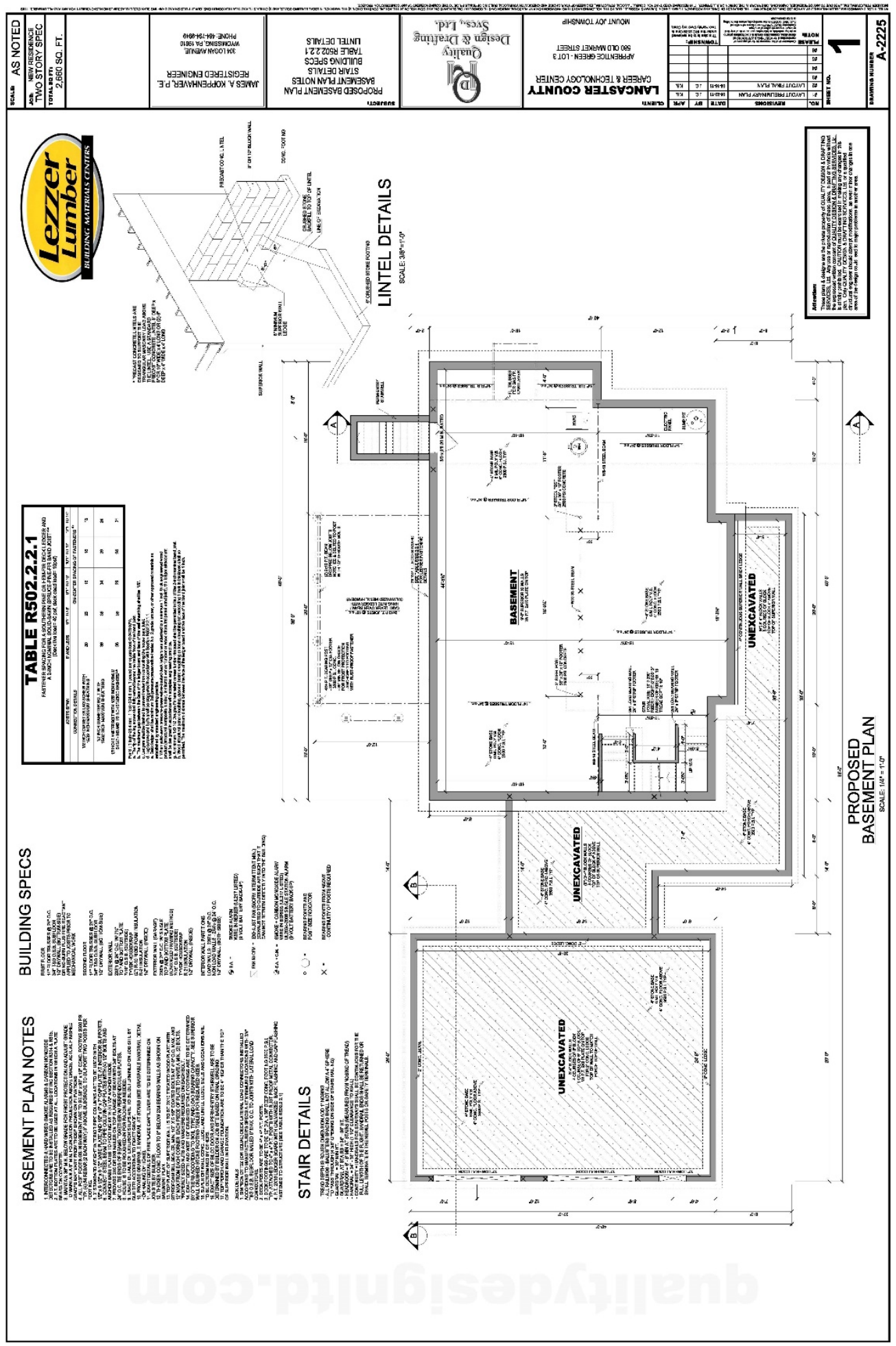




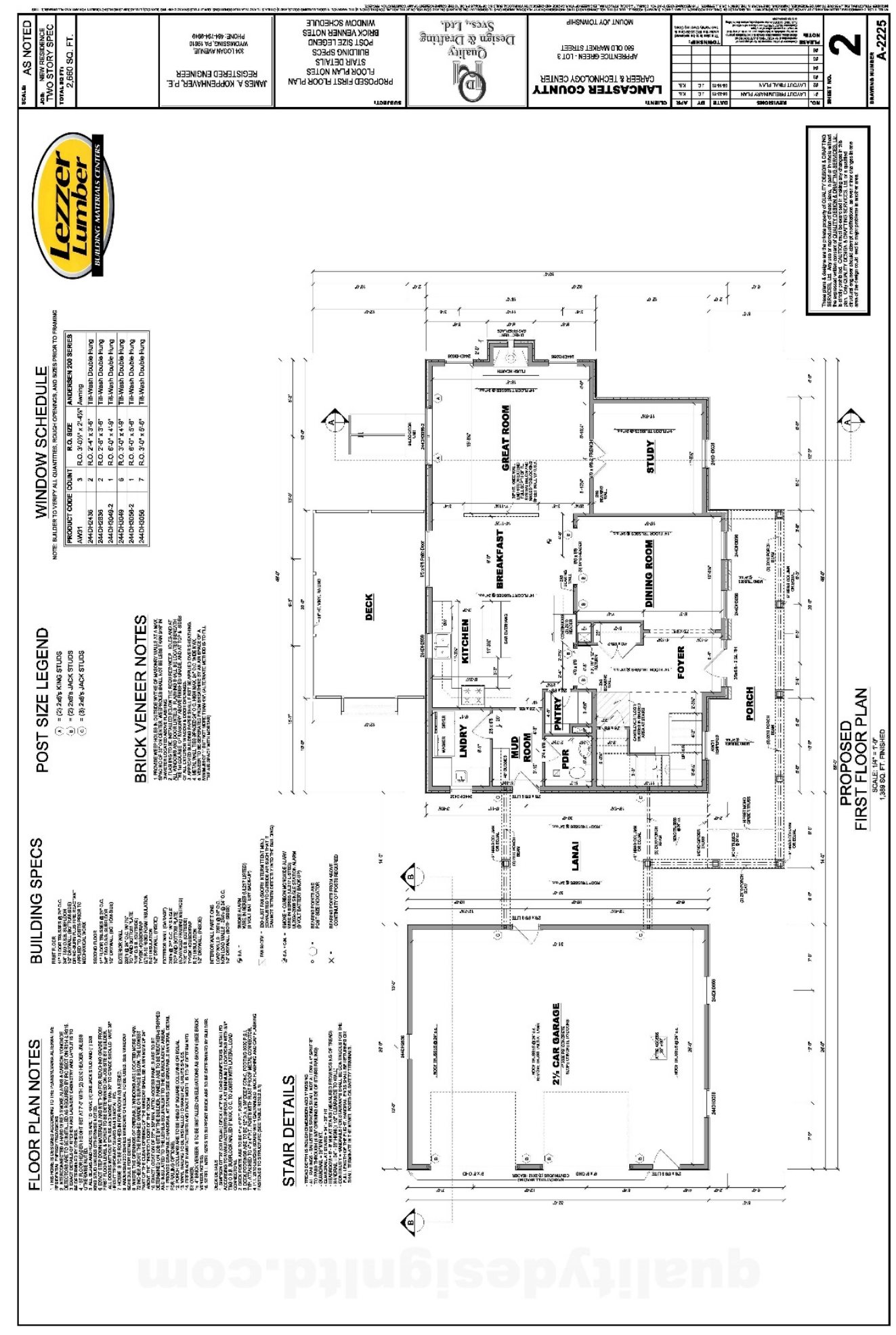




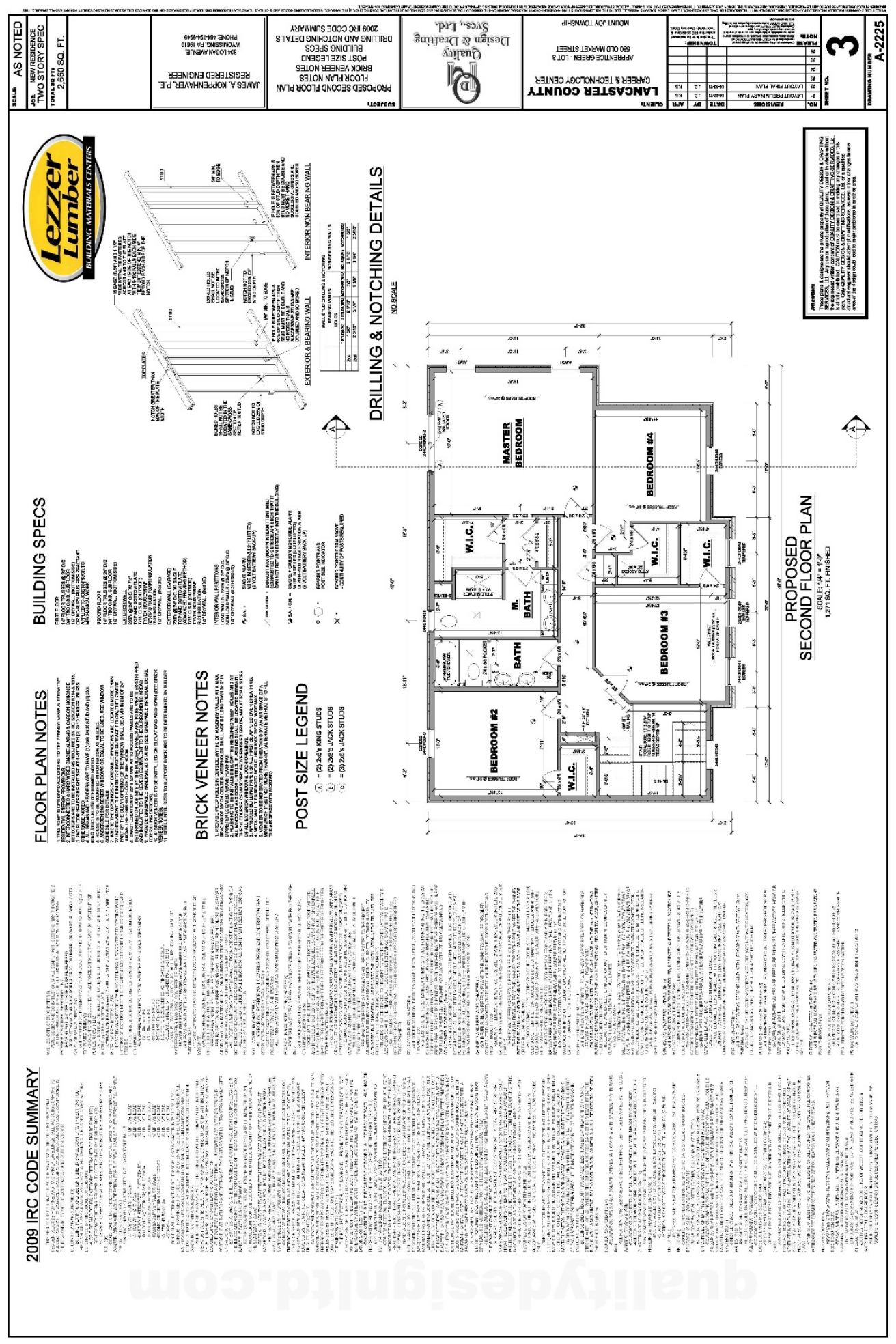




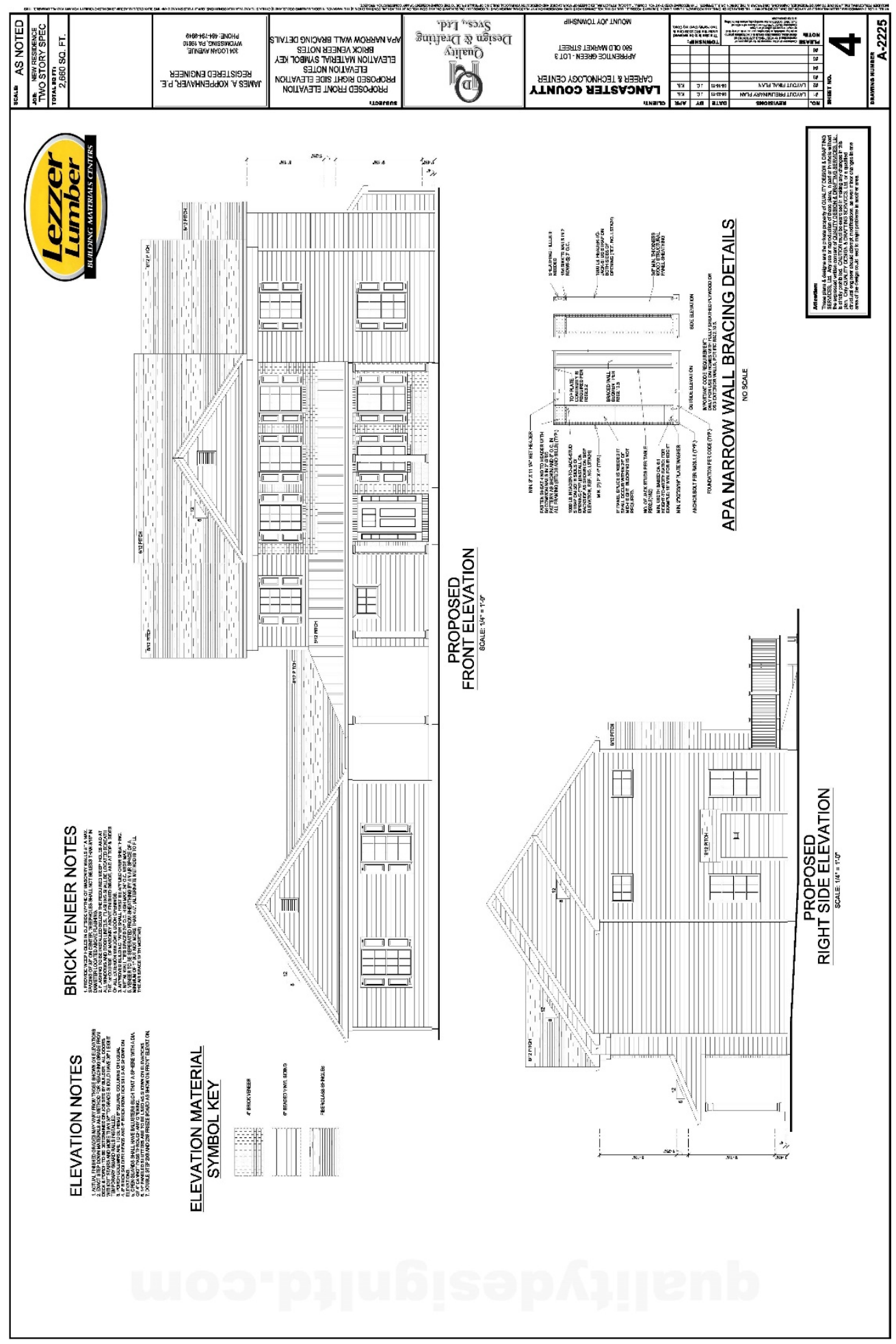




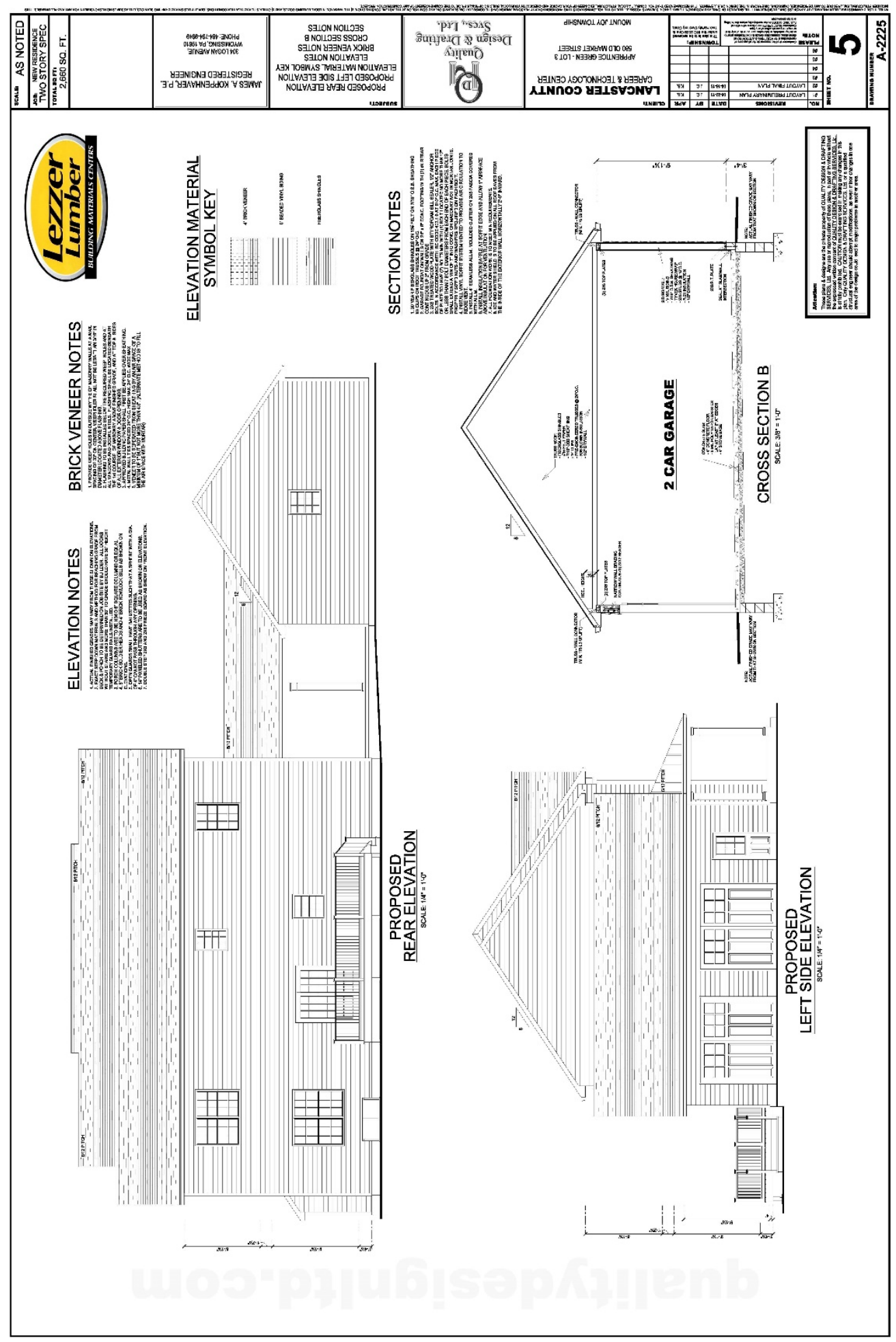




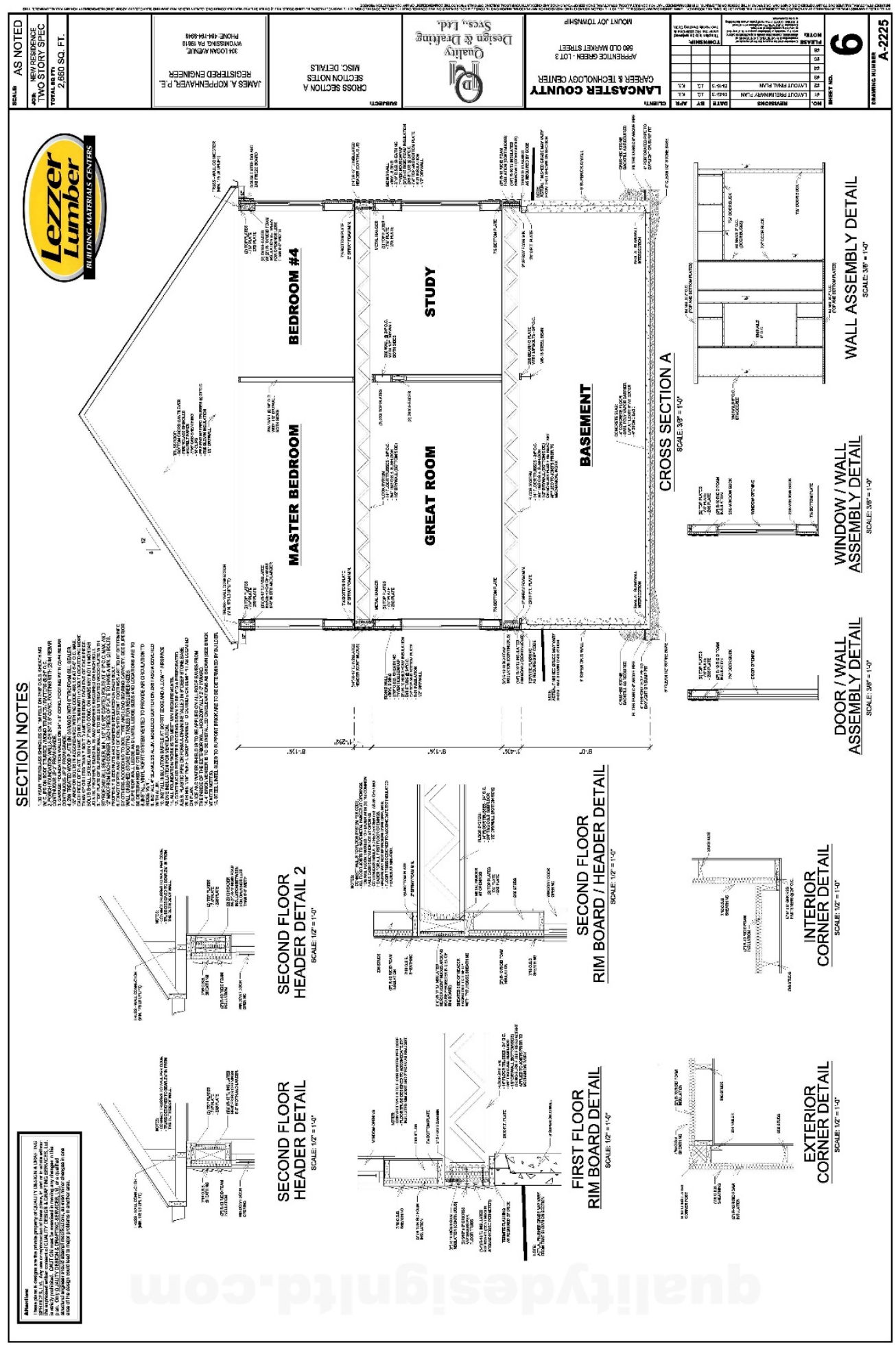




\section{Appendix B: Cost Analysis}

EP\&B cost comparisons were developed and represented at the national level from three primary sources:

- Home Innovation Research Labs' database that was originally compiled in 2008 and has been updated and expanded over the following 5 years

- RSMeans Residential Cost Data 2014 (RSMeans 2014)

- Websites for major national manufactures and retailers.

If additional labor time was needed for specific tasks that were not directly addressed by standard cost guides, the labor rate from RSM 2014 was used. The reported costs contain overhead and profit that are expected to be charged by trades and suppliers (i.e., builder's costs). No builder overhead and profit have been added.

The costs were evaluated for the entire wall system to capture the interaction effects (impact of the header type on the number of supporting studs, impact of the cladding type of the backing material, etc.). The system approach also allows for evaluating the cost impact of increasing the wall's R-value relative to the entire cost of the wall system.

Each wall configuration and a detail of the estimated costs are summarized in Table 8 . The representative wall sections show vinyl siding only. The estimated costs apply to the representative $200-\mathrm{ft}^{2}$ wall section, including finishes and a double 3050 window.

The results indicate that the cost of the EP\&B system is comparable and in some cases lower than the cost of walls with the same R-value. The cost normalized by the R-value is also similar between walls types within the same R-value range. Therefore, the added benefits of the EP\&B system do not come with an extra price and in some cases result in a moderate cost saving relative to comparable $\mathrm{R}$-value alternatives. 
Table 8. Representative Wall Section Configuration Cost Estimates

\begin{tabular}{|c|c|c|c|c|c|c|c|c|}
\hline 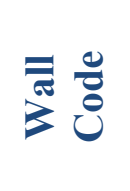 & Wall Configuration & $\begin{array}{l}7 \\
7 \\
700 \\
100\end{array}$ & 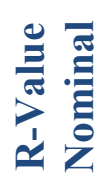 & 䨪产 & $\begin{array}{l}\text { Total } \\
\text { Cost }\end{array}$ & $\operatorname{Cos} t / \mathbf{f t}^{2}$ & 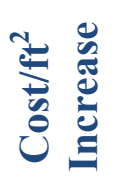 & 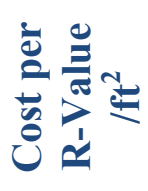 \\
\hline \multicolumn{9}{|c|}{ Vinyl Siding } \\
\hline $1 \mathrm{VS}$ & $2 \times 4 @ 16$ in. o.c. & 1 & 13 & 4.4 & $\$ 3,499.48$ & $\$ 17.50$ & N/A & $\$ 1.35$ \\
\hline $2 \mathrm{VS}$ & $2 \times 6 @ 24$ in & 2 & 20 & 6.4 & $\$ 3,509.98$ & $\$ 17.55$ & Ref & $\$ 0.89$ \\
\hline $3 \mathrm{VS}$ & $2 \times 6$ & 3 & 20 & 6.4 & 98 & 17.88 & $\$ 0.34$ & $\$ 0.90$ \\
\hline $4 \mathrm{VS}$ & EP\&E & 4 & 23 & 4.4 & $\$ 3,935.18$ & $\$ 19.68$ & $\$ 2.13$ & $\$ 0.87$ \\
\hline $5 \mathrm{VS}$ & $\begin{array}{c}2 \times 4 \mathrm{w} / 2 \mathrm{in.} \\
+1 / 2 \text { in. ext. foam }\end{array}$ & 5 & 25 & 6.9 & $\$ 4,305.02$ & $\$ 21.53$ & $\$ 3.98$ & $\$ 0.86$ \\
\hline $6 \mathrm{VS}$ & $\begin{array}{r}2 \times 6 \mathrm{w} / 2 \text { in } \\
+1 / 2 \text {-in. ext. fo }\end{array}$ & 6 & 32 & 8.9 & $\$ 4,435.72$ & $\$ 22.18$ & $\$ 4.63$ & $\$ 0.69$ \\
\hline $7 \mathrm{VS}^{\mathrm{a}}$ & EP\&B $2 \times$ & 7 & 29 & 6.4 & & & $\$ 3.19$ & $\$ 0.73$ \\
\hline $8 \mathrm{VS}^{\mathrm{a}}$ & $1.5 \times 7.5$ & 8 & 30 & 6.4 & & & 2.67 & 0.68 \\
\hline 9VS & $\begin{array}{c}2 \times 4 \text { double stud } \\
\text { w/1-in. gap }\end{array}$ & 9 & 29 & 8.9 & $\$ 3,994.43$ & $\$ 19.97$ & $\$ 2.42$ & $\$ 0.69$ \\
\hline \multicolumn{9}{|c|}{ Fiber Cement Siding } \\
\hline 1FCS & & 1 & 13 & 4.4 & & & $\mathrm{n} / \mathrm{s}-\mathrm{e}-\mathrm{e}-\mathrm{e}$ & $\$ 1.46$ \\
\hline 2FCS & & 3 & 20 & 6.4 & & & ref & 0.96 \\
\hline 3FCS & $2 \times$ & 2 & 20 & 6.4 & & & $\$ 0.34$ & $\$ 0.98$ \\
\hline 4FCS & EP\&B $2 \times 4 / 2 \times 6$ & 4 & 23 & 4.4 & & & 2.13 & $\$ 0.93$ \\
\hline $5 \mathrm{FCS}$ & $2 \times 4 \mathrm{w} / 2 \mathrm{in}$. ext. foam & 5 & 23 & 6.4 & & & 2.67 & $\$ 0.96$ \\
\hline 6FCS & $2 \times 6 \mathrm{w} / 2 \mathrm{i}$ & 6 & 30 & 8.4 & & & & $\$ 0.75$ \\
\hline $7 \mathrm{FCS}^{\mathrm{a}}$ & & 7 & 2 & 6. & & & $\$ 3.19$ & $\$ 0.78$ \\
\hline $8 \mathrm{FCS}^{\mathrm{a}}$ & $\mathrm{EP} \& \mathrm{~B} 2 \times 6 / 1.5 \times 7.5$ & 8 & 30 & 6.4 & $\$ 4,332.20$ & $\$ 21.66$ & $\$ 2.67$ & $\$ 0.73$ \\
\hline 9FCS & $\begin{array}{c}2 \times 4 \text { double stud } \\
\text { w/1-in. gap }\end{array}$ & 9 & 29 & 8.9 & $\$ 4,283.25$ & $\$ 21.42$ & $\$ 2.42$ & $\$ 0.74$ \\
\hline
\end{tabular}

${ }^{a}$ EP\&B wall configurations with $2 \times 6$ studs were analyzed using both $2 \times 8$ plates ( $71 / 4$-in. width) and ripped plates to a $71 / 2$-in. dimension. The added cost of ripping plates is included as well as the added cost of installing a 1 -in. layer and a $3 / 4$-in. layer of foam sheathing for the $2 \times 8$ plates. 


\section{Appendix C: Wood Moisture Content Sensor Calibration}

The manufacturer-stated accuracy for the sensor models used is $\pm 2 \%$ relative humidity and $\pm 0.3^{\circ} \mathrm{C}$. The Home Innovation Research Labs has performed numerous calibrations to verify sensor accuracy and correlations with moisture content. Moisture content correlations have been performed by comparing to readings on handheld electrical conductance type moisture meters and moisture content readings with wet/oven-dry sample measurement calculations. The wood moisture content values reported through the sensor technology are the ratio of the water content of wood relative to the dry weight as a percentage. The sensor manufacturer calibrates its devices based on wood species; the U.S. Department of Agriculture outlined temperature compensation relationships. For calibration purposes, a set of sensors were installed in OSB samples and placed inside an environmental chamber that can control relative humidity and temperature. Figure 55 shows the set of sensors in the environmental chamber where temperature and humidity were tightly controlled at various levels of humidity for calibration purposes. At various levels of humidity and when equilibrium was achieved (equilibrium moisture content) based on specimen weight consistency, the specimens were removed, weighed, oven dried, and weighed once again. The resultant ratio of the measurements provides the gravimetric moisture content of the specimen.

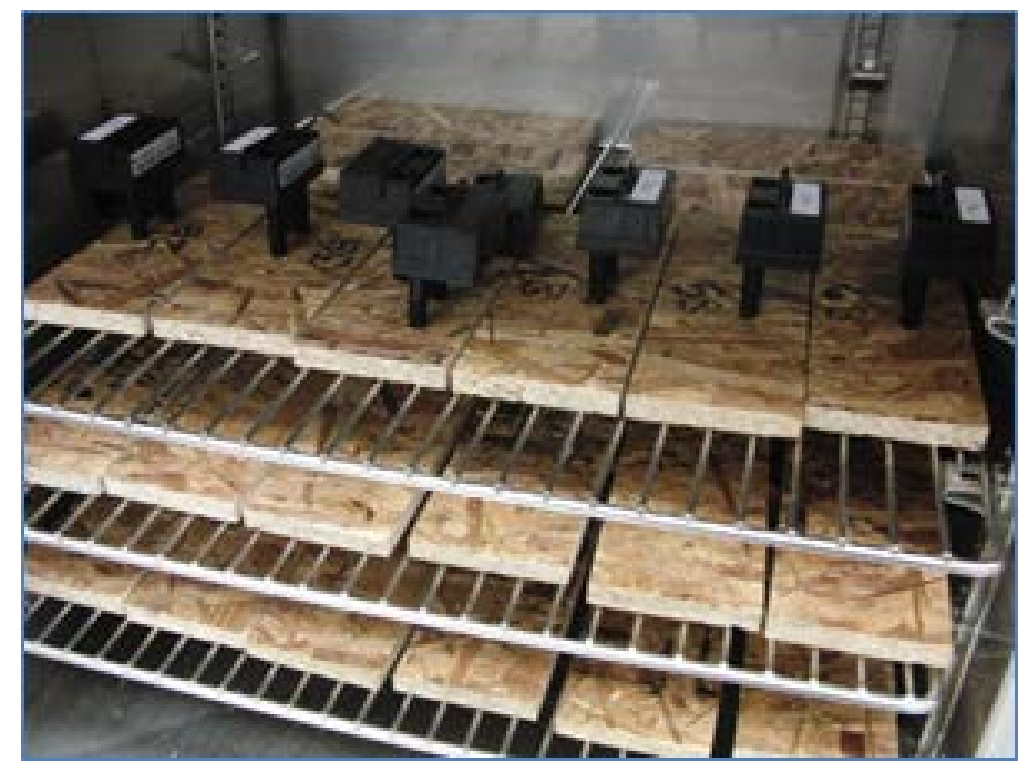

Figure 55. Sensors in the environmental chamber for calibration

Figure 56 plots the sensor moisture content reading, the oven-dry moisture content, and various reference curves from literature. It also shows the calibration relationship between the sensor reading and the measured OSB specimen moisture content. In all cases, the reported sensor reading is higher than the gravimetric calculation by at most $2 \%$ moisture content. The National Institute of Standards and Technology reference curves align well with the gravimetric measurements. The results presented here are based on calibration of the sensor reading for OSB readings only, based on the gravimetric measurements as shown in Figure 56. Measurements from stud readings are left unchanged based on the sensor manufacturers' calibration to solid lumber species. 


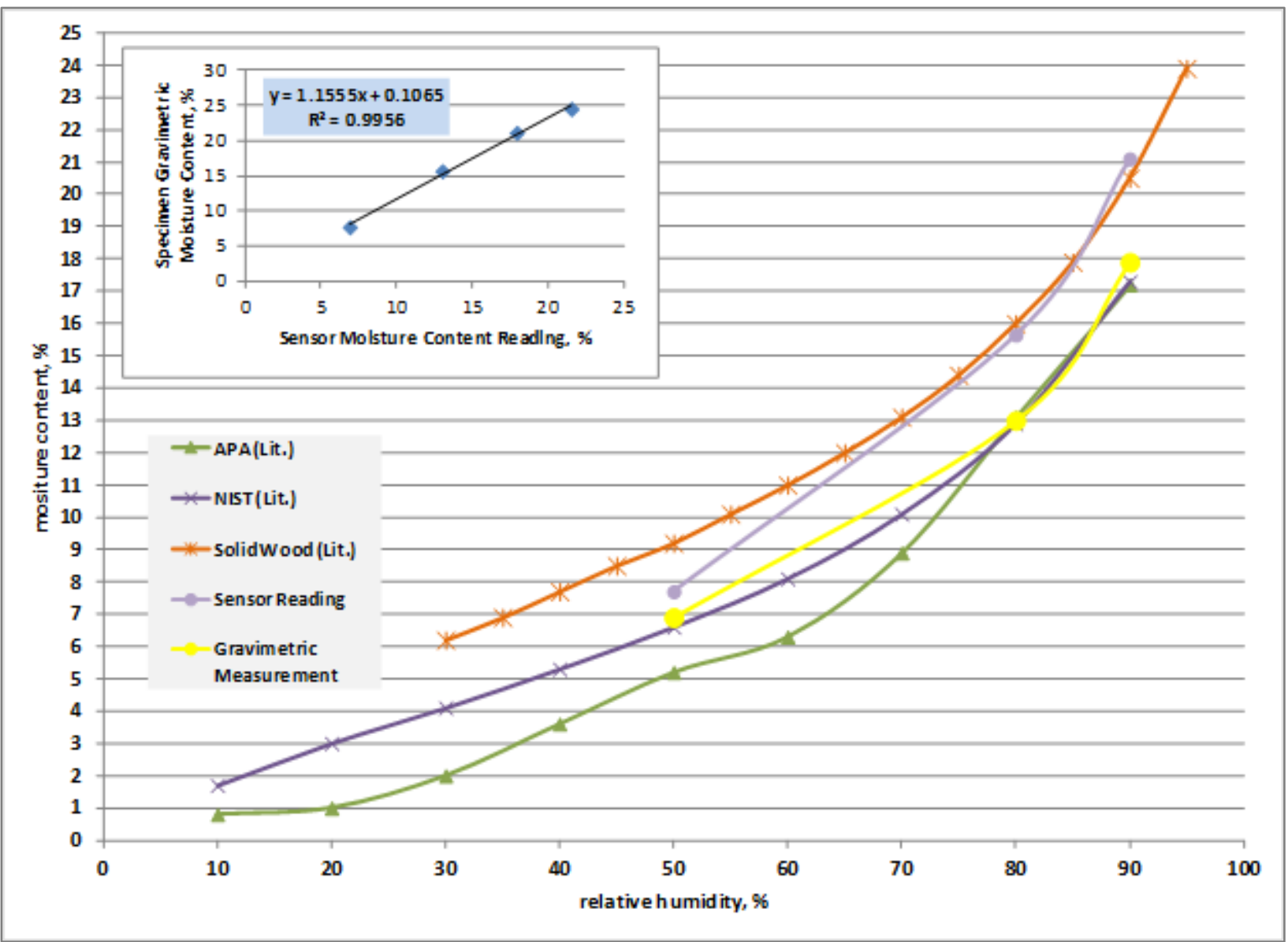

Figure 56. Moisture content sensor calibration curves 


\section{Appendix D: New Construction Test House Certifications}

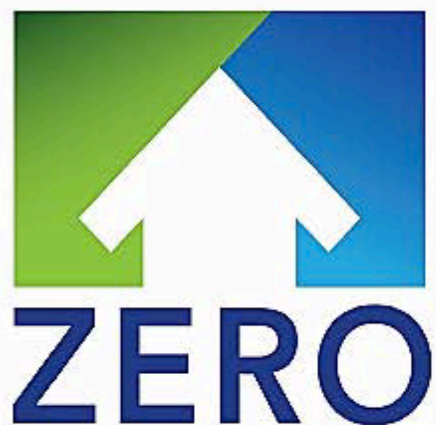

ENERGY READY HOME

YOUR HOME WAS DESIGNED, ENGINEERED, AND CONSTRUCTED IN CONFORMANCE TO U.S. DEPARTMENT OF ENERGY (DOE) GUIDELINES FOR EXTRAORDINARY LEVELS OF EXCELLENCE AND QUALITY.
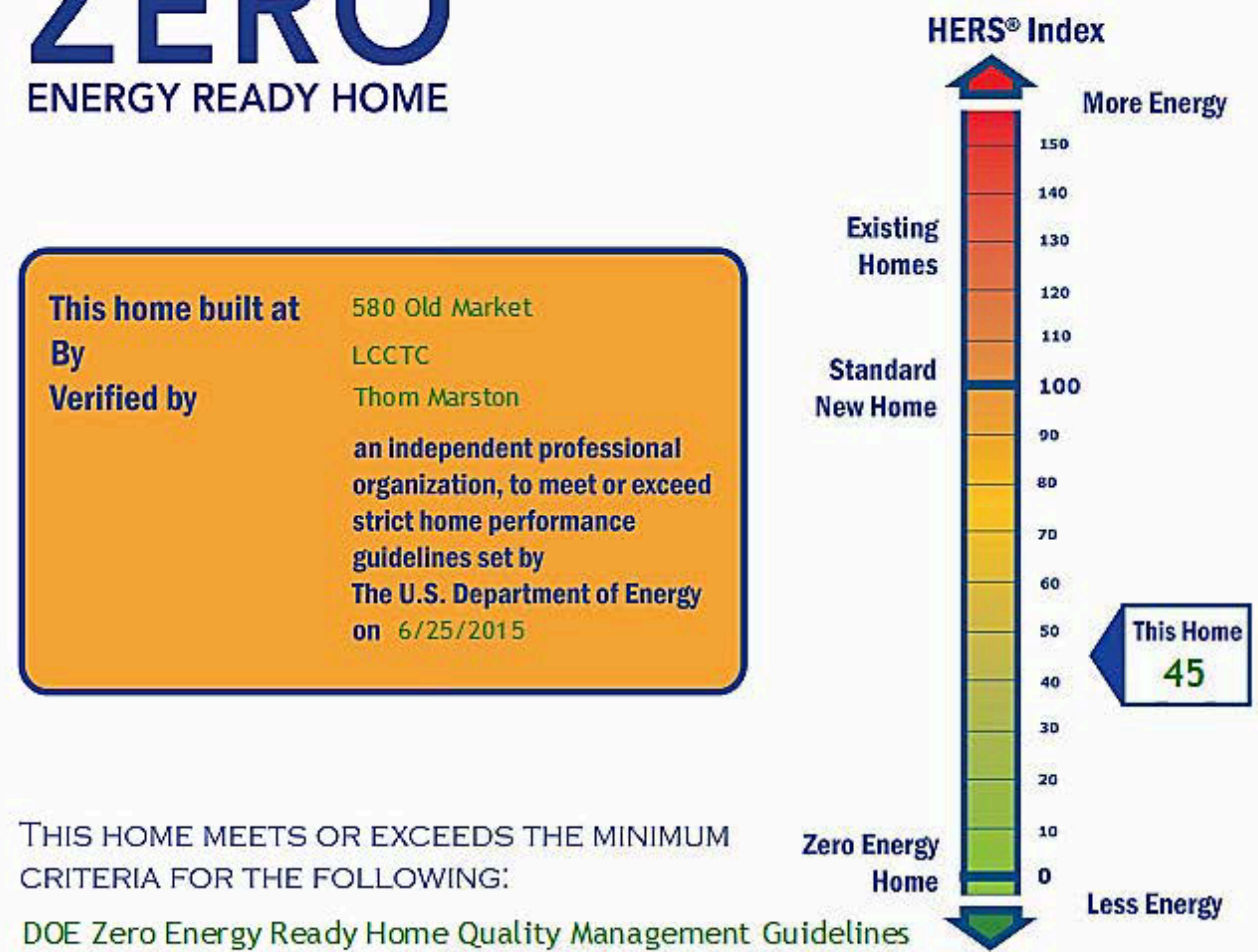

THIS HOME MEETS OR EXCEEDS THE MINIMUM CRITERIA FOR THE FOLLOWING:

DOE Zero Energy Ready Home Quality Management Guidelines

SAM RASHKIN, CHIEF ARCHITECT BUILDING TECHNOLOGIES

U.S. DEPARTMENT OF ENERGY
REM/Rate - Residential Energy Analysis and Rating Software v14.5.1 


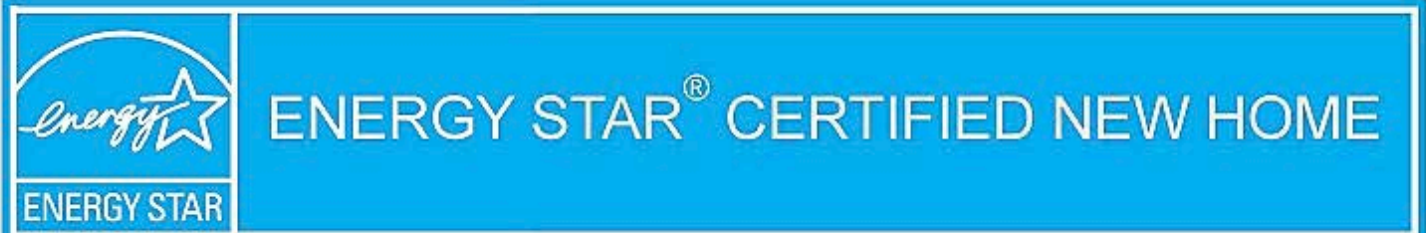

Builder Name: LCCTC

Permit Date/Number:

Home Address: 580 Old Market

Mt. Joy, PA 17752
Rating Company: Energy Services Group

Rater Identification Number: 2305868

Rating Date: 06/04/2015

Version: 3.0

\section{Standard Features of an ENERGY STAR Certified New Home}

Your ENERGY STAR certified new home has been designed, constructed, and independently verified to meet rigorous

requirements for energy efficiency set by the U.S. Environmental Protection Agency (EPA), including:

\section{Thermal Enclosure System}

A complete thermal enclosure system that includes comprehensive air sealing, qualityinstalled insulation and high-performing

windows to deliver improved comfort and

lower utility bills.

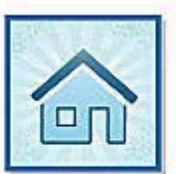

Air Infiltration Test: H tg: 1200 Clg: 1200 CFM50

Primary Insulation Levels:

Ceiling: R-49.0 FndWall: R-31.5

AGWall: R-31.0 Floor: R-30.0

\section{Flo}

Primary Window Efficiency:

U-Value: 0.300 , SHGC: 0.290

Heating, Cooling, and Ventilation System

A high-efficiency heating, cooling system,

and ventilation system that is designed and

installed for optimal performance.

Total Duct Leakage:

300.00 CF $M 25$.

Slab: $R-0.0$

Duct Leakage to Outdoors:

15.00 CFM25.

Primary Heating (System Type - Fuel Type - Efficiency):

Electric, H tg: 9.2 H SPF. Clg: 16.0 SEER.

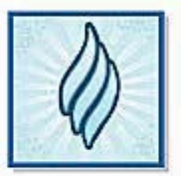

Primary Cooling (System Type - Fuel Type - Efficiency): Electric, Htg: 9.2 H SPF. Clg 16.0 SEER.

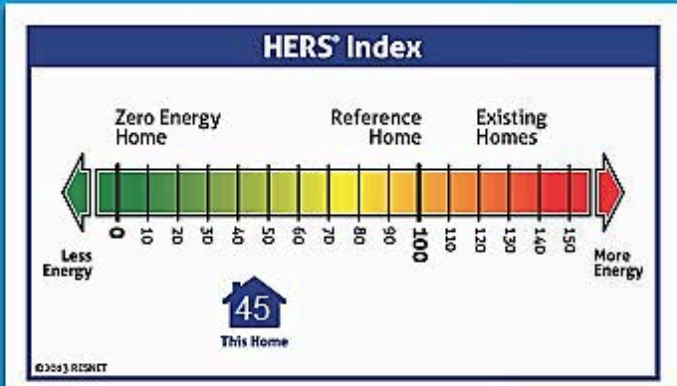

Water Management System

A comprehensive water management system to protect roofs, walls, and foundations.

Flashing, a drainage plane, and site grading to move water from the roof to the ground and then away from the home.

Water-resistant materials on below-grade walls and underneath slabs to reduce the potential for water entering into the home.

Management of moisture levels in building materials during construction.
Energy Efficient

Lighting and Appliances

Energy efficient products to help reduce utility

bills, while providing high-quality performance.

ENERGY STAR Qualified Lighting: $100 \%$

ENERGY STAR Qualified Appliances and Fans:

Refrigerators: 0 Dishwashers: 0

Ceiling Fans: $0 \quad$ Exhaust Fans: 0

Primary Water Heater (System Type * Fuel Type • Efficiency):

Conventional, Electric, $0.94 \mathrm{EF}, 50.0 \mathrm{Gal}$.

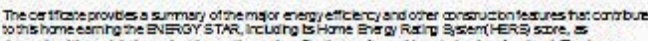

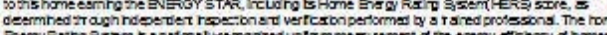

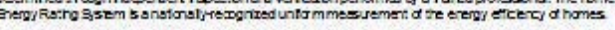

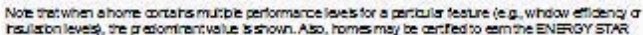

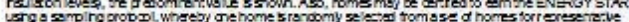

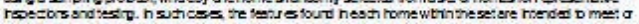

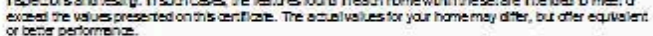

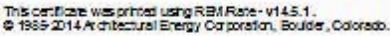




\section{Home Energy Rating Certificate}

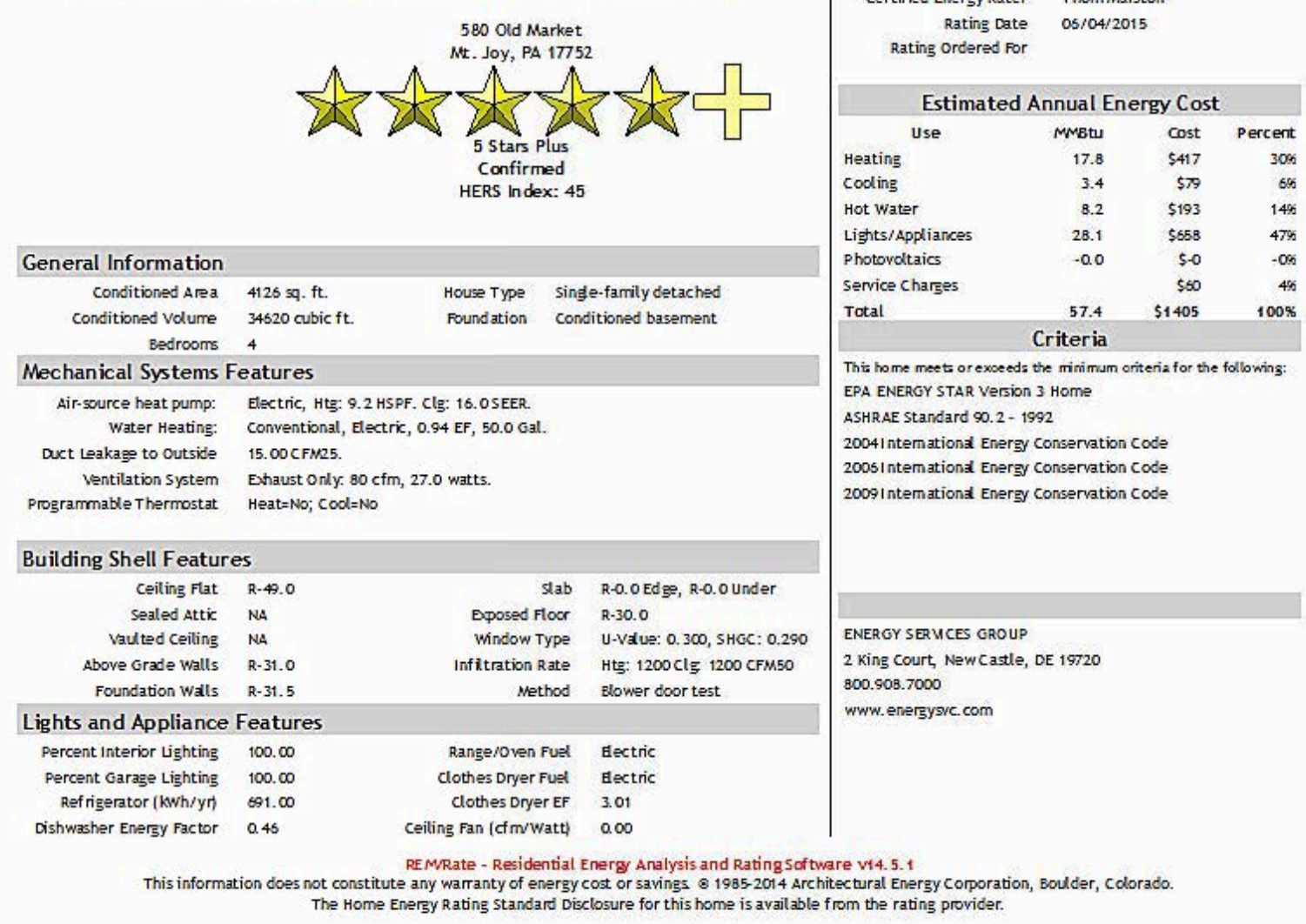


